\title{
Mass spectrometry of alkylbenzenes and related compounds. Part I. Gas-phase ion chemistry of alkylbenzene radical cations
}

\author{
Dietmar Kuck \\ Universität Bielefeld, Fakultät für Chemie, Universitätsstraße 25, D-4800 Bielefeld 1, \\ Federal Republic of Germany
}

\section{INTRODUCTION}

From the vantage point of an organic chemist, many previously obscure fragmentation and isomerization processes of gaseous organic ions have become chemically reasonable reaction pathways. The term scrambling, used formerly as a synonym for mechanistic dilemmas concerning crazy atoms, has almost vanished from mass spectrometry literature in recent years, mostly because of the recognition of well-defined ionic intermediates and reaction mechanisms occurring before, during, or even after the actual cleavage of a molecular bond. The conceptual links between organic mass spectrometry and general organic chemistry have grown in many ways. In this respect, positively charged aromatic species have played a key role, owing to their inherent stability. The investigation of alkylbenzenes, in particular, has been a central focus of mass spectrometry since its application to the analysis of petroleum and gasoline in the mid-twentieth century, and has provided much insight into the intrinsic stability and reactivity of organic ions. Besides, and in connection with, the evergreens of organic mass spectrometry (e.g., the $\mathrm{C}_{7} \mathrm{H}_{7}{ }^{+} / \mathrm{C}_{7} \mathrm{H}_{8}{ }^{+}$ion problem and the McLafferty rearrangement), new information has emerged during three decades of investigating the mass spectrometry of alkylbenzenes.

This two-part review summarizes the mass spectrometry of alkylbenzenes and related compounds. Part one collects the gas-phase chemistry of ionized alkylbenzenes and part two describes that of protonated alkylbenzenes. This is in part due to the different relations to organic chemistry of the open-shell, radical ions $\left(\mathrm{M}^{+*}\right)$ on the one hand, and closed-shell ions such as $[\mathrm{M}+\mathrm{H}]^{+}$, on the other. These two classes of ions also have different relevance to analytic applications of mass spectrometry. The radical ions of alkylbenzenes are discussed in Part I, owing to their historical priority and their broad occurrence in standard electron ionization (EI) mass spectrometry. Protonated benzene and alkylbenzenes (al- 
kylbenzenium or arenium ions) and related species emerged mainly with the advent of chemical ionization $(\mathrm{CI})$ mass spectrometry and other techniques based on gas-phase ion-molecule reactions. Common or distinct reaction behavior of ionized and protonated alkylbenzenes, however, is pointed out in both presentations, and the occurrence of the one class of ions along with or during the fragmentation of the other is stressed. Modern concepts of organic mass spectrometry like the role of distonic ions and ion-neutral complexes during the unimolecular fragmentation are particularly valuable in the light of the "classic" mass spectrometry of alkylbenzenes.

\section{HISTORICAL}

Mass spectrometry of alkylbenzenes was reviewed for the first time in 1963 by Grubb and Meyerson (1). Most information on the chemistry of alkylbenzene ions in the gas phase was derived by very careful analysis of the EI mass spectra recorded at $70 \mathrm{eV}$ electron energy; and major insights concerning the mechanisms of fragmentation arose from studies of substituent effects and isotopic mass shifts from the standard spectra. Fragmentation of the long-lived ions, giving rise to diffuse (metastable) peaks with single focus instruments, helped to differentiate successive and competitive fragmentation steps and to recognize slow rearrangement processes.

Measurements of ionization and appearance energies were the only means to determine heats of formation of gaseous molecular and fragment ions, respectively. The "aromatic series" of fragment ions $\mathrm{C}_{7} \mathrm{H}_{7}{ }^{+}, \mathrm{C}_{5} \mathrm{H}_{5}{ }^{+}, \mathrm{C}_{4} \mathrm{H}_{3}{ }^{+}, \mathrm{C}_{3} \mathrm{H}_{3}{ }^{+}(\mathrm{m} / \mathrm{z}$ $91,65,51,39)$ became a focus of interest. In spite of the limited methodical arsenal $(2,3)$, a large amount of knowledge was elaborated by Meyerson and his colleagues and reviewed by Grubb and Meyerson (1). Their combined careful evaluation of the experiments with an impressive chemical intuition, earned their work on organic mass spectrometry of alkylbenzenes a place of prominence in many textbooks (4-7).

Within ten years after the first review, mass spectrometry literature was deluged with reports on intramolecular rearrangements in gaseous organic ions. Bursey and colleagues collected these phenomena in a comprehensive, trisected review (8-10); and a part of the first article (8) comprised the mass spectrometry of alkylbenzenes. The techniques mentioned above had matured and were utilized in refined ways. Important improvements and completely new developments of the instrumental armamentarium, elaborated in the early 1970s, cannot be enumerated here, and the reader is referred to appropriate reports. Holmes (11) recently discussed and illustrated the combined application of modern mass spectrometric techniques for structural assignment of gaseous organic ions. The reader is referred to appropriate reviews on gas-phase ion chemistry (12-23).

This tremendous progress presents a ripe opportunity to review mass spectrometry and gas-phase ion chemistry of alkylbenzenes once again. When possible, interconnection with solution chemistry will be discussed to emphasize the importance of mass spectrometry to general organic chemistry as viewed by nonmass spectrometrists. 
This review covers mainly literature from the period 1970 to 1989; however, credit will be given to earlier work. The review treats the gas-phase ion chemistry of alkylbenzenes predominantly from the vantage point of an organic chemist. Therefore, higher alkylbenzenes, containing more than one aromatic nucleus, for example, will be considered in somewhat more detail than is usual in the literature.

\section{IONIZED BENZENE, PHENYL, AND BENZENIUM IONS}

Benzene (1) is the archetypical aromatic compound. The radical cation of benzene, $\mathbf{1}^{+}$, the closely related phenyl cation, $2^{+}$, and the benzenium ion, $3^{+}$, constitute prototype ions in gas-phase ion chemistry of alkylbenzenes. All three ions have been studied extensively, but here they will be given only brief treatment.
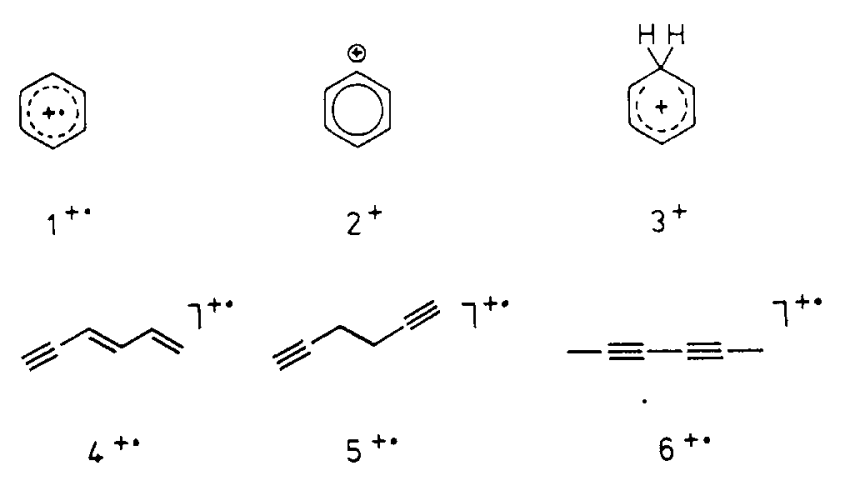

Formula $2^{+}$represents the most prominent fragment ion in the standard EI mass spectra of $\mathbf{1}^{+}$, whereas $3^{+}$is generated from $\mathbf{1}^{+}$by hydrogen atom abstraction from hydrogen donors and from $2^{+}$by addition of dihydrogen in ion-molecule reactions (24). In turn, $\mathbf{1}^{+}$and, predominantly, $2^{+}$are the main fragments of $3^{+}$ (25). All three ions form the well-known triplet of adjacent peaks at $m / z 77-79$ in the EI mass spectra of higher alkylbenzenes and related compounds $(26,27)$.

The lowest energy required for fragmentation of ions $1^{+*}, 2^{+}$, and $3^{+}$decreases with increasing number of hydrogen atoms. All of these reactions are highly endothermic: $\Delta H_{r}\left(1^{+} \rightarrow 2^{+}\right) \simeq 85 \mathrm{kcal} \cdot \mathrm{mol}^{-1}, \Delta H_{r}\left(2^{+} \rightarrow \mathrm{C}_{4} \mathrm{H}_{3}{ }^{+}\right) \simeq 108 \mathrm{kcal} \cdot \mathrm{mol}^{-1}$ $\simeq \Delta H_{r}\left(2^{+} \rightarrow \mathrm{C}_{6} \mathrm{H}_{4}^{+^{\bullet}}\right)$, and $\Delta H_{r}\left(3^{+} \rightarrow 2^{+}\right) \simeq 65 \mathrm{kcal} \cdot \mathrm{mol}^{-1}$, allowing for energydemanding isomerization process prior to fragmentation. For more detailed thermochemical data, the reader is referred to appropriate compilations (28-32).

Since Momigny's early observation (33) that the $70 \mathrm{eV}$ mass spectra of the acyclic $\mathrm{C}_{6} \mathrm{H}_{6}$ isomer 4 is identical to that of 1 , whereas those of others (e.g., 5 and 6) are not, rearrangement reactions of ionized benzene, $1^{+}$, have been investigated in great detail. From the unimolecular fragmentations of various labeled and doubly labeled benzene isotopomers occurring in the ions source and in the first fieldfree region of a mass spectrometer, time-dependent hydrogen and carbon "scrambling" was deduced (34-38). Work performed subsequent to the 1973 review (8) confirmed these findings. Thus, Beynon et al. (39) demonstrated that the metastable isotopomer $\left[1,2-{ }^{13} \mathrm{C}_{2}-3,4,5,6-\mathrm{D}_{4}\right]-1^{+\cdot}$ undergoes complete and independent 
randomization of all hydrogen and carbon atoms prior to loss of $\mathrm{C}_{2} \mathrm{H}_{2}$ and $\mathrm{C}_{3} \mathrm{H}_{3}$. A ring-walk mechanism for the hydrogen-only equilibration was proposed by Gallup et al. (40) by a computational approach. $\mathrm{C}_{6} \mathrm{H}_{6}{ }^{+\cdot}$ ions with internal energies below fragmentation threshold (stable ions) were studied by Borchers and Levsen (41), who suggested a partial interconversion of $\mathbf{1}^{+\cdot}$ and acyclic isomers $5^{+\bullet}$ and $6^{+*}$. Combined with evidence from the CID spectra of a ${ }^{13} \mathrm{C}$-labeled isotopomer of 4 by Köppel et al. (42), the data suggest that long-lived $\mathrm{C}_{6} \mathrm{H}_{6}{ }^{+\cdot}$ ions exist predominantly in the cyclic form $1^{+\cdot}$, with an appreciable barrier toward skeletal isomerization. In line with this, charge stripping spectra of $\mathbf{1}^{+\bullet}, 5^{+\bullet}$, and $\mathbf{6}^{+\cdot}$ were reported by Cooks et al. (43) to reflect distinct energy wells for cyclic and acyclic $\mathrm{C}_{6} \mathrm{H}_{6}{ }^{+}$ions. In contrast, previous measurements of the kinetic energy release of fragmenting $\mathrm{C}_{6} \mathrm{H}_{6}{ }^{+}$ions generated from $\mathrm{C}_{6} \mathrm{H}_{6}{ }^{2+}$ by charge exchange had suggested an acyclic structure exclusively (44). Overall, kinetic energy release data (45) did not provide convincing evidence for the existence of isomeric $\mathrm{C}_{6} \mathrm{H}_{6}{ }^{+\cdot}$ ions.

More recent work on $\mathrm{C}_{6} \mathrm{H}_{6}{ }^{+\cdot}$ ions confirmed that $1^{+*}$ is, indeed, the most stable isomer. Baer et al. (46) reported detailed photoelectron photoion coincidence (PEPICO) measurements on $5^{+\cdot}$ and $6^{+\cdot}$ in comparison to $\mathbf{1}^{+\cdot}$ and considered isolated electronic states and noninterconverting isomers highly unlikely for lowenergy ions. Gross et al. (47) reacted $\mathrm{C}_{6} \mathrm{H}_{6}{ }^{+*}$ ions from 1 and various other precursors with 2-propyl iodide and found three classes of $\mathrm{C}_{6} \mathrm{H}_{6}{ }^{+\cdot}$ species. One class, $\mathbf{1}^{+}$, was identified by ready formation of 2-propylbenzenium ions, in contrast to linear but also to cyclic $\mathrm{C}_{6} \mathrm{H}_{6}{ }^{+}$isomers such as ionized fulvene (48). Pronounced differences between $\mathrm{C}_{6} \mathrm{H}_{6}{ }^{+\cdot}$ ions formed by $\mathrm{CE}$ of $\mathrm{C}_{6} \mathrm{H}_{6}{ }^{2+}$ from 1 and linear isomers were observed by Guilhaus et al. (49). More recently, Kinter and Bursey (50) reported endothermic proton transfer form $1^{+}, 5^{+*}$, and $6^{+}$in a triple quadrupole mass spectrometer. For a comprehensive review of the chemistry and physics of gaseous $\mathrm{C}_{6} \mathrm{H}_{6}{ }^{+}$ion, the reader is referred to a critical review published in 1982 (51).

Phenylium ions $\left(2^{+}\right)$are the most stable $\mathrm{C}_{6} \mathrm{H}_{5}{ }^{+}$isomers. Eyler and Campana (52) recently described the chemistry of different $\mathrm{C}_{6} \mathrm{H}_{5}{ }^{+}$isomers, referring to the formation of $\mathrm{C}_{6} \mathrm{H}_{5}{ }^{+}$and larger hydrocarbon ions by ion-molecule reactions in flames. Ions $2^{+}$were characterized by their lack of reactivity with acetylene; accordingly, a recent SIFT study by Knight et al. (53) demonstrated considerable amounts of reactive (presumably linear) $\mathrm{C}_{6} \mathrm{H}_{5}{ }^{+}$ions generated from 1 . A MINDO/3 study (54) provided estimates on the barriers toward hydrogen and carbon scrambling in $2^{+}$ions. More recently, Ausloos et al. (55) presented a study on the formation and the bimolecular reactions of $2^{+}$ions, suggesting an energy barrier toward ring opening of $2.0 \pm 0.3 \mathrm{eV}$. For access to the vast literature on the gasphase chemistry of $2^{+}$ions, the reader is referred to the above cited references.

Benzenium ions $\left(3^{+}\right)$represent the archetype protonated alkylbenzene and is, beyond any doubt, the most stable $\mathrm{C}_{6} \mathrm{H}_{7}{ }^{+}$isomer. In a recent detailed ICR study, Lias and Ausloos (56) suggested protonated forms of fulvene to be the next stable $\mathrm{C}_{6} \mathrm{H}_{7}{ }^{+}$isomers. Skeletal rearrangements of $\mathrm{C}_{6} \mathrm{H}_{7}{ }^{+}$ions, however, have not been studied in great detail in contrast to the fast proton (or hydride) "ring walk", which is by far the most prominent isomerization reaction of $3^{+}$. It will be discussed in extenso in Part II. 


\section{RADICAL CATIONS OF METHYL- AND ETHYLBENZENES}

Corresponding to benzene (1), toluene (7), being the smallest "true" alkylbenzene, is the direct parent for three types of $\mathrm{C}_{7}$ ions: the radical cation $7^{+\cdot}$ and the closed-shell cations $\mathrm{C}_{7} \mathrm{H}_{7}{ }^{+}\left(8^{+}\right)$and $\mathrm{C}_{7} \mathrm{H}_{9}{ }^{+}\left(9^{+}\right)$. For these ions, energy requirements for fragmentation are considerably lower than for the corresponding $\mathrm{C}_{6}$ ions $1^{+\bullet}, 2^{+}$, and $3^{+}(31)$. The presence of the simple $C_{1}$ side group, however, also opens a number of favorable reaction paths leading to hydrogen migration and skeletal rearrangement. The latter process (being reversible in most cases) is known best in general organic chemistry for the benzyl-tropylium system, $\mathbf{8}^{+} \leftrightarrows$ $11^{+}$, perhaps for historic reasons. The parent $\mathrm{C}_{7} \mathrm{H}_{8}{ }^{+\cdot}$ system, however, undergoes a similar reorganization of the carbon framework $\left(7^{+\cdot} \leftrightarrows 10^{+\cdot}\right)$, leading to degeneracy of the hydrogen and carbon atoms as well. Even the $\mathrm{C}_{7} \mathrm{H}_{9}{ }^{+}$ions $\left(9^{+}\right)$, representing the simplest protonated alkylbenzene (toluenium ions), interconvert with the ring-expanded isomers (dihydrotropylium ions, $9^{+} \leftrightarrows 1^{+}$) $(25,57)$. In spite of the relevance of ions $9^{+}$to solution chemistry, the latter rearrangement has been neglected compared with those of its $\mathrm{C}_{7} \mathrm{H}_{8}{ }^{+\cdot}$ and $\mathrm{C}_{7} \mathrm{H}_{7}{ }^{+}$counterparts; $9^{+}$and related small benzenium ions will be treated in Part II. The rearrangements of $\mathrm{C}_{7} \mathrm{H}_{7}+$ ions and its homologs also deserve special discussion, which will follow that of the $\mathrm{C}_{7} \mathrm{H}_{8}{ }^{+}$rearrangements described in the next section.

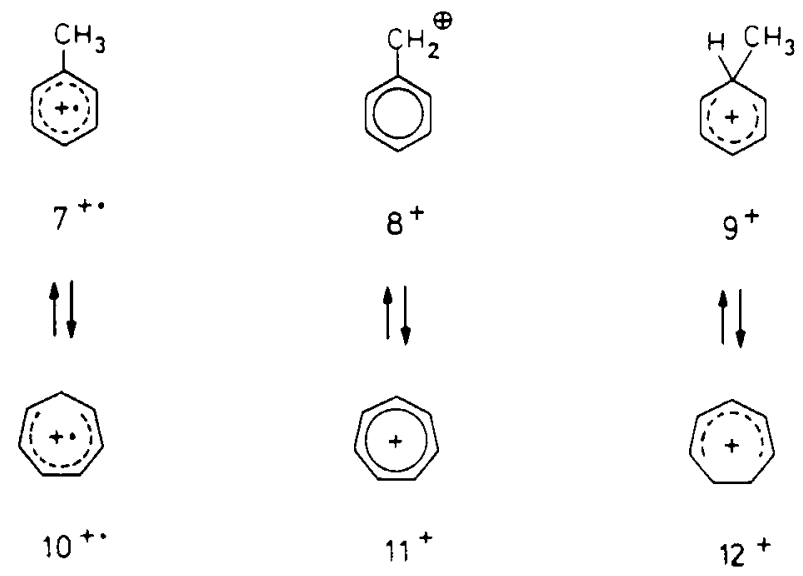

\section{A. Isomerization of $\mathrm{C}_{7} \mathrm{H}_{8}{ }^{+*}$ and other methylbenzene ions}

1. $\mathrm{C}_{7} \mathrm{H}_{8}{ }^{+\cdot}$ ions

The ring expansion reaction of $7^{+\bullet} \rightarrow \mathbf{1 0}^{+}$, suggested by Rylander, Meyerson, and Grubb in $1957(58)$ has been reviewed since $(1,8)$. Hydrogen and carbon atoms lose their positional identity prior to the energetically most favorable fragmentation (i.e., loss of $\mathrm{H}^{*}$ ). Isomeric ions $8^{+}$and $\mathbf{1 1}^{+}$ions are formed. The latter process, being the less energy-demanding reaction channel $\left(\Delta H_{r}\left(7^{+\cdot} \rightarrow 8^{+}\right)=53\right.$ $\left.\mathrm{kcal} \cdot \mathrm{mol}^{-1}, \Delta H_{r}\left(7^{+\cdot} \rightarrow 11^{+}\right)=45 \mathrm{kcal} \cdot \mathrm{mol}^{-1}\right)$, requires ring expansion to $10^{+^{\bullet}}$. An independent, consecutive interconversion, however, takes place at the level of the $\mathrm{C}_{7} \mathrm{H}_{7}{ }^{+}$fragment ions (Sect. IV.B). Ring contraction during the fragmentation 
of vicinally ${ }^{13} \mathrm{C}_{2}$-labeled $\mathbf{1 0}^{+\cdot}$ was shown by Davidson and Skell (59), who also found retention during the fragmentation of vicinally ${ }^{13} \mathrm{C}_{2}$-labeled $16^{+}$. Thus, earlier suggestions based on the fragmentation of deuterium-labeled $7^{+\cdot}$ ions $(58,60,61)$, pointing to irreversible ring expansion $7^{+} \rightarrow 10^{+\cdot}$, had to be substantiated.

Previous work on the $70 \mathrm{eV}$ fragmentation of $1, \alpha-{ }^{13} \mathrm{C}_{2}$-labeled $7^{+\cdot}$ by Rinehart et al. (62) and of $2,6{ }^{13} \mathrm{C}_{2}$-labeled $7^{+}$by Siegel (63) had shown that the carbon atoms equilibrate prior to formation of the secondary fragment ions $\mathrm{C}_{5} \mathrm{H}_{5}{ }^{+}$; however, the problem as to whether $C$ scrambling precedes the fragmentation of the parent ions $7^{+\cdot}$ or whether it occurs in the primary fragments $8^{+}$remained unsolved. Labeling studies by Howe and McLafferty (64) revealed that the degree of hydrogen scrambling, $\alpha(\alpha=1$ for full randomization), and the isotope effect $\left(i=[\mathrm{M}-\mathrm{H}]^{+} /[\mathrm{M}-\mathrm{D}]^{+}\right)$on the fragmentation of $7^{+^{*}}$ and $\mathbf{1 0}^{+\cdot}$ are strongly energy dependent. These criteria were found to be similar for both ions, decreasing with increasing internal energy: $1.00 \geqslant \alpha \geqslant 0.7$ and $2.8 \geqslant i \geqslant 1.4$. Earlier, Meyer and Harrison (65) also reported isotope effects on the loss of $\mathrm{H}^{*}$ from $7^{+\cdot}$ (e.g., $\alpha=3.6$ ). In later work, Baldwin et al. (66) suggested the occurrence of four independent mechanisms for interchange of $\mathrm{H}$ and $\mathrm{C}$ atoms in $7^{+}$, if the fragments from more highly excited ions are sampled. Levsen and Beckey (67) observed reduced hydrogen scrambling for $7^{+\cdot}$ ions generated by field ionization (FI). The interplay of increased internal energy and decreased ion lifetime yields $\alpha=0.95$ and $i=2.3$ for ions fragmenting after $1.7 \times 10^{-9} \mathrm{~s}$. By combining the FI and CID techniques, these authors reported (68) an increase of structure-specific fragmentation of long-lived ions $7^{+*}, \mathbf{1 0}^{+*}$, and $16^{+\cdot}$ (i.e., less structural reorganization of long-lived $\mathrm{C}_{7} \mathrm{H}_{8}{ }^{+}$ions formed by FI).

On the basis of experimental data (31), ions $\mathbf{1 0}^{+\cdot}$ are considerably less stable $\left(\simeq 20 \mathrm{kcal} \cdot \mathrm{mol}^{-1}\right)$ than the "aromatic" isomer $7^{+\cdot}$, in contradiction to semiempirical (MINDO/3) calculations by Dewar and Landman (69). This discrepancy was attributed to an abnormally large difference between the adiabatic and the vertical ionization energy of 10 (69); however, later calculations using MNDO (70) on the homologous $\mathrm{C}_{8} \mathrm{H}_{10}{ }^{+}$ions did not reproduce this effect. From experimentally obtained data, the activation barrier for the isomerization $7^{+\cdot} \rightarrow \mathbf{1 0}^{+\bullet}$ was thus estimated to be $25 \leqslant E_{a} \leqslant 45 \mathrm{kcal} \cdot \mathrm{mol}^{-1}$ (71), in accord with experimental approaches to substituted $\mathrm{C}_{7} \mathrm{H}_{8}{ }^{+}$ions (see below).

A number of other $\mathrm{C}_{7} \mathrm{H}_{8}{ }^{+} \cdot$ isomers were found to be involved in the rearrangements of $\mathrm{C}_{7} \mathrm{H}_{8}{ }^{+\cdot}$ ions (Scheme I). This had been suggested from the striking similarity of various $\mathrm{C}_{7} \mathrm{H}_{8}$ isomers, including highly strained polycyclic hydrocarbons $(60,72-74)$. Ionized norcaradiene $13^{+*}$, suggested earlier by Hoffman $(75)$, was also corroborated by the MINDO/3 calculations as an important intermediate on the "minimum energy reaction path" (MERP) (69). $13^{+\cdot}$ is accessible from $7^{+\cdot}$ via the distonic ion $7 \mathbf{a}^{+}$by simple 1,2-H shift and electrocyclic ring closure (MERP a), the former step being energy-determining $\left(E_{a} \simeq 34 \mathrm{kcal} \cdot \mathrm{mol}^{-1}\right)$. Reversible reopening of the three-membered ring in $\mathbf{1 3}^{+}$is certainly a very facile step for positively charged ions $(69,76)$. An alternative isomerization route (MERP b) was calculated to require closely similar amounts of energy, involving ionized 5-methylene-1,3-cyclohexadiene $\mathbf{1 4}^{+\bullet}$, a well-known tautomer of $7^{+\cdot}$ [ortho-isotoluene, 
re-examined by Gajewski and Gortva (77)], and then the distonic norcaradiene isomer $\mathbf{1 5}^{+\bullet}$. The relatively high energy barriers of the $1,2-$ and $1,3-\mathrm{H}$ shifts (MERPs $\mathrm{a}$ and $\mathrm{b}$ ) may reflect the radical character of the $\mathrm{C}_{7} \mathrm{H}_{8}{ }^{+}$ions.

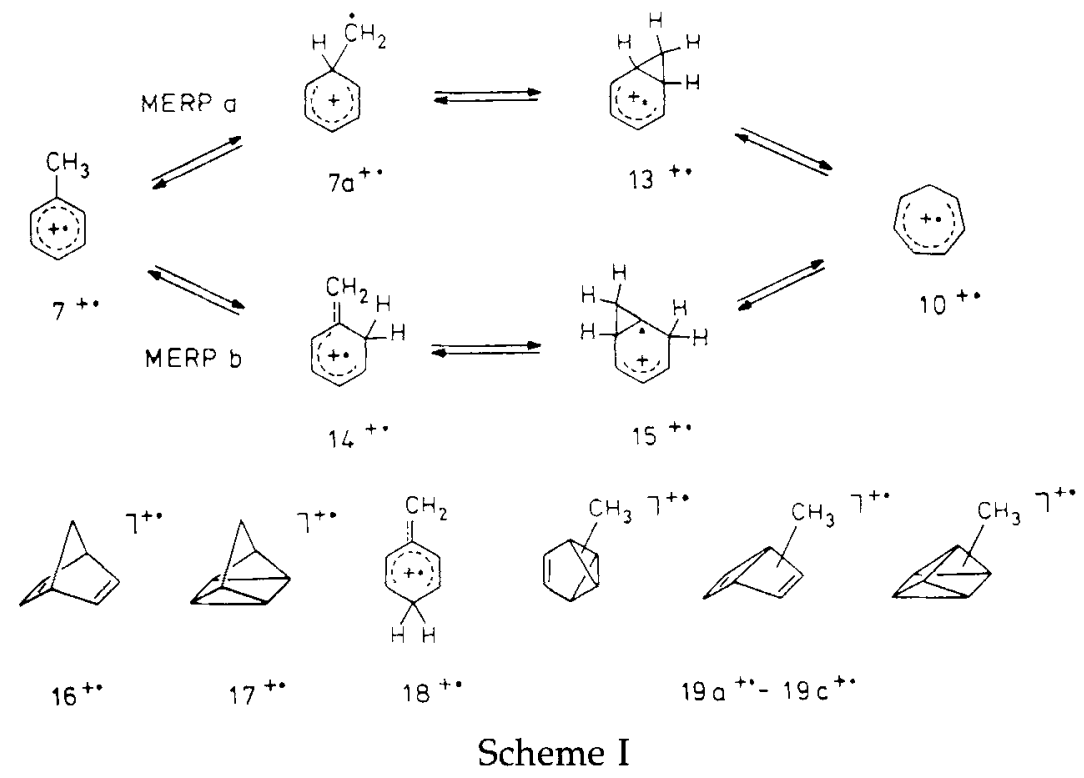

From the semiempirical calculations (69), qualitatively reliable mechanistic models for the $\mathrm{C}_{7} \mathrm{H}_{8}{ }^{+}$rearrangement(s) were suggested; however, obvious mechanistic possibilities remained unexamined. For example, the interconversion of $7 \mathbf{a}^{+\cdot}$ and $\mathbf{1 4}^{+\cdot}$ or the probably very favorable ring opening of ionized norbornadiene, $\mathbf{1 6}^{+\cdot}$ $\rightarrow 7 \mathbf{a}^{+}$, were not described. Early experimental work by Meyerson et al. (78) and later by Davidson and Skell (59) showed that $16^{+}$interconverts with the other $\mathrm{C}_{7} \mathrm{H}_{8}{ }^{+}$isomers, in competition with a specific retro-Diels-Alder-type fragmentation. Unfortunately, no metastable ions were investigated in the latter work (59). The retro-Diels-Alder reaction of $16^{+\bullet}$ was used to determine the heat of formation of the neutral precursor (79).

Whereas ions $14^{+\cdot}$ were generated independently from a variety of other precursors (see below) and are accepted intermediates for the isomerization of $7^{+}$ and $10^{+\bullet}(66)$, ionized 3-methylene-1,4-cyclohexadiene (para-isotoluene) $18^{+\bullet}(77)$ has not been studied in much detail. Although Baldwin et al. (66) suggested a single exchange path between the $\alpha$ - and ortho-H atoms in $7^{+\cdot}$, a ring-walk $7 \mathbf{a}^{+}$ $\leftrightarrows \mathbf{1 4}^{+^{\bullet}} \leftrightarrows \mathbf{1 8}^{+^{-}}$appears possible. A MERP for the corresponding process for the homologous $\mathrm{C}_{8} \mathrm{H}_{10}{ }^{+\cdot}$ ions was calculated by $\mathrm{MNDO}$ and found to be applicable to high-energy ions fragmenting in the ions source (70). The ring-only hydrogen exchange in $7^{+*}$, suggested by experiment (66) and calculated to be the energetically most favorable pathway, is preferred to the randomization process of $7^{+}$ via valence isomers $19 \mathbf{a}^{+\cdot}-19 \mathrm{c}^{+\cdot}(69)$.

Ion $14^{+\cdot}$ has been studied by a number of authors using the McLafferty reaction of higher alkylbenzenes and related precursors. As shown by Nibbering 
and de Boer (80), metastable $\mathrm{C}_{7} \mathrm{H}_{8}{ }^{+}$ions formed from 2-phenylethanol undergo hydrogen randomization prior to loss of $\mathrm{H}^{\circ}$. The first application of the CID technique to differentiate $\mathrm{C}_{7} \mathrm{H}_{8}{ }^{+*}$ isomers was reported by McLafferty et al. (81), who found distinct CID spectra for ions $7^{+}, \mathbf{1 0}^{+*}$, and $16^{+\cdot}$ on the one hand, but identical for $16^{+\cdot}$ and the rearrangement ions (presumably $1^{+\cdot}$ ), suggesting a common structure. Levsen et al. (82) observed a similar behavior for deuterium-labeled rearrangement ions $1^{+^{+}}$at threshold, whereas ions of higher internal energies exhibited individual fragmentation by direct cleavage to form $8^{+}$ ions. Another report by Burgers et al. (83), making use of CID and chargestripping mass spectrometry, afforded convincing evidence that ionized orthoisotoluene $1^{+\cdot}$ represents a distinct, long-lived isomer on the $\mathrm{C}_{7} \mathrm{H}_{8}{ }^{+\cdot}$ hypersurface. By performing appearance energy measurements on metastable $\mathbf{1 4}^{+}$ions, these authors reported the heat of formation of $14^{+\cdot}$ to be $229 \mathrm{kcal} \cdot \mathrm{mol}^{-1}$ (i.e.,

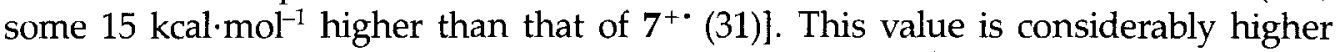
than that from the MINDO/3 calculations $\left(219 \mathrm{kcal} \cdot \mathrm{mol}^{-1}\right)$ (69) and suggests that former appearance energy measurements on $\mathrm{C}_{7} \mathrm{H}_{8}{ }^{+}$ions, generated by McLafferty rearrangement of higher alkylbenzenes $(84,85)$, yield the heat of formation of the more stable isomers $7^{+\cdot}$ or $1^{+*}$. This interpretation (83) is in line with photoionization (PI) measurements on alkylbenzenes (86), showing two onsets in the $\mathrm{C}_{7} \mathrm{H}_{8}{ }^{+}$PI efficiency curve. Earlier, Williams and Bowen (87) arrived at a similar conclusion; however, their thermochemical estimation yielded a value $\left(\Delta H_{f}\left(\mathbf{1 4}^{+}\right)=243 \mathrm{kcal} \cdot \mathrm{mol}^{-1}\right)$, which has to be considered too high. $A b$ initio heats of formation for ions $7^{+\bullet}, \mathbf{1 0}^{+\bullet}$, and $14^{+\cdot}$ corroborate the overall experimental evidence in that ions $\mathbf{1 0}^{+\cdot}$ and $\mathbf{1 4}^{+\cdot}$ are close in energy and $\simeq 15$ $\mathrm{kcal} \cdot \mathrm{mol}^{-1}$ less stable than ionized toluene $7^{+\bullet}(86)$.

More recently, Bartmess (88) reported on both tautomers, $\mathbf{1 4}^{+\bullet}$ and $18^{+\bullet}$, generated directly by EI of the neutral, long-known, but highly sensitive (77) isotoluenes 14 and 18 in an ICR mass spectrometer. From measurements of both the gas-phase acidity and ionization energy of the trienes, the para isomer $18^{+*}$ was reported to be $18 \mathrm{kcal} \cdot \mathrm{mol}^{-1}$ less stable than $7^{+*}$, in good agreement with recent data $(83,86)$ for the ortho isomer $14^{+\cdot}$. The mixtures of $\mathrm{C}_{7} \mathrm{H}_{7}{ }^{+}$fragment ions from $\mathbf{1 4}^{+\cdot}$ and $1^{+\cdot}$, as determined again by ion-molecule reaction with the neutral precursors, were reported to differ markedly and in a way completely in line with the isomerization scheme outlined above; that is, assuming that $\mathbf{1 4}^{+}$undergoes ring expansion via $7^{+\cdot}$ and $13^{+\cdot}$ to give tropylium ions $\left(\left[11^{+}\right] /\left[8^{+}\right]\right.$ $\simeq 0.6)$ in contrast to $\mathbf{1 8}^{+\cdot}$ which yields almost exclusively benzyl ions $\left(\left[\mathbf{1 1}^{+}\right] /\left[\mathbf{8}^{+}\right]\right.$ $\leqslant 0.1)(88)$.

Summarizing the information on $7^{+\cdot}$ and its isomers at this point, a clear picture arises. The experimental and computational evidence agrees reasonably weil in describing the different isomerization channels. The barrier toward ring expansion $7^{+\cdot} \rightarrow 10^{+\bullet}$ is in the range of $30-40 \mathrm{kcal} \cdot \mathrm{mol}^{-1}$, in agreement with estimates based on the fragmentation behavior of various ionized toluene derivatives (71), including diphenylalkanes (89) (Sect. VI). The "pre-equilibrium" of the $\mathrm{C}_{7} \mathrm{H}_{8}{ }^{+}$ions was also deduced by extensive studies aimed to understand the $\mathrm{C}_{7} \mathrm{H}_{7}{ }^{+}$ion system (90-92). From CID spectra of $\mathrm{C}_{7} \mathrm{H}_{7}{ }^{+}$ions generated from 
various precursors, Winkler and McLafferty $(90,91)$ deduced a rapid equilibration $7^{+} \leftrightarrows 10^{+*}$ for ions near threshold for loss of $\mathrm{H}^{\cdot}$. Earlier observations by Venema et al. (93), who reported partial ring contraction of $10^{+\cdot}$ type ions, were in line with these conclusions. As shown later by Kuck and Grützmacher (89), ring contraction, however, is not ubiquitous for ionized cycloheptatriene derivatives.

By applying ICR techniques, Jackson, Lias, and Ausloos $(92,94)$ showed, in agreement with Dunbar and Shen et al. $(95,96)$ as well as with Sen Sharma and Kebarle (97), that $\mathrm{C}_{7} \mathrm{H}_{7}{ }^{+}$ions produced from $7^{+\bullet}$ and $\mathbf{1 0}^{+}$, as well as from $\mathbf{1 6}^{+\cdot}$ and a large variety of toluene derivatives, comprise a mixture of isomers, one of which $\left(8^{+}\right)$is reactive with neutral nucleophiles (e.g., 7 or alkyl halides), the other $\left(\mathbf{1 1}^{+}\right.$) is inert (Scheme V, Sect. IV.B). Energy dependence studies and labeling evidence support the isomerization $7^{+\bullet} \leftrightarrows 10^{+\bullet}$ prior to formation of the $8^{+} / \mathbf{1 1}^{+}$ mixture. Apparently conflicting observations concerning the $\left[8^{+}\right] /\left[\mathbf{1 1}^{+}\right]$ratio from the CID $(90,91)$ and ICR work $(92,94,95)$ were adjusted by further CID experiments reported by McLafferty and Bockhoff (98), showing that the equilibrium $7^{+\cdot} \leftrightarrows$ $10^{+\cdot}$ governs the predominant formation of $1^{+}$at threshold, whereas at higher energies, the interconversion of the fragment ions gains importance. From further ICR experiments making use of CE to generate energetically well-defined ions $7^{+\bullet}$ and $16^{+}$, Ausloos (99) concluded that low-energy $7^{+\bullet}$ ions undergo repeated ring expansion-reversion cycles prior to loss of $\mathrm{H}^{\circ}$. In contrast to most of the previous work, a recent CID study (100) revealed that $\left[11^{+}\right] /\left[\mathbf{8}^{+}\right]$does not exceed a value of 0.5 , suggesting that $7^{+\cdot}$ ions do not generate $11^{+}$ions at threshold for loss of $\mathrm{H}^{*}$ (Sect. IV.B). Similar to the majority of the work discussed above, however, these results rely on $\mathrm{C}_{7} \mathrm{H}_{8}{ }^{+}$ions having enough energy to undergo unimolecular fragmentation.

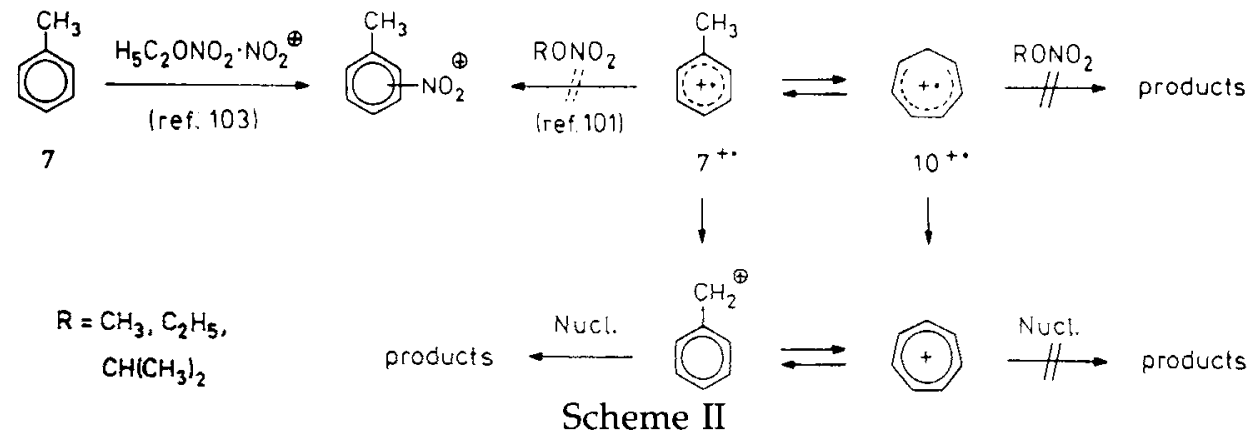

A distinction of nondecomposing $\mathrm{C}_{7} \mathrm{H}_{8}{ }^{+\cdot}$ isomers was reported in early ICR work by Hoffman, Bursey, and Benezra $(101,102)$ (Scheme II). By using $\mathrm{NO}_{2}{ }^{*}$ transfer from alkyl nitrates as a structural probe, $7^{+\cdot}$ apparently gives the $\mathrm{C}_{7} \mathrm{H}_{8} \mathrm{NO}_{2}{ }^{+}$ adduct ion whereas both $10^{+\cdot}$ and $16^{+\cdot}$ are unreactive (101). Likewise, the authors found that the rearrangement ion $14^{+\cdot}$ does not interconvert with $7^{+\cdot}(102)$. In contrast to the earlier work (101), Ausloos and Lias (103), however, reported a charge transfer (CE) study, showing that the $\mathrm{C}_{7} \mathrm{H}_{8} \mathrm{NO}_{2}{ }^{+}$adduct ions are formed by a "switching reaction" leading to gas-phase nitration of neutral 7 (104) rather 
than by transfer of $\mathrm{NO}_{2}^{*}$ to $7^{+\cdot}$. Nevertheless, these authors did not rule out the previous conclusion that the $\mathrm{C}_{7} \mathrm{H}_{8}{ }^{+\cdot}$ rearrangement ions from $n$-butylbenzene are essentially $14^{+\cdot}$ rather than $7^{+*}$. Notwithstanding, studies on the bimolecular reactivity of ionized alkylbenzenes remained rare for a number of years, although this powerful technique has offered a fascinating access to the ions' (unimolecular) potential barriers and a much closer view to the depths of the ions' potential wells.

Indeed, the earlier ICR evidence (101-103) is consistent with the unimolecular and collision-induced fragmentation behavior of $\mathrm{C}_{7} \mathrm{H}_{8}{ }^{+\cdot}$ ions, showing that $7^{+*}$, on the one hand, and $10^{+}, \mathbf{1 4}^{+*}$, and $16^{+}$, on the other, reside in well-separated energy wells. As discussed above, however, the discrete existence of the latter three isomers remained questionable. In recent work, Rabrenovic, Brenton, and Ast (105) showed that, upon unimolecular loss of $\mathrm{C}_{2} \mathrm{H}_{2}$, ions $7^{+\cdot}, \mathbf{1 0}^{+\bullet}, \mathbf{1 6}^{+\bullet}$, and $17^{+*}$ release significantly less kinetic energy $(25 \pm 1 \mathrm{meV})$ than the rearrangement ions $14^{+\cdot}(38 \pm 1 \mathrm{meV})$, as reported earlier by Cooks et al. (106). Likewise, the latter ions exhibit distinct CID spectra in the $\mathrm{C}_{6}$ ion region (105). Similar results were reported by Burgers et al. (83). Moreover, by means of charge stripping (CS) measurements, the two research groups were able to differentiate between ions $7^{+\bullet}, \mathbf{1 0}^{+}$, the rearrangement ions $14^{+*}$, and the (mutually indistinguishable) biand tetracyclic isomers $16^{+\cdot}$ and $17^{+\bullet}$. In a more recent work, Kingston et al. (107) reported also qualitative differences in the charge exchange/charge stripping mass spectra of ions $7^{+\cdot}$ and $\mathbf{1 0}^{+\bullet}$.

A considerable number of PI and photodissociation (PD) mass spectrometric studies have been reported concerning $\mathrm{C}_{7} \mathrm{H}_{8}{ }^{+}$ions. Traeger and McLoughlin (108) published threshold energies for loss of $\mathrm{H}^{\cdot}$ from $7^{+\bullet}$ and $10^{+\bullet}$, determined at high sensitivity in order to minimize the kinetic shift, which had caused severe overestimation of the heats of formation of $8^{+}$and $\mathbf{1 1}^{+}$(28). A more comprehensive PI study was reported by Traeger and McLoughlin (109), including the heats of formation of additional $\mathrm{C}_{7} \mathrm{H}_{8}{ }^{+}$ions. For both of the neutral precursors 7 and 10, PD measurements indicate the formation of ions $11^{+}$at threshold energies (108). In a dye-laser PD-ICR study, Eyler (110) reported the absolute cross-section for loss of $\mathrm{H}^{*}$ from $7^{+\bullet}$. Dunbar and $\mathrm{Fu}$ (111) carried out PD spectrometry on ions $7^{+*}, 10^{+*}$, and $16^{+*}$, demonstrating that these stable $\mathrm{C}_{7} \mathrm{H}_{8}{ }^{+}$ions do not interconvert to more than a few percent. Again, complete hydrogen randomization and pronounced isotope effects $(i=2.3$ at $\lambda=400$ $\mathrm{nm}$ ) were observed by using this technique (112). Photoproduced $\mathrm{C}_{7} \mathrm{H}_{7}{ }^{+}$ions from $7^{+\cdot}$ again undergo the electrophilic attack on neutral precursors (Scheme $V$, Sect. IV.B), indicating the formation of $8^{+}$. The same characteristic feature, along with some hydrogen scrambling, was observed by Yamamoto and coworkers $(113,114)$ upon radiolysis of 7 . The rate constant for this reaction [Scheme $\mathrm{V}$, Eq. (a)] was determined $(95,97,115)$. In agreement with the evidence derived from EI/CID and ion-molecule reactivity (90-92), Dunbar (95) observed a mixture of $8^{+}$and $11^{+}$ions being formed upon PD, and the mixture still contains increasing portions of the more stable $11^{+}$with decreasing excess energy of $7^{+\cdot}$. In addition, the PD spectrum of rearrangement ions $14^{+\cdot}$ was studied by Dunbar and Klein (116) and was found to be distinct from those of $7^{+\cdot}$ and $10^{+}$, 
substantiating again that ions $\mathbf{1 4}^{+\cdot}$ represent a stable entity under low-energy conditions.

The question of the existence of isolated excited electronic states, in contrast with quasi-equilibrium theory (QET), has been a matter of much debate over the years, particularly for the $\mathrm{C}_{6} \mathrm{H}_{6}{ }^{+\cdot}$ system, and also did not leave the homologous ions $\mathrm{C}_{7} \mathrm{H}_{8}{ }^{+} \cdot$ untouched. Buttrill (117) claimed to have observed discrete states of $7^{+\cdot}$ by time-resolved PI mass spectrometry. This work has been criticized $(118,119)$ on the basis of the known photoelectron spectrum of 7 (120) and calculations of the internal energy distribution (121). Smith and Futrell (122) analyzed the fragmentation of $7^{+\cdot}$ by tandem sector-ICR mass spectrometry and found very slow fragmentation of metastable ions associated with large isotope effects. The data were interpreted to show the validity of QET for $7^{+\cdot}$ ions.

The gas-phase reactions of metal ions $\left(\mathrm{Co}^{+}, \mathrm{Rh}^{+}\right)$with neutral $\mathrm{C}_{7} \mathrm{H}_{8}$ hydrocarbons $(7,10$, and 16$)$ were studied by Jacobsen et al. $(123,124)$. The adduct ions with 7 were found to differ significantly from those from the other isomers in that they did not suffer fragmentation of the carbon skeleton. Reeher et al. (125) investigated the neutral fragments generated from $1^{+*}, 7^{+*}$, and other methylbenzenes and concluded that in many dissociations more than a single neutral fragment is formed. Finally, it should be mentioned that the interconversion of $7^{+\cdot}, \mathbf{1 0}^{+}$, and $14^{+\cdot}$ and of higher ionized alkylbenzenes and alkylcycloheptatrienes have been studied by Andrews et al. $(126,127)$ by using matrix isolation techniques, unraveling interesting parallels to the gas-phase chemistry.

\section{Substituted $\mathrm{C}_{7} \mathrm{H}_{8}{ }^{+\cdot}$ ions}

The overall picture of hydrogen and skeletal rearrangements for $\mathrm{C}_{7} \mathrm{H}_{8}{ }^{+}$ions can be applied to the next higher homologs and analogs; that is, ionized xylenes $\left(\mathbf{2 0 0 ^ { + } -}-20 \mathrm{p}^{+\cdot}\right)$, ethylbenzene $\left(21^{+\bullet}\right)$, and other short-chain alkylbenzene ions, as well as to functionalized derivatives. With additional substituents at the aromatic ring, the number of competing fragmentation reactions increases markedly, thus enabling more detailed information on the ions' isomerization behavior.

The EI mass spectra of the xylenes 20 are known to be indistinguishable $(1,8)$. Labeling evidence and appearance energy measurements on $20 \mathrm{o}^{+\cdot}-20 \mathrm{p}^{+\cdot}$ and $21^{+\cdot}$ pointed to ring expansion $\left(2^{+^{*}} \rightarrow \mathbf{2 2}^{+^{-}} \leftarrow \mathbf{2 1}^{+^{\circ}}\right)$ prior to loss of $\mathrm{CH}_{3}(27,28,58,128)$. Meyer et al. (129) reported very similar mass spectra for various $\mathrm{C}_{8} \mathrm{H}_{10}$ isomers, including, besides 20-22, a number of spirocyclic dienes such as 23. The acyclic isomer 24 exhibits significant differences, suggesting that, in fact, common cyclic intermediates are involved in the fragmentation of $20^{+\cdot}-\mathbf{2 3}^{+\bullet}$. Fragmentation of metastable ions $\mathbf{2 0}^{+\cdot}-\mathbf{2 2}^{+\cdot}$ were shown to be very similar (130). From a corresponding study of methyl and dimethyl ethylbenzenes, Meyer and Harrison (131) concluded that fragmentation takes place after ring expansion to the corresponding ionized di- or trimethylcycloheptatrienes (e.g., $25^{+*}$ ). The loss of $\mathrm{CH}_{3}^{*}$ was proposed to occur after initial 1,2-H shift and insertion of the (carbene-like) $\mathrm{CHCH}_{3}$ grouping at random between two carbon atoms of the ring to give $26^{+}$as the eventually fragmenting species (Scheme III). 

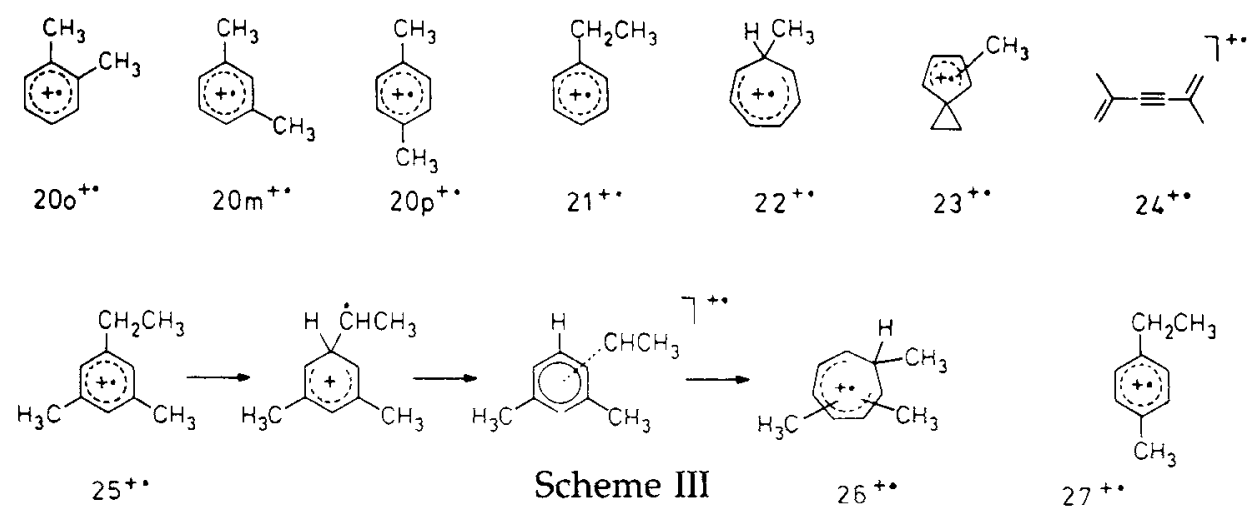

The authors showed that for low-energy $25^{+\bullet}$ ions, all of the three original methyl groups become equivalent. In light of later results $(70,71,89,93)$, it is interesting that ionized para-ethyltoluene $27^{+*}$ appears somewhat more reluctant to undergo ring expansion. The isomerization of $27^{+\bullet}$ (131) was reexamined recently by using CE and CID techniques (132), and energy-dependent, incomplete interconversion of all possible dimethylcycloheptatriene ions was suggested. A partial ring contraction was found for long-lived ions $22^{+\cdot}$ formed directly from the neutral triene (93). Stapleton et al. (71) estimated lower and higher energy limits of the activation barriers toward ring expansion of ions $7^{+\bullet}, 20^{+\bullet}, 21^{+\bullet}, 27^{+\bullet}$, and some other (lower) alkylbenzene ions. From the occurrence or nonoccurrence of fragmentation reactions and from comparison of the kinetic energy releases during the breakdown of isomeric ions, the authors deduced the energy-determining role of the skeletal rearrangement of $20^{+\cdot}$ as well as of ionized mesitylene and durene. In line with Harrison's results $(131,132)$, the skeletal reorganization in toluene ions bearing an additional ethyl or higher side-chain (e.g., $27^{+*}$ ) involves preferentially the latter (larger) substituent, thus decreasing the corresponding transition state below the threshold of fragmentation.

Similar arguments, based on drastically different kinetic energy releases, were applied to halogen-substituted toluenes and ethylbenzenes, in addition to previous work by Williams and co-workers $(133,134)$. A later CID study by McLafferty and Bockhoff (98) indicated the ring expansion reaction to occur even for ionized benzyl chloride and bromide at very low excess energies (see, however, ref. 100). In a related communication, Köppel and McLafferty (135) reported partial ring expansion in ionized 4-bromo-1-ethyl-benzene (see next section). The rearrangements of ionized halogenotoluenes were also treated by Tajima and Tsuchiya (136) and by Holmes et al. (137), the latter authors reporting characteristically different peak shapes for the loss of $\mathrm{I}^{\circ}$ from the ionized iodotoluenes. Previous work by Brown (138-143) on the energetics and kinetics of mass spectral fragmentation of various toluene derivatives may be recalled. These and additional early studies by Lightner, Majeti, et al. $(144,145)$ were also interpreted in terms of (irreversible) ring expansion yielding substituted $22^{+\cdot}$ ions.

The suggested rate-determining character of hydrogen migration after ring expansion of halogen-substituted alkylbenzene ions $(71,131,134)$ is questionable be- 
cause of the low energy requirements for this process $(69,70)$. Rather, the 1,2- or $1,3-\mathrm{H}$ shifts preceding (or even initiating) the actual ring expansion step appear to be rate and energy determining. This is consistent with earlier investigations by Meyerson and Fields (146) on polymethylbenzenes, showing a marked influence of the steric and/or electronic environment of the methyl group that is to be incorporated into the seven-membered ring. This point was substantiated by the MINDO/3 calculations on the isomerization of $\mathrm{C}_{7} \mathrm{H}_{8}{ }^{+\cdot}(69)$ and later MNDO studies on $\mathrm{C}_{8} \mathrm{H}_{10}{ }^{+}[(70)$, see below], as well as by experimental work by McLafferty and Bockhoff (147) on heterosubstituted $7^{+\cdot}$ ions.

A deeper insight into the rearrangement processes of $\mathrm{C}_{8} \mathrm{H}_{10}{ }^{+\cdot}$ ions $20 \mathbf{p}^{+\bullet}, \mathbf{2 1}^{+\bullet}$, and $22^{+\circ}$ was achieved by Grotemeyer and Grützmacher $(70,148)$, who performed extensive labeling experiments combined with energy (MNDO) and kinetic (RRKM) calculations. This study demonstrates the interplay of internal energy and kinetics on the competition between isomerization and fragmentation reactions. Although loss of $\mathrm{CH}_{3}{ }^{-}$from $22^{+\cdot}$ is the energy-determining step, the preceding rearrangements $20 \mathrm{p}^{+\cdot} \rightarrow \mathbf{2 2}^{+^{-}}$and $21^{+\cdot} \rightarrow \mathbf{2 2}^{+^{-}}$are rate-determining. At threshold energies, the rates of the reverse processes $22^{+\cdot} \rightarrow 20 \mathrm{p}^{+^{\bullet}}$ and $22^{+} \rightarrow 21^{+}$, respectively, are higher than or similar to those for the fragmentation of $22^{+\bullet}$; hence metastable ions $20 \mathrm{p}^{+\cdot}$ undergo complete carbon and hydrogen scrambling $\left(20 \mathrm{p}^{+\bullet} \leftrightarrows 22^{+\bullet}\right)$, whereas metastable ions $21^{+\cdot}$ exhibit competing behavior, $40 \%$ of the ions decomposing after rearrangement to $22^{+\cdot}$ and $60 \%$ after additional interconversion with $20 \mathrm{p}^{+\cdot}$ via $22^{+\cdot}$ (Scheme IV). From the same dynamic model, the prevailing specificity observed (93) for loss of $\mathrm{CH}_{3}$ from metastable $\mathbf{2 2}^{+\cdot}$ is explained by "kinetic trapping" (70) of the major portion of these $\mathrm{C}_{8} \mathrm{H}_{10}{ }^{+\cdot}$ ions as unreactive isomers $20 \mathrm{p}^{+}$.

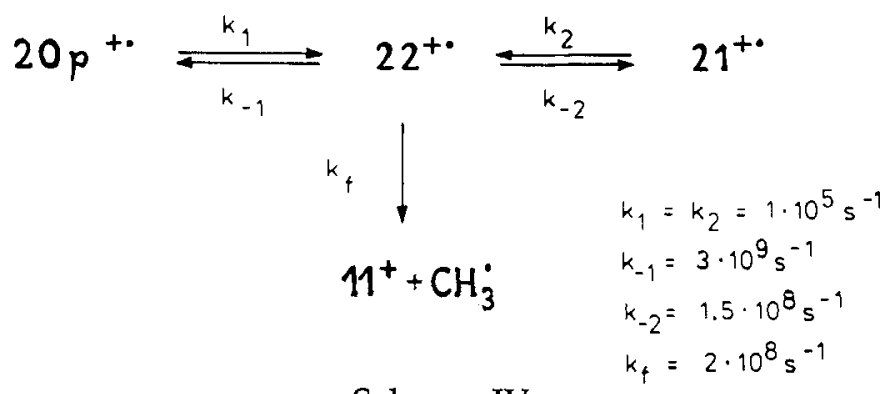

Scheme IV

Summarizing at this point, we know that the fragmentation of di- and more highly substituted lower alkylbenzenes and of related halogen-substituted derivatives occurs mainly by (mostly rate-determining) ring expansion to the corresponding ionized alkylcycloheptatrienes. Recontraction of the seven-membered ring appears possible starting from ionized alkylbenzenes, but appears to be irrelevant to the fragmentation of the isomeric $22^{+}$derivatives. This is in part due to the deep potential wells assumed for ionized polymethylbenzenes $(70,71,147)$. Consistent evidence was obtained from binuclear analogs [e.g., ionized ( $\beta$-phenethyl)-cycloheptatriene (89)], but completely contrasting behavior was found for protonated alkylcycloheptatrienes (149), as discussed in Part II of this review. 
In light of the variety of slow isomerization processes, it is not surprising that $\mathrm{C}_{7} \mathrm{H}_{8}{ }^{+}$type rearrangements are usually not seen for field-ionized species. Levsen and Beckey (150) compared FI and normal EI mass spectra of 20m, 21, some butylbenzenes, and varicus heterofunctionalized toluene derivatives and suggested that fragmentation occurs by direct cleavage of a benzylic bond [however, cf., metastable $7^{+\cdot}$ formed by FI (150)]. For the same reasons, attempts to produce distinct mass spectra of the isomeric xylenes proved unsuccessful since Meyerson's early report (1). In contrast, the utilization of negative CI allowed to distinguish the meta isomer $20 \mathrm{~m}(151)$ as did the nearly thermoneutral proton transfer equilibria in the ICR cell (152); in either case, the carbon framework of 20 were certainly preserved. Moreover, Mukhtar et al. (153) applied laser PD on the $\mathrm{CH}_{3}{ }^{\circ}$

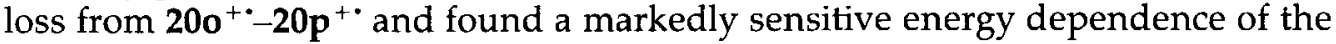
kinetic energy released from $20 \mathrm{p}^{+}$compared with the other isomers. This effect was interpreted by Curtis et al. (154). By using soft ionization (atmospheric pressure ionization, API) and "low-energy" CID techniques in a triple-quadrupole mass spectrometer, further slight differences were found. In addition, the latter authors discussed previous, conflicting results (71) on the basis of Grützmacher's dynamic isomerization model of $\mathrm{C}_{8} \mathrm{H}_{10}{ }^{+\cdot}(70)$ and interpreted Meyerson's (1) and their own labeling data on the loss of $\mathrm{H}^{\cdot}$ from high-energy labeled $20 \mathbf{p}^{+\cdot}$ ions in terms of Harrison's (131) preference and isotope factors. Somewhat later, Kingston et al. (107) observed only slight differences in the fragmentation of $20 \mathrm{o}^{+\cdot}-\mathbf{2 0} \mathrm{p}^{+}$ by performing charge-stripping/charge exchange (CS/CE) measurements in a triple-sector instrument; isomeric ions $21^{+*}$, by contrast, exhibited marked differences.

Photodissociation mass spectrometry appears, in principle, more promising to distinguish isomeric alkylbenzenes. This topic was reviewed by Dunbar $(155,156)$. The PD spectra of the simpler ionized alkylbenzenes were published by Dymerski et al. (157) and found to correlate well with the corresponding photoelectron spectra. The PD spectra of the three ionized trimethylbenzenes were recorded by Teng and Dunbar (158) and exhibit slightly different dissociation maxima. Halogen-substituted toluenes were also examined in great detail (159). For the series of the halogenotoluene ions, a considerable red shift of the PD bands was found upon fluoro to iodo substitution, according to decreasing C-Hal bond strength. Remarkable differences were also found within the sets of the isomeric fluoroand iodotoluene cations. Isomerization of ionized benzyl chloride $28^{+} \cdot$ under the conditions of PD-ICR mass spectrometry was suggested (159) to occur by ionmolecule collisions. This emerged from the remarkable finding that $28^{+*}$, absorbing in the red $(600 \mathrm{~nm})$, reacts with its neutral precursor 28 to yield a blueabsorbing $(450 \mathrm{~nm})$ product ion, perhaps ionized chlorotoluene $\left(29^{+}\right)$. Morgenthaler and Eyler (160) reported that no rearrangement product forms under their experimental conditions; but Honovich and Dunbar (161) attributed the chameleon-like behavior of $28^{+}$to a collision-induced bimolecular rearrangement. Again, reference is given to a study of absorption spectra and rearrangement reactions of ionized halogenotoluenes in solid argon matrix (162).

Very recently, Olesik et al. (163) reported on the dissociation dynamics of the ionized halogenotoluenes. PEPICO measurements and RRKM/QET simulations, 
combined with the cietermination of the kinetic energy released during halogen loss, indicate that only the iodotoluene ions undergo direct bond cleavage to give $\mathrm{C}_{7} \mathrm{H}_{7}{ }^{+}$(tolyl) ions. In line with CID data of the $\mathrm{C}_{7} \mathrm{H}_{7}{ }^{+}$product ion mixtures, the fragmentation of chloro- and bromotoluene ions appears to occur exclusively after rearrangement, and the rate-energy curves $k(E)$ for a set of isomeric chloro- and bromotoluene ions are in accord with slightly different activation energies $\left(E_{a}\right)$. Ionized iodotoluenes appear as a special case in that two dissociation channels were observed, one of them yielding $\mathbf{1 1}^{+}$via an unidentified isomer. Similar conclusions were drawn by Dunbar et al. (164) from a PD study on ionized metabromo and meta-iodotoluene. For the latter ions, these authors deduced that the isomerization barrier for skeletal rearrangement is close to that of direct bond cleavage $\left(53 \mathrm{kcal} \cdot \mathrm{mol}^{-1}\right)$.

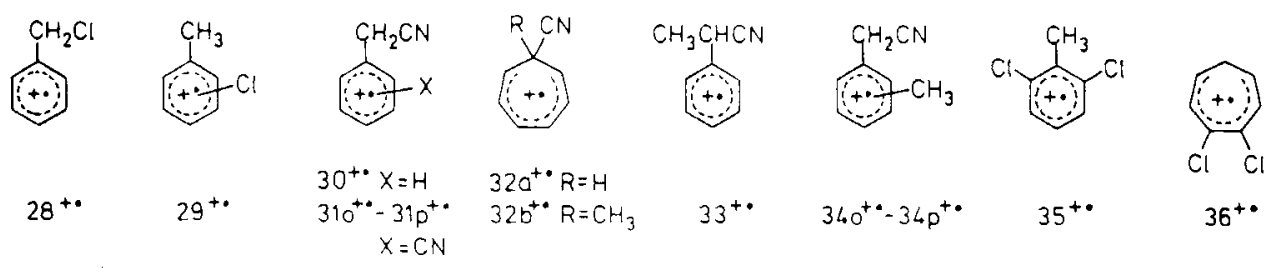

Considerable work has been carried out on the isomerization and fragmentation of other heterosubstituted $\mathrm{C}_{7} \mathrm{H}_{8}{ }^{+}$and $\mathrm{C}_{8} \mathrm{H}_{10}{ }^{+\cdot}$ ions. Using extensive isotope labeling, Molenaar-Langeveld et al. (165) suggested that ring expansion processes are suppressed in ionized benzyl and cyanobenzyl cyanides $30^{+\cdot}$ and $310^{+\cdot}-31 \mathrm{p}^{+\cdot}$, although some carbon and extensive hydrogen scrambling was found prior to loss of HCN, in contrast to previous work (166). In line with this finding, ionized 7 -cyano- and 7-cyano-7-methylcycloheptatriene $\left(32 \mathbf{a}^{+\cdot}\right.$ and $\left.\mathbf{3 2} \mathbf{b}^{+\cdot}\right)$ were shown to undergo ring contraction prior to fragmentation $(167,168)$. The latter work includes the investigation of isomeric ions $33^{+\cdot}, 34 \mathrm{o}^{+\cdot}, 34 \mathrm{p}^{+\cdot}$, and those of some ionized dimethyl benzonitriles. In total, the results on cyanosubstituted alkylbenzenes are in line with Hoffmann's suggestion (76) that electron-withdrawing groups facilitate the formation of norcaradiene-type structures (13) compared with those derived from cycloheptatriene (10). Hoffman and Amos (169) compared the mass spectra of 2,6-dichlorotoluene 35 and 3,4-dichlorocycloheptatriene 36 and concluded that almost complete equilibration occurred after decomposition of the molecular ions. In the light of the detailed arguments discussed above, a ring expansion $\left(35^{+\cdot} \rightarrow 36^{+\bullet}\right)$ at the level of the molecular ions appears much more likely.

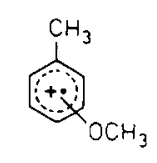

$37 m^{+}, 37 p^{+*}$

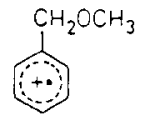

$38^{+\cdot}$

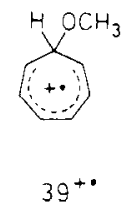

$39^{+\cdot}$

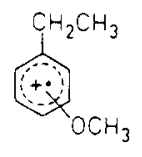

$40 \mathrm{~m}^{+\cdot}, 40 \mathrm{p}^{+\cdot}$

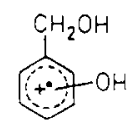

$410^{+*}-41 p^{+*}$

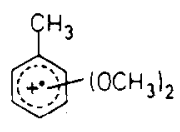

$42^{+*}$

A number of detailed reports describe $\mathrm{C}_{7} \mathrm{H}_{8}{ }^{+}$and $\mathrm{C}_{8} \mathrm{H}_{10}{ }^{+\cdot}$ ions bearing oxy functions. In contrast to the cyano group, alkoxy and hydroxy substituents favor 
the formation of both benzyl- and tropylium-type ions $\left(\mathbf{8}^{+}\right.$and $\left.\mathbf{1 1}^{+}\right)$, hence the interconversion of the molecular ions may be pre-empted in these cases. Early work (170), however, had shown that ionized methoxytoluenes $37 \mathrm{~m}^{+\cdot}$ and $37 \mathrm{p}^{+\cdot}$ expel $\mathrm{H}^{*}$ not only from the ring-methyl group but also from the ring, suggesting the formation of hydroxytropylium ions especially from $37 \mathrm{~m}^{+\cdot}(171)$. In this classic work (170), ionized methyl ethers $38^{+\cdot}$ and $39^{+\cdot}$ as well as the ethylanisoles $40 \mathrm{~m}^{+\cdot}$ and $40 \mathrm{p}^{+}$were also studied in great detail. Ring expansion at the level of the molecular ions, however, was excluded from Molenaar-Langeveld and Nibbering's (172) extensive labelling study of ionized meta-hydroxybenzyl alcohol $41 \mathrm{~m}^{+}$.

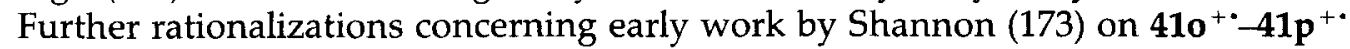
was given (172), invoking the electronic effect of the ring-OH group upon fragmentation. On the basis of the different reactivity of the $\mathrm{C}_{7} \mathrm{H}_{7}{ }^{+}$ions from $38^{+}$ and $39^{+}$, Venema et al. (174) concluded that the latter (short-lived) ions do not undergo ring contraction, in contrast to the metastable $39^{+\cdot}$ ions studied by Cooks et al. (106).

Florencio et al. (174) compared the mass spectral fragmentation of the complete set of the dimethoxytoluenes 42. From the kinetic energy release measured for various fragmentation reactions, it is evident that the molecular ions retain the six-membered structure prior to fragmentation. Some fragment ions may have rearranged subsequently to dimethoxytropylium structures. Considerable additional work was published on the fragmentation of hydroxy- and methoxy-substituted alkylbenzenes $(85,138,139,141-145,176-178)$, the majority of which indicates suppression of the ring expansion by electron-donating substituents. Therefore, the mass spectrometric distinction of positional isomers of phenols, anisoles etc. is often particularly reliable. This holds especially for ortho isomers in cases of specific interaction of the vicinal substituents; but, besides this well-known "orthoeffect" (179), alkylbenzenes bearing electron-donating substituents at the meta and para positions can be readily distinguished.

Very recently, similar conclusions were drawn by Chang and Johnston (180) from resonance-enhanced multiphoton ionization (REMPI) mass spectrometry of several $\mathrm{C}_{7} \mathrm{H}_{8} \mathrm{O}$ and $\mathrm{C}_{8} \mathrm{H}_{10} \mathrm{O}$ isomers. Electron-withdrawing groups, however, do not allow such ready distinction between meta and para isomers. Besides work by Lightner et al. $(144,145)$ and by Kuck and Grützmacher $(85)$ on substituted lower alkylbenzenes bearing electron-withdrawing substituents at the ring, a classic paper by Meyerson et al. (181) on nitrotoluenes and more recent ones by Butcher and Thomas (182) and by Baldwin and co-workers (183) on the isomeric ring-nitro-substituted alkylbenzenes may be mentioned.

\section{B. The $\mathrm{C}_{7} \mathrm{H}_{7}{ }^{+}$fragment ions and their homologs, $\mathrm{C}_{8} \mathrm{H}_{9}{ }^{+}$and $\mathrm{C}_{9} \mathrm{H}_{11}{ }^{+}$ \\ 1. $\mathrm{C}_{7} \mathrm{H}_{7}+$ ions}

A review on mass spectrometry of alkylbenzenes cannot ignore the features of the best-known of all organic ions ever investigated in the gas phase: $\mathrm{C}_{7} \mathrm{H}_{7}{ }^{+}$. It is formed as the most prominent primary fragment ion from ionized alkylbenzenes and has, therefore, been studied in great detail. Indeed, even though they have 
been mentioned several times in the previous section, $\mathrm{C}_{7} \mathrm{H}_{7}{ }^{+}$and related fragment ions demand further consideration.

The stability of the benzyl ion $\left(8^{+}\right)$, the product of "simple" cleavage of $7^{+\bullet}$ and homologous ionized alkylbenzenes, has been settled by a considerable number of investigations to be somewhat less than that of the isomeric tropylium ion $\left(11^{+}\right)$. Whereas the latter ion forms stable salts $(184,185)$, the former has been observed only as transient species in solution (186). Accepted values for the heats of formation of gaseous tropylium ion are in the range $203 \leqslant \Delta H_{f}\left(\mathbf{1 1}^{+}\right) \leqslant 211$ $\mathrm{kcal} \cdot \mathrm{mol}^{-1}(28,31,108,187-191)$ whereas those of benzyl ion are within $211 \leqslant \Delta H_{f}\left(8^{+}\right)$ $\leqslant 219 \mathrm{kcal} \cdot \mathrm{mol}^{-1}(92,191-197)$. Besides these, other, somewhat higher values were determined for both isomers $(28,31)$, but the overall outcome is that $\Delta H_{f}\left(8^{+}\right)-$ $\Delta H_{f}\left(1^{+}\right) \simeq 9 \mathrm{kcal} \cdot \mathrm{mol}^{-1}(95,191,198)$. This trend is reproduced also by ab initio (194) and semiempirical (199) calculations.

The thermochemistry of other $\mathrm{C}_{7} \mathrm{H}_{7}{ }^{+}$isomers, of which the tolyl ions $\left(430^{+}-\right.$ $43 p^{+}$) are the most important, has not been determined by experiment until very recently; however, Dewar, Cone, and Landman (199-201) performed detailed MINDO/3 calculations on the rearrangements of $\mathrm{C}_{7} \mathrm{H}_{7}{ }^{+}$and various substituted $\mathrm{C}_{7} \mathrm{H}_{7}{ }^{+}$ions. $A b$ initio calculations on the isomeric $43^{+}$ions were reported by Dill et al. (202). A valence-bond treatment on $11^{+}$ions was published earlier by Gallup and Norbeck (203). Two very recent papers $(164,197)$ reported the first experimentally determined heats of formation for tolyl ions. From the PEPICO investigation of the corresponding nitrotoluenes (197), $\Delta H_{f}\left(43 \mathrm{~m}^{+}\right)=252$ and $\Delta H_{f}\left(43 \mathrm{p}^{+}\right)$ $=257 \mathrm{kcal} \cdot \mathrm{mol}^{-1}$ were obtained, and the PD study on bromo- and iodotoluenes (164) yielded $\Delta H_{f}\left(43 \mathrm{~m}^{+}\right)=258 \mathrm{kcal} \cdot \mathrm{mol}^{-1}$, in fair agreement with the ab initio results (202).
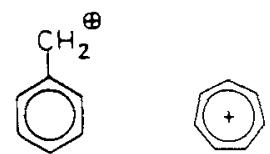

$8^{+}$

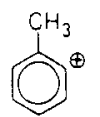

$430^{+}$

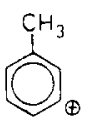

$43 \mathrm{~m}^{+}$

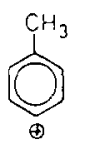

$43 p^{+}$

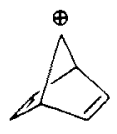

$66^{+}$

According to the above thermochemistry, $\mathbf{1 1}^{+}$represents the thermodynamically controlled product of fragmentation for the unsubstituted alkylbenzenes. Given particularly low internal (excess) energies and enough time, the precursor molecular ions (e.g., $7^{+\bullet}, \mathbf{2 0}^{+*}$, and $21^{+}$) may rearrange to the corresponding ionized cycloheptatriene (e.g., $\mathbf{1 0}^{+\cdot}$ or $2^{+*}$ ), which then fragments by direct bond cleavage to give $\mathbf{1 1}^{+}$or the corresponding substituted tropylium ion. This has been shown by a number of groups by applying soft EI, CI, and PI ionization conditions. At higher excitation energies, isomerization of the precursor ions might be suppressed kinetically and hence more benzyl-type ions might form by direct ' $\beta$-cleavage' (5) of the original carbon skeleton. Due to increased excess energies, however, interconversion then can take place on the level of the fragment ions (e.g., $\mathbf{8}^{+} \leftrightarrows \mathbf{1 1}^{+}$). The energy barrier of this isomerization is predicted by the MINDO/3 calculations (199) to be $\simeq 33 \mathrm{kcal} \cdot \mathrm{mol}^{-1}$ [i.e., of similar height as that estimated for the formally related rearrangement $\left.7^{+\bullet} \leftrightarrows \mathbf{1 0}^{+\cdot}(69)\right]$. 
Most of the various labeling experiments point to degeneracy of the $\mathrm{C}$ and $\mathrm{H}$ atoms in $\mathrm{C}_{7} \mathrm{H}_{7}{ }^{+}$ions prior to secondary fragmentation, viz. loss of $\mathrm{C}_{2} \mathrm{H}_{2}$ to give $\mathrm{C}_{5} \mathrm{H}_{5}{ }^{+}$, requiring additional internal energy of $\simeq 96 \mathrm{kcal} \cdot \mathrm{mol}^{-1}(31,198)$. A certain vagueness, being readily adopted in textbooks on general organic chemistry, however, emerged in separating the two interconversions discussed above. Several dedicated double-labeling studies $(59,62,63)$ were performed, starting with $\mathrm{C}_{7} \mathrm{H}_{8}$ precursors; but only the direct study of tropylium halides, excluding $\mathrm{C}_{7} \mathrm{H}_{8}{ }^{+} \cdot$ type rearrangements to intervene, assured the existence of the $\mathrm{C}_{7} \mathrm{H}_{7}{ }^{+}$type equilibrium. Thus, as shown by Siegel (204), $\mathbf{1 1}^{+} \mathrm{I}^{-}$, which does not form molecular ions but "parent" $\mathrm{C}_{7} \mathrm{H}_{7}{ }^{+}$ions (205), exhibits extensive albeit incomplete carbon equilibration after $\mathrm{EI}$ at 70 and $20 \mathrm{eV}$, increasing with decreasing ionization energy. (However, as stated recently by Buschek et al. (100), interference of $\mathrm{C}_{7} \mathrm{H}_{8}{ }^{+}$ions stemming from thermal degradation of $11^{+}$salts $(206,207)$ has to be considered).

The identification of the $8^{+}, \mathbf{1 1}^{+}$, and $\mathbf{4 3}^{+}$and their quantitative determination in the gaseous ion mixture have been a central question over the years. Detailed CID measurements by McLafferty and Winkler $(90,91)$ and later by Köppel et al. (208) showed that all of these ions as well as a further isomer, presumably norbornadienyl $\left(\mathbf{4 4}^{+}\right)$, can be produced and detected in various relative abundances, ranging from apparently "pure" $8^{+}$(by low-energy EI from 1,2-diphenylethane) to pure $11^{+}$(by high pressure EI of 7) and to pure tolyl ions $43 m^{+}$and $43 p^{+}$. The main feature to distinguish $\mathbf{8}^{+}$and $\mathbf{1 1}^{+}$ions by CID is the abundance ratio of $\mathrm{C}_{6} \mathrm{H}_{5}{ }^{+}$and $\mathrm{C}_{6} \mathrm{H}_{2}{ }^{+}\left(\left[77^{+}\right] /\left[74^{+}\right]\right)$. The tolyl ions are accessible either by lowenergy $\mathrm{EI}$ of the appropriate nitrotoluenes or by $\mathrm{CI}\left(\mathrm{CH}_{4}\right)$ or $\mathrm{Cl}\left(\mathrm{CH}_{4} /\right.$ toluene) of halogeno- (in particular, fluoro-) toluenes, as introduced by Leung et al. (209). In the presence of arenes, $8^{+}$ions are quenched from the mixture by electrophilic attack [methylene transfer, Scheme V, Eq. (a)].

By extending one of these approaches, Baer et al. (197) recently applied the PEPICO method to the fragmentation of nitrotoluenes to study the thermochemistry of ions $\mathbf{4 3} \mathrm{m}^{+}$and $\mathbf{4 3} \mathrm{p}^{+}$(vide supra). The ortho isomer $\mathbf{4 3 0 ^ { + }}$, however, still remains experimentally undetermined (see also ref. 424). The CI approach proved most useful to generate a variety of tolyl ions, yielding the corresponding protonated arene (arenium ion) by subsequent addition of the reagent gas molecule $(19,209)$. Some further examples of this reaction sequence will be presented in Part II. Notwithstanding the overall consistency of these findings, a recent debate on the reliability of the CID technique to determine quantitatively the composition of a mixture of isomeric gaseous ions was centered in part around the $\mathrm{C}_{7} \mathrm{H}_{7}{ }^{+}$ problem $(210,211) . \mathrm{C}_{7} \mathrm{H}_{7}{ }^{+}$ions with different (unimolecular) reactivity were found by Hoffman and Wallace (212) upon EI-induced fragmentation of benzylphenylacetate.

Recently, the differentiation of $\mathbf{8}^{+}$and $\mathbf{1 1}^{+}$isomers by CID, ICR, and PD/ICR techniques was critically reinvestigated by Buschek et al. (100). In contrast to previous work, these authors found more distinct $\left[77^{+}\right] /\left[74^{+}\right]$abundance ratios for $\mathbf{8}^{+}(3.15 \pm 0.2)$ and $11^{+}(0.35 \pm 0.03)$, by correcting for impurities and incomplete quenching of $8^{+}$during formation of "pure" $11^{+}$ions. Moreover, lowenergy $7^{+\cdot}$ ions were found to yield, at threshold for loss of $\mathrm{H}^{\circ}$, a 55:45 mixture of $8^{+}$and $11^{+}$, suggesting that $7^{+\cdot}$ ions do not form $\mathbf{1 1}^{+}$at the dissociation limit. 
From a recent application of the NRMS technique, Buschek and Holmes (213) suggested that ortho-tolyl radicals generated from $43 \mathrm{o}^{+}$upon $C E$ with xenon do not rearrange to benzyl radicals on the time scale of the experiment $\left(\simeq 0.7 \cdot 10^{-6}\right.$ s). The increase of the $\left[77^{+}\right] /\left[74^{+}\right]$abundance radio from $\mathrm{C}_{7} \mathrm{H}_{7}{ }^{+}$ions with increasing collision energy was reported previously $(214,215)$.

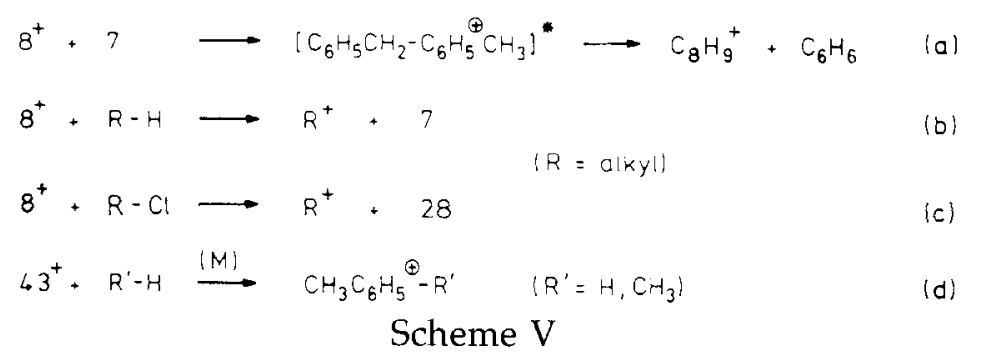

Another, independent approach to analyze mixtures of $\mathrm{C}_{7} \mathrm{H}_{7}{ }^{+}$ions has been to utilize their intermolecular reactivity (Scheme V). As stated above, tropylium ions $\mathbf{1 1}^{+}$were found to be inert throughout all experiments; thus no positive probe reaction has been found hitherto for this isomer. In contrast, benzyl ions $\left(7^{+}\right)$ react by electrophilic attack on neutral arenes $(92,95,96)$ and by halide abstraction from $t$-butyl halides $(92,94,194,216)$, whereas tolyl ions $\left(\mathbf{4 3}{ }^{+}\right)$undergo formal insertion into $\sigma$-bonds of saturated $\mathrm{CI}$ gas molecules $\left(\mathrm{H}_{2}, \mathrm{CH}_{4}\right)(19,209)$. Further reactions of $8^{+}$such as hydride transfer from alkanes and condensation reactions with alkenes were investigated by Ausloos et al. (94). Ions $8^{+}$formed upon radiolysis of $2^{+\cdot}$ were shown to react with $\left(\mathrm{CH}_{3}\right)_{2} \mathrm{NH}$ (217). In line with this, Venema and Nibbering (174) and Bruins and Nibbering (218) observed bimolecular nucleophilic attack of $\left(\mathrm{CH}_{3}\right)_{2} \mathrm{O},\left(\mathrm{CH}_{3}\right)_{2} \mathrm{NH}$, and $\left(\mathrm{CH}_{3}\right)_{3} \mathrm{~N}$ on protonated benzyl methyl ether (38) and on free $8^{+}$ions generated therefrom (see also ref. 219). Sen Sharma and Kebarle (97) studied the gas-phase reactivity of $\mathbf{8}^{+}$and $\mathbf{1 1}^{+}$under high pressure conditions (HPMS), producing the latter ions by smooth hydride abstraction from 10 with $t-\mathrm{C}_{4} \mathrm{H}_{9}{ }^{+}$, again as totally inert species. An attempt by McCrery and Freiser (220) to activate $\mathbf{1 1}^{+}$photochemically to initiate its isomerization to $8^{+}$failed, resulting instead in the unprecedented photodissociation of the reactive $\mathrm{C}_{7} \mathrm{H}_{7}{ }^{+}$isomer $\left(8^{+}\right.$, Scheme $\left.\mathrm{V}\right)$ to $\mathrm{C}_{5} \mathrm{H}_{5}{ }^{+}$and $\mathrm{C}_{2} \mathrm{H}_{2}$.

The electrophilic substitution of arenes by ions $8^{+}$was originally shown to occur by Wexler and Clow (221), Giardini-Guidoni and Zocchi (222) in highpressure EI sources, as well as by Yamamoto et al. $(113,114,223)$, who chemically isolated the various diphenylmethane derivatives formed during ${ }^{60} \mathrm{Co}-\gamma$ radiolysis of the alkylbenzenes. In line with the findings from unimolecular decomposition, the latter authors observed partial isotope scrambling in the neutral radiolysis products (113). In the more recent CE/ICR study, Ausloos (99) used the methylene transfer reaction to probe the degree of hydrogen scrambling in ions $\mathbf{8}^{+}$as a function of internal energy. The reaction was shown to occur without significant scrambling of the methylene hydrogen atoms, in accordance with a recent CI/MIKES study of benzylbenzenium ions by Kuck and Bäther (224) (see Part II). Ausloos (99) confirmed that, besides the low- 
energy isomerizations of the parent ions $7^{+\cdot}$ and $21^{+*}$, the fast equilibrium $8^{+}$ $\leftrightarrows \mathbf{1 1}^{+}$occurs at high energies, remarkably close to the fragmentation threshold, in contrast to the interpretation of CID results $(91,98)$.

Heterosubstituted $\mathrm{C}_{7} \mathrm{H}_{7}{ }^{+}$ions have been of particular interest because of the site-specific substituent effects on $8^{+}$in contrast to $\mathbf{1 1}^{+}$. In terms of simple PMO theory (225) $8^{+}$can be described as an "alternant" hydrocarbon whereas $\mathbf{1 1}^{+}$represents a "nonalternant" one. Given a good leaving group in the precursor benzyl derivative, the formation of $\mathrm{C}_{7} \mathrm{H}_{6} \mathrm{X}^{+}$ions serve as a convenient probe to distinguish the various factors governing mass spectrometric fragmentation, including the question of the validity of QET to (large) organic ions. Substituent effects on the formation of $\mathrm{C}_{7} \mathrm{H}_{7}{ }^{+}$ions were studied in great detail by Ward et al. (226) and by Brown $(138,141,142)$ with substituted benzyl phenyl ethers as well as by McLafferty et al. $(121,227)$ with substituted 1,2-diphenylethanes.

As mentioned in the previous section, substituents affect the relative stability of both the isomeric $\mathrm{C}_{7} \mathrm{H}_{8}{ }^{+}$radical cations and the $\mathrm{C}_{7} \mathrm{H}_{7}{ }^{+}$fragment ions. In their classical work on appearance energies of $\mathrm{C}_{7} \mathrm{H}_{6} \mathrm{X}^{+}$from substituted toluenes, Tait et al. (176) suggested that the majority of the fragment ions have the tropylium structure, with the exception of $\mathrm{C}_{7} \mathrm{H}_{6}\left(\mathrm{OCH}_{3}\right)^{+}$which prefers the benzyl skeleton. In agreement with previous work by Harrison et al. (228) and with the substituent effects found in solution, stabilization of the benzyl structure is strongest with para- $\mathrm{OCH}_{3}$ and less with the para-OH substituent. On the other hand, Shapiro and Serum, in a later study (229), proposed that the strongly electron-withdrawing nitro group also favors the formation of the benzylic structure. In line with this, Dewar and Landman (200) suggested from their MINDO/3 calculations that the ring expansion of both $\mathrm{C}_{7} \mathrm{H}_{6}(\mathrm{OH})^{+}$and $\mathrm{C}_{7} \mathrm{H}_{6}\left(\mathrm{NO}_{2}\right)^{+}$requires activation energies as high as 45 and $33 \mathrm{kcal} \cdot \mathrm{mol}^{-1}$, respectively, in spite of serious ambiguities concerning the thermochemistry of the isomerization. In a further MINDO/3 study (201), the stabilization of $\mathbf{8}^{+}$ relative to $11^{+}$by a whole array of substituents was estimated, $\mathrm{NO}_{2}$ appearing almost as effective as $\mathrm{OH}$ and $\mathrm{CH}_{3}$. As expected, the $\mathrm{NH}_{2}$ group was calculated to be even more stabilizing than $\mathrm{OCH}_{3}$, the strongest effects were predicted at the $\alpha$ and para position of $8^{+}$and somewhat less in $11^{+}$. Bruins et al. (230), however, found that metastable $\mathrm{C}_{7} \mathrm{H}_{6}\left(\mathrm{NH}_{2}\right)^{+}$ions generated from benzyl amine on one hand and $p$-toluidine on the other do not interconvert prior to loss of HCN. The former ion was suggested to be the $\alpha$-isomer $\mathrm{C}_{6} \mathrm{H}_{5} \mathrm{CH}^{+} \mathrm{NH}_{2}$ giving benzenium ions $\left(\mathrm{C}_{6} \mathrm{H}_{7}{ }^{+}\right)$in a specific secondary fragmentation, in contrast to $\mathrm{C}_{7} \mathrm{H}_{6}\left(\mathrm{NH}_{2}\right)^{+}$ions from $p$-toluidine.

Recent reports from Cassidy et al. and Russell et al. $(231,232)$ suggest, on the basis of data from an impressive combination of techniques (see also ref. 107), the existence of at least five stable $\mathrm{C}_{7} \mathrm{H}_{6}(\mathrm{OH})^{+}$isomers, including $\alpha$-hydroxybenzyl, hydroxytropylium, and $p$-hydroxybenzyl ions. Their heats of formation were found to increase in this order, in contrast to arguments based on MINDO/3 $(200,201)$. In accordance with the above experiments and calculations, as well as chemical intuition, most of the hydroxy-substituted $\mathrm{C}_{7} \mathrm{H}_{7}{ }^{+}$ions, however, appear to reside in deep potential wells. 
2. $\mathrm{C}_{8} \mathrm{H}_{9}+$ ions

Methyl-substituted $\mathrm{C}_{7} \mathrm{H}_{7}{ }^{+}$ions represent a case of particular interest because these ions are readily formed in the mass spectra of various alkylbenzenes. As found in general, the presence of additional or extended alkyl groups might both stabilize certain isomeric intermediates and offer further fragmentation channels of low-energy requirement, rendering the ions' overall reactivity more specific. This trend is clearly confirmed in the series of homologous ions $\mathrm{C}_{7} \mathrm{H}_{7}{ }^{+}, \mathrm{C}_{8} \mathrm{H}_{9}{ }^{+}$, and $\mathrm{C}_{9} \mathrm{H}_{11}{ }^{+}$.

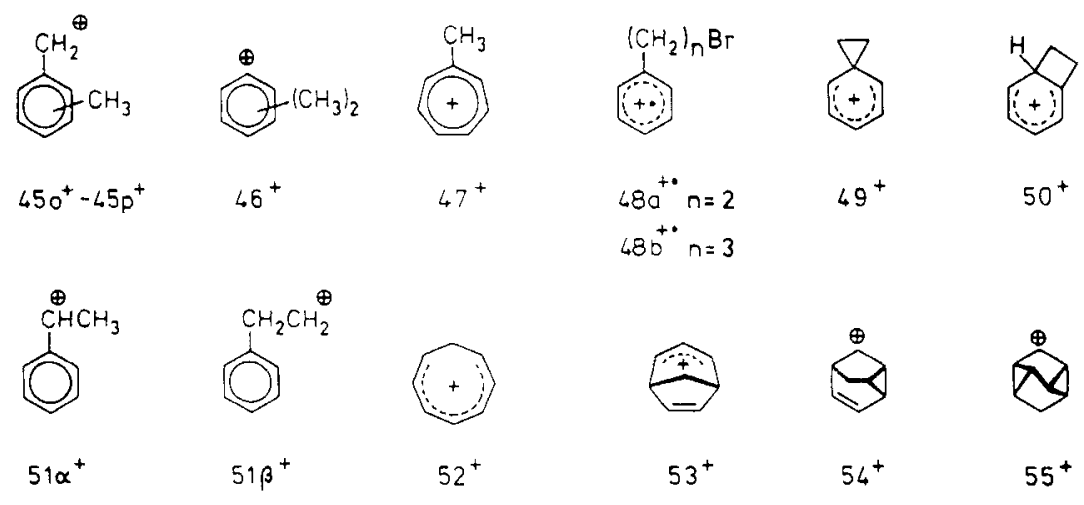

$\mathrm{C}_{8} \mathrm{H}_{9}{ }^{+}$ions were studied by Meyerson and Rylander $(26,58,128)$ and Meyer and Harrison (131), who invoked the formation of methyltropylium ions $47^{+}$along with or instead of methylbenzyl $\left(45^{+}\right)$and xylyl ions $\left(46^{+}\right)$. The heats of formation of $\mathrm{C}_{8} \mathrm{H}_{9}{ }^{+}$ions from various isomeric precursors were found to be constant $(176,233)$, suggesting the formation of common structures. Additional, long-lasting impact on the $\mathrm{C}_{8} \mathrm{H}_{9}{ }^{+}$problem came from pronounced differences in the mass spectral fragmentation of various $\omega$-halogenoalkylbenzenes (inter alia, $48 a^{+\cdot}$ and $48 b^{+\cdot}$ ) observed by McLafferty (234), which led several authors (235-237) to suggest the existence of gaseous ethylenebenzenium ions $\left(49^{+}\right)$. This isomer, originally proposed by Cram $(238,239)$ and verified later as a stable species in superacidic solution $(240,241)$, became a matter of debate through the years, together with the presumed existence of the $\beta$-phenethyl ion $\left(51 \beta^{+}\right)$along with the corresponding $\alpha$ isomer $\left(51 \alpha^{+}\right)$. The formation of other isomers such as homotropylium (cyclooctatrienyl) ions $\left(52^{+}\right)$, suggested earlier (128), and protonated benzocyclobutene $\left(50^{+}\right)$was proposed by Nibbering et al. $(242,243)$ because labeling evidence with low-energy $\mathrm{C}_{8} \mathrm{H}_{9}{ }^{+}$ions pointed to almost complete hydrogen randomization prior to loss of $\mathrm{C}_{2} \mathrm{H}_{2}$. AE measurements of $\mathrm{C}_{8} \mathrm{H}_{9}{ }^{+}$ions from homologous and substituted precursors led Grützmacher (244) to argue against anchimeric assistance via $49^{+}$and the formation of $52^{+}$during the generation of $\mathrm{C}_{8} \mathrm{H}_{9}{ }^{+}$from $48 \mathbf{a}^{+}$. Uccella (245) described similar behavior of metastable $\mathrm{C}_{8} \mathrm{H}_{9}{ }^{+}$ions from $48 \mathrm{a}$ and various structural isomers. The results were rationalized by assuming reversible isomerization, $\left(45 \mathrm{p}^{+}, 45 \mathrm{~m}^{+}\right) \leftrightarrows 47^{+} \leftrightarrows 51 \alpha^{+} \leftrightarrows 51 \beta^{+}$, followed by elimination of $\mathrm{C}_{2} \mathrm{H}_{2}$ from $51 \mathrm{a}^{+}$to yield $\mathrm{C}_{6} \mathrm{H}_{7}{ }^{+}$. Unlike the $\mathrm{C}_{9} \mathrm{H}_{11}{ }^{+}$homologs (see below), fragmentation of $\mathrm{C}_{8} \mathrm{H}_{9}{ }^{+}$ions is still rather energy-demanding $\left(\Delta H_{r} \geqslant 55\right.$ 
$\left.\mathrm{kcal} \cdot \mathrm{mol}^{-1}\right)(28,31)$, allowing for complete skeletal reorganization. None of the studies reported so far, however, provide conclusive evidence for the existence of stable isomers $49^{+}$and $51 \beta^{+}$in the gas phase.

Some theoretical work on the stabilities of isomeric $\mathrm{C}_{8} \mathrm{H}_{9}{ }^{+}$ions has been published. $\mathrm{Ab}$ initio calculations by Hehre (246) yielded $\Delta H_{r}\left(51 \beta^{+} \rightarrow \mathbf{4 9}^{+}\right) \simeq-35$ $\mathrm{kcal} \cdot \mathrm{mol}^{-1}$, without activation barrier; later, Apeloig et al. (247), obtained $\Delta H_{r}\left(\mathbf{4 9 ^ { + }}\right.$ $\left.\rightarrow 51 \alpha^{+}\right) \simeq-6 \mathrm{kcal} \cdot \mathrm{mol}^{-1}$. In superacidic medium, the later isomerization requires an activation energy of $\simeq 13 \mathrm{kcal} \cdot \mathrm{mol}^{-1}(240)$. In an extension of Dewar and Landman's (201) MINDO/3 data on the "aromatic" isomers, Jefford et al. (248) calculated a series of fourteen bi-, tri-, and tetracyclic isomers using the same approach. Three $\mathrm{C}_{8} \mathrm{H}_{9}{ }^{+}$congeners of an energetically highly unfavorable square-pyramidal species of theoretical interest (viz. $[16+\mathrm{CH}]^{+}$) appear surprisingly stable, viz. $53^{+}-55^{+}$, with heats of formation only $\simeq 30 \mathrm{kcal} \cdot \mathrm{mol}^{-1}$ higher than those of the methylbenzyl ions $45^{+}(201)$. Thus, prior to loss of $\mathrm{C}_{2} \mathrm{H}_{2}, 53^{+}-55^{+}$may well play a role in the $\mathrm{C}_{8} \mathrm{H}_{9}{ }^{+}$manifold. In terms of atom connectivity, $53^{+}$is closely related to $47^{+}$, whereas $54^{+}$and $55^{+}$could form from $51 \alpha^{+}$or $51 \beta^{+}$.

A series of reports by McLafferty et al. $(135,249-252)$ describe their attempts to identify various stable $\mathrm{C}_{8} \mathrm{H}_{9}{ }^{+}$isomers using the CID technique. The existence of stable $51 \alpha^{+}, 51 \beta^{+}$, and $49^{+}$ions was suggested from the first CID data (249). Somewhat later (250), using improved instrumentation, the observation of $\mathbf{5 1} \alpha^{+}$ formed from $48 \mathrm{a}$ and related precursors at high energies as well as of $51 \beta^{+}$formed at low energies was rejected; instead, ions $49^{+}$and $52^{+}$were claimed to be identified in binary mixtures with an unknown isomer " $X$." With increasing ionization energies, the mixture was found to be enriched in " $X$. " In another short communication (135), these authors reported on the prevailing formation of ions $\mathbf{4 7}^{+}$ from metastable 1-bromo-4-ethylbenzene ions, along with presumably some $\mathbf{5 1} \alpha^{+}$ and ethyltolyl ions, referring to the preceding ring expansion on the level of the molecular ions (Sect. IV.A). Subsequently, the integrated information was published (251), asserting the identification of thirteen stable isomers of gaseous $\mathrm{C}_{8} \mathrm{H}_{9}{ }^{+}$ions by the CID approach. The $\beta$-phenethyl ion $\mathbf{5 1} \beta^{+}$was excluded from the collection, in line with previous experimental $(240,241)$ and computational data (246). Noteworthily, ion " $\mathrm{X}$ " was included and the structure of cyclopropanorbornene-8-yl was tentatively assigned to it. In light of Jeffords' MINDO/3 results (248), "high-energy" ions $\mathbf{5 3}^{+}-\mathbf{5 5} 5^{+}$appear very attractive to demystify ion "X." In a later study on low-energy $\mathrm{C}_{8} \mathrm{H}_{9}{ }^{+}$ions (252), generated from metastable ions $21^{+\cdot}$ and $22^{+\cdot}$ and ionized cumene, it was suggested that $\mathbf{4 7}^{+}$is the most stable of all $\mathrm{C}_{8} \mathrm{H}_{9}{ }^{+}$isomers. At elevated internal energies, the next stable isomer, $51 \alpha$, tends to rearrange to $47^{+}$.

In contrast, as shown by Dunbar et al. (253) using PD spectroscopy, 51 $\boldsymbol{\alpha}^{+}$ appeared to be the only gaseous $\mathrm{C}_{8} \mathrm{H}_{9}{ }^{+}$isomer formed upon protonation of styrene, cyclooctatetraene, and barrelene with $\mathrm{H}_{3} \mathrm{O}^{+}$. By this experimental work, the aromatic, low-energy and the "polycyclic, high-energy" parts of the $\mathrm{C}_{8} \mathrm{H}_{9}{ }^{+}$ manifold, approached by the two MINDO/3 studies $(201,248)$, are joined nicely in a common, most stable isomer.

Study of the proton abstraction from ionized alkylbenzenes in the ICR mass 
spectrometer, allowed determination of thermochemical data such as proton affinities of the corresponding radicals, $\mathrm{PA}\left([\mathrm{M}-\mathrm{H}]^{\circ}\right)$. Thus, DeFrees et al. (254) found PA(8) $=198 \mathrm{kcal} \cdot \mathrm{mol}^{-1}$ and $\mathrm{PA}\left(\mathbf{1 1}^{\circ}\right)=200 \mathrm{kcal} \cdot \mathrm{mol}^{-1}$, and Meot-Ner (255) reported PA values within the same narrow range for $8^{\circ}, 51 \alpha^{*}$, and some other substituted benzyl radicals. In the same way, starting with the isomeric methylbenzyl ions $45 \mathbf{o}^{+}-\mathbf{4 5} \mathrm{p}^{+}$as the proton donors, Pollack et al. (256) determined the heats of formation of the three neutral xylylenes (quinodimethanes). They estimated a value of $\Delta H_{f}\left(45^{+}\right)=205( \pm 1) \mathrm{kcal} \cdot \mathrm{mol}^{-1}$, based on $\Delta H_{f}\left(8^{+}\right)=214$ $\mathrm{kcal} \cdot \mathrm{mol}^{-1}$, which is slightly higher than $\Delta H_{f}\left(47^{+}\right) \simeq \Delta H_{f}\left(51 \alpha^{+}\right) \simeq 199 \mathrm{kcal} \cdot \mathrm{mol}^{-1}$, determined by McLoughlin et al. (188) using PI spectrometry of alkylbenzenes. These data agree surprisingly well with the MINDO/3 results. Further work by Wolf et al. $(257,258)$ concerning the gas-phase chemistry of $51 \alpha^{+}$and related ions is also pertinent.

Although ions $\mathbf{4 9}^{+}$and $50^{+}$have not been isolated as stable gaseous species, direct evidence for their existence was reported very recently by Fornarini and Muraglia (259). $\alpha^{13} \mathrm{C}$-labeled $49^{+}$was claimed to be produced upon $\gamma$ radiolysis of $\beta$-phenethyl chloride and the corresponding alcohol followed by quenching with methanol. The formation of isomer $50^{+}$, also compatible with the observations, was not discussed. The formation of $51 \beta^{+}$within an ion-molecule complex with simple arenes was postulated recently by Bäther and Grützmacher (260).

\section{2. $\mathrm{C}_{9} \mathrm{H}_{11}+$ ions}

A typical phenomenon in organic mass spectrometry is that the number of investigations on a given ion decreases with its complexity. Hence, $\mathrm{C}_{9} \mathrm{H}_{11}{ }^{+}$ions, being the higher homologs of both $\mathrm{C}_{7} \mathrm{H}_{7}{ }^{+}$and $\mathrm{C}_{8} \mathrm{H}_{9}{ }^{+}$, have been much less studied than the latter ions. Nevertheless, the first postulation of ion-neutral complexes to be formed during the unimolecular fragmentation of gaseous ions, being broadly discussed nowadays $(261,262)$, was concerned with $\mathrm{C}_{9} \mathrm{H}_{11}{ }^{+}$ions (Scheme VI). In order to explain the degeneracy of the side-chain carbon atoms in $\mathrm{C}_{9} \mathrm{H}_{11}{ }^{+}$from ionized $t$-butylbenzene $\left(56^{+\bullet}\right)$ and (3-pentyl)-benzene $\left(57^{+\bullet}\right)$, Rylander, Meyerson, and Hart $(263,264)$ proposed the formation of a "phenylated cyclopropane" (i.e., the complex $\left.58^{+} \equiv\left[2^{+} \cdot c-\mathrm{C}_{3} \mathrm{H}_{6}\right]\right)$ prior to decomposition to $\mathrm{C}_{7} \mathrm{H}_{7}{ }^{+}$and $\mathrm{C}_{2} \mathrm{H}_{4}$. A recent memorandum on this particular $\mathrm{C}_{9} \mathrm{H}_{11}{ }^{+}$species by Meyerson (265) spans more than 30 years of (amazing!) organic mass spectrometry.

Later, Neeter and Nibbering (266) ruled out this unconventional model by investigating metastable, labeled $\mathrm{C}_{9} \mathrm{H}_{11}{ }^{+}$ions from $56^{+\cdot}$. Proton exchange occurring between the $\mathrm{C}_{3}$ side group and the ring as well as ${ }^{13} \mathrm{C}$ retention indicated consecutive $1,2-\mathrm{H}$ and $1,2-\mathrm{C}$ shifts prior to fragmentation. Secondary fragmentation of metastable $\mathrm{C}_{9} \mathrm{H}_{11}{ }^{+}$ions, studied extensively by Uccella and Williams (267), was found to depend markedly on the presence of a propylbenzene type substructure preformed in the corresponding precursor. For $\mathrm{C}_{9} \mathrm{H}_{11}+$ ions containing a preformed $C_{3}$ side group at the ring (e.g., 61a ${ }^{+}, 61 b^{+}$), only the six hydrogen atoms at the aliphatic moiety equilibrate prior to the relatively energetically favorable loss of $\mathrm{C}_{2} \mathrm{H}_{4}\left[\Delta H_{r} \simeq 34 \mathrm{kcal} \cdot \mathrm{mol}^{-1}(28,31)\right]$. In contrast, $\mathrm{C}_{9} \mathrm{H}_{11}{ }^{+}$ 
ions with $C_{1}$ or $C_{2}$ side groups at the ring (e.g., $59 a^{+}, 59 b^{+}$) exhibit complete hydrogen randomization. This effect was attributed to the fact that the loss of $\mathrm{C}_{2} \mathrm{H}_{4}$ from benzyl ions bearing $\mathrm{C}_{1}$ and $\mathrm{C}_{2}$ groups at the ring requires an energydetermining skeletal organization to a $C_{3}$ type ion $\left(59^{+} \rightarrow 60^{+} \rightarrow 61^{+}\right)$. Eqivalence of the side-chain hydrogen atoms in $\mathrm{C}_{9} \mathrm{H}_{11}{ }^{+}$ions from (bromopropyl)- and (nitropropyl)-benzenes was also reported by Nibbering and de Boer $(242,268)$. Additional evidence was published by Köppel et al. $(269,270)$, pointing to a number of competing isomerization processes excluding the formation of $58^{+}$.

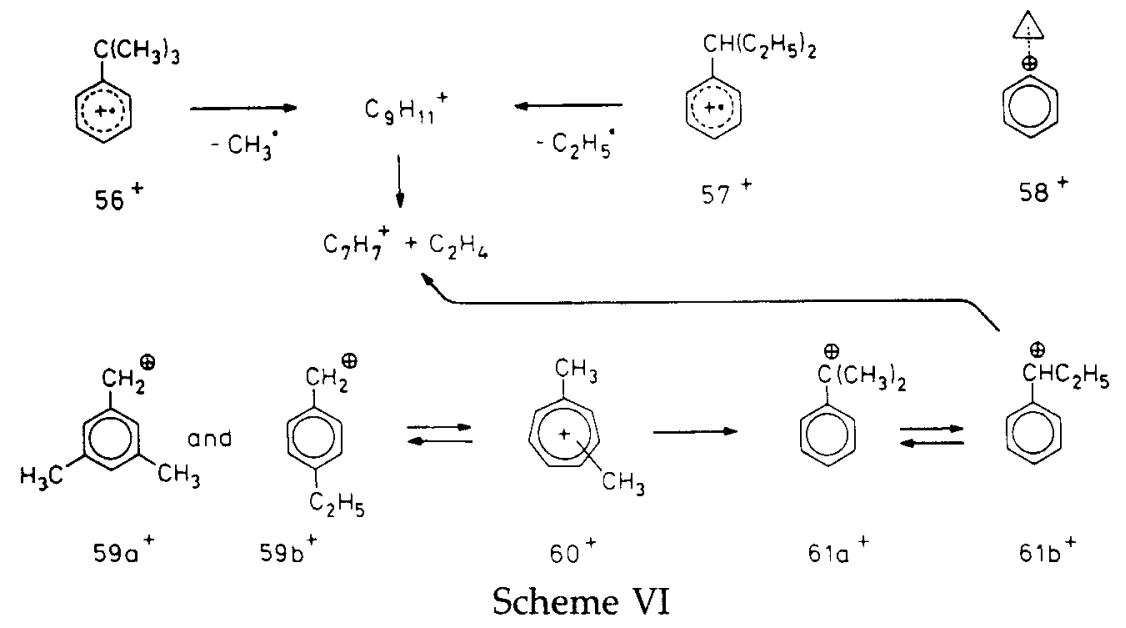

A totally independent approach by Houriet et al. (271) was based on the bimolecular formation of both short-lived and of collisionally deactivated, long-lived, $\mathrm{C}_{9} \mathrm{H}_{11}{ }^{+}$species from allyl ions and 1 . The expulsion of $\mathrm{C}_{2} \mathrm{H}_{4}$ from labeled adduct ions indicated the formation of two different $\mathrm{C}_{9} \mathrm{H}_{11}{ }^{+}$intermediates (without extensive carbon scrambling) and energy-dependent hydrogen scrambling. One intermediate proposed was a cyclic $\mathrm{C}_{9} \mathrm{H}_{11}{ }^{+}$(protonated indan) tautomer. Lay and Gross (272) used the bimolecular approach as a "gas-phase derivatization" of isomeric $\mathrm{C}_{3} \mathrm{H}_{5}{ }^{+}$ ions under both low and high-pressure conditions. Two stable, noncyclized $\mathrm{C}_{9} \mathrm{H}_{11}{ }^{+}$ $\sigma$ complexes were identified by CID spectrometry to be formed upon collisional stabilization of the $\left[\mathrm{C}_{3} \mathrm{H}_{5}^{+} \cdot \mathrm{C}_{6} \mathrm{H}_{6}\right]$ adducts, depending on the structure of the precursor $\mathrm{C}_{3} \mathrm{H}_{5}{ }^{+}$ion. Further work on bimolecularly formed $\mathrm{C}_{9} \mathrm{H}_{11}{ }^{+}$ions was reported by $\mathrm{Co}-$ losimo and Bucci (273) and recently by kieu My et al. (274) using ${ }^{13} \mathrm{C}$ labeling and kinetic energy release measurements to distinguish possible isomers.

Although not strictly belonging to this series, the benzo-analogs of $\mathrm{C}_{7} \mathrm{H}_{7}+$ ions, $\mathrm{C}_{11} \mathrm{H}_{9}{ }^{+}$, may be mentioned. The benzotropylium structure was suggested for these ions, loss of $\mathrm{C}_{2} \mathrm{H}_{2}$ being the main fragmentation channel in analogy to $\mathrm{C}_{7} \mathrm{H}_{7}{ }^{+}$ions (275-278).

\section{RADICAL CATIONS OF HIGHER n-ALKYLBENZENES}

\section{A. The McLafferty rearrangement of ionized $n$-alkylbenzenes}

This section covers the ion chemistry of ionized alkylbenzenes with mediumsized and long aliphatic side chains. Some of their fragmentation characteristics 
has been discussed in the previous section; so emphasis here is to reactions that are characteristic for this subclass of alkylbenzene ions.

As evident from the earlier discussion, enlargement of the side chain to $C_{3}$ or higher alkyl groups leads to decreased fragmentation barriers. In turn, primary decomposition reactions are largely no longer obscured by energy-demanding isomerization process of the molecular ions. An energetically favorable and highly significant fragmentation channel is opened with side chains larger than $\mathrm{C}_{2}$; that is, beginning with ionized $n$-propylbenzene $62^{+\cdot}$ (Scheme VII), viz. formation of $\mathrm{C}_{7} \mathrm{H}_{8}{ }^{+}$or substituted analogs. This reaction was uncovered in the early days of organic mass spectrometry $(2,279)$ and proposed later $(280)$ to proceed via a sixmembered transition state $(1,5)$, hence representing a variant of the McLafferty rearrangement. For $62^{+\cdot}$ and its higher homologs, "simple" $\beta$-cleavage $\left(\rightarrow \mathrm{C}_{7} \mathrm{H}_{6} \mathrm{X}^{+}\right)$ and " $\mathrm{H}$ migration accompanying $\beta$-cleavage" are competing fragmentation channels, opening two entries to the subsequent, complex chemistry of the $C_{7}$ fragment ions discussed above. Loss of $\mathrm{H}^{*}$ from $\mathbf{1 4}^{+}$as a secondary fragmentation, discussed in detail for longlived $\mathrm{C}_{7} \mathrm{H}_{8}{ }^{+}$ions $(64,82)$, however, was found to be a minor or even negligible process upon $70 \mathrm{eV}$ EI $(281,282)$.

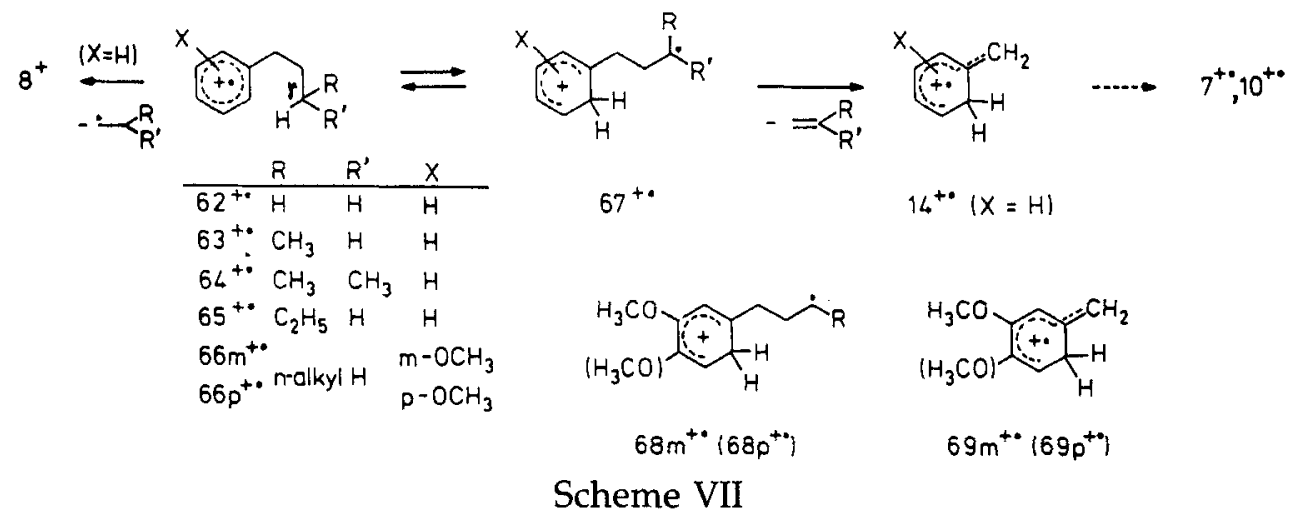

The initial formation of ionized iso-toluenes such as $\mathbf{1 4}^{+\cdot}$ instead of $\mathbf{7}^{+\cdot}$ or $\mathbf{1 0}^{+\cdot}$ is well-accepted today; however, subsequent rearrangement of $\mathbf{1 4}^{+\cdot}$ to the latter isomers appears likely (Sect. IV.A.1). Substantial support for the formation of $14^{+}$type ions comes from the finding that the McLafferty rearrangement occurs in a two-step mechanism (283) via the distonic ion intermediate $67^{+\cdot}$ (i.e., from the reversibility of the first step).

In the early days, the "mass 92 " peak in the spectra of alkylbenzenes was a mass spectrometric curiosity. First reports (2) on mass spectral analysis of petroleum concentrated on odd-numbered fragment ion masses (284). In Meyerson's (279) systematic correlation of alkylbenzene structures with their mass spectra, the $\mathrm{C}_{7} \mathrm{H}_{8}{ }^{+}$ion, however, was shown to become increasingly abundant with increasing length of the aliphatic chain and to depend on its degree of branching. Using pinpointed deuterium labeling, McCollum and Meyerson (285) revealed that, in the case of $n$-butylbenzene $\left(63^{+}\right)$, the migrating hydrogen atom originates with $95 \%$ selectivity from the $\gamma$ position with respect to the ionized benzene ring. "Localized activation" of the $\mathrm{C}^{\gamma}-\mathrm{H}$ bond in $64^{+\cdot}$ by the second methyl group 
drastically enhanced the rearrangement reaction, as confirmed later by Lightner et al. (282), whereas introduction of another methyl group almost completely suppressed this process. The analogous rearrangement reaction was found by Gilpin (286) to occur for ionized 2-phenylethanol.

In addition to the influence of decreased $\mathrm{C}-\mathrm{H}$ bond dissociation energy at the hydrogen donor site $\left(\mathrm{C}^{\gamma}\right)$, the electron density at the acceptor site was found to affect the rearrangement reaction. Thus, electron-donating groups meta to the alkyl chain greatly enhance the alkene elimination relative to the loss of alkyl. From an analysis of naturally occurring long-chain alkyl- and alkenylphenols, -anisoles, and -resorcinols, Occolowitz (287) attributed the increase of $\mathrm{C}_{7} \mathrm{H}_{7} \mathrm{X}^{+\cdot}$ ion formation to a site-specific electronic stabilization of the fragment ion by meta-hydroxy and meta-methoxy groups, whereas $\mathrm{C}_{7} \mathrm{H}_{6} \mathrm{X}^{+}$fragments are favored by corresponding para and ortho substituents. Gorfinkel et al. (288) confirmed these substituent effects, showing that the mass spectra of meta-(monoalkyl)-phenols and -anisoles, in particular, are governed by the $\mathrm{C}_{7} \mathrm{H}_{7}(\mathrm{OH})^{+}$and $\mathrm{C}_{7} \mathrm{H}_{7}\left(\mathrm{OCH}_{3}\right)^{+\cdot}$ peaks. These findings are strongly consistent with the formation of iso-toluene ions $14^{+\cdot}$ and $69^{+*}$. Thus, in contrast to isomeric methyl- or ethylphenols and -anisoles $(171,289,290)$ and substituted phenetholes $(170,291)$, the isomers of long-chain alkylarenes were found to be distinguishable by a sitespecific, medium-range hydrogen transfer reaction. As pointed out by Kuck and Grützmacher (85) (Sect. VI.C), however, the site-specific substituent effect is most probably due to the stabilization of the intermediate ions [(i.e., $\Delta H_{f}\left(68 \mathbf{m}^{+\cdot}\right) \ll$ $\left.\Delta H_{f}\left(\mathbf{6 8} \mathbf{p}^{+\bullet}\right)\right]$ rather than of the product ions $\left(\Delta H_{f}\left(69 \mathbf{m}^{+\bullet}\right) \simeq \Delta H_{f}\left(69 \mathbf{p}^{+\bullet}\right)\right]$.

Another strong argument by Budzikiewicz et al. (5) in favor of the $\gamma \rightarrow$ ortho hydrogen transfer relied on apparent steric shielding of the ortho positions. In contrast to ionized 4 -(n-octadecyl)-m-xylene, $n$-octadecylmesitylene does not undergo the McLafferty rearrangement, suggesting steric suppression of the $\gamma$ $\mathrm{H}$ migration by the two ortho-methyl groups. Kingston et al. (292), however, recently demonstrated that this long-standing rule (293) is not valid if the 4methyl group is absent. They found that various tri- and tetramethyl-isopentylbenzene ions do eliminate $\mathrm{C}_{4} \mathrm{H}_{8}$ in spite of the 2,6-dimethyl substitution. Pertinent examples of 4-unsubstituted alkylbenzenes and related compounds were quoted (291), corroborating this finding. According to the authors, the paramethyl group (instead of the two ortho-methyl groups) suppresses the $\gamma-\mathrm{H}$ rearrangement in agreement with McLafferty's interpretation (293). In view of the two-step mechanism established for ionized $n$-alkylbenzenes (see below) and 1,3-diarylalkanes (Sect. VI.C), however, the McLafferty rearrangement is governed by the reactivity of both the donor $\left(\mathrm{C}^{\gamma}\right)$ and the acceptor site $\left(\mathrm{C}^{\text {ortho }}\right)$, both being favorable in Kingston's examples. The crucial para-methyl group, on the other hand, can be assumed to facilitate the competing $\beta$-cleavage rather than blocking the $\gamma-\mathrm{H}$ migration, the overall results thus pointing to steric and electronic origins of the blocking effect. For a recent comment, see ref. 352.

Due to the low-energy, low-entropy characteristics of the rearrangement reaction, the effects of internal energy and ion lifetime on the abundance ratio $\left[\mathrm{C}_{7} \mathrm{H}_{7} \mathrm{X}^{+\cdot}\right] /\left[\mathrm{C}_{7} \mathrm{H}_{6} \mathrm{X}^{+}\right]$proved most useful (see also Sect. V.B). Most studies concentrated on $n$-butylbenzene $\left(63^{+}\right)$as the parent hydrocarbon. Nicoletti and 
Lightner $(294,295)$ measured the ratios $Z_{r}=\left[\mathrm{C}_{7} \mathrm{H}_{7} \mathrm{X}^{+\cdot}\right] /\left[\mathrm{M}^{+\cdot}\right]$ and $Z_{c}=$ $\left[\mathrm{C}_{7} \mathrm{H}_{6} \mathrm{X}^{+}\right] /\left[\mathrm{M}^{+\cdot}\right]$ for ten pairs of meta- and para-substituted $n$-butylbenzenes at 70 and $12 \mathrm{eV} \mathrm{EI}$, supporting the $\gamma \rightarrow$ ortho hydrogen transfer mechanism. In contrast to electron-donating groups, electron-withdrawing substituents were shown to exhibit no distinct effect. Hammett plots gave $\sigma \simeq 0.2$ for the rearrangement process in the meta isomers $(288,294)$. Nakata and Tatematsu (296) stressed the radical character of the $\gamma-\mathrm{H}$ rearrangement and offered a simple LCAO-MO explanation for the substituent effect of electron donor groups. In later studies, Lightner et al. $(144,145)$ reported substituent effects on appearance energy differences for the formation of $\mathrm{C}_{7} \mathrm{H}_{6} \mathrm{X}^{+}$ions, without considering the competitive shift caused by the rearrangement reaction.

In a comprehensive report, Lightner et al. (297) presented ionization energies of pairs of meta- and para-substituted $n$-butylbenzenes and appearance energies of the $\mathrm{C}_{7} \mathrm{H}_{7} \mathrm{X}^{+\cdot}$ and $\mathrm{C}_{7} \mathrm{H}_{6} \mathrm{X}^{+}$ions. Whereas the activation energies $\left(E_{a}=\right.$ $\mathrm{AE}$ - IE) correlate with $Z_{c}$ in a straightforward manner (i.e., low $E_{\text {a }}$ giving high $Z_{c}$ ), the inverse was found for $Z_{r}$. This observation rendered ambiguous a common mechanistic conclusion for the rearrangement reaction. Nevertheless, it follows from Lightner's work that, for a given pair of substituted $n$-butylbenzenes, drastic differences in the ratios $Z_{r}$ are possible in spite of essentially constant $E_{\mathrm{a}}$ values [e.g., for $\mathrm{X}=\mathrm{OCH}_{3}, Z_{r(\text { meta })} / Z_{r \text { (para) }}=23$ was found in spite of a relatively small energy difference, $E_{a(\text { meta })}-E_{a(\text { para })} \approx 0.2 \mathrm{eV}$ (297)]. In line with this apparent contradiction, Kuck and Grützmacher (85) found similar effects with substituted 1,3-diphenylpropanes (Sect. VI).

MacLeod and Djerassi (298) observed an apparent isotope effect on the McLafferty rearrangement of $63^{+\cdot}\left(i=k_{\mathrm{H}} / k_{\mathrm{D}}=1.25\right)$. Later work showed, however, that these values cannot reflect (primary) isotope effects by which the rate-determining step of the fragmentation can be determined. The values are obscured by the hydrogen exchange between the (donor) alkyl chain and the (acceptor) arene ring. Duffield et al. (299) proposed hydrogen exchange between the $\gamma$ and (ring$\alpha)$ positions of ionized $N$-(n-butyl)- and $N$-(n-pentyl)-pyrroles, to explain unexpected mass shifts, and considered the possibility of a distonic ion intermediate corresponding to $67^{+\cdot}$. Similar observations were reported by Gerrard and Djerassi (300) and by Nibbering and de Boer $(301,302)$ on $62^{+\cdot}(\mathrm{R}=\mathrm{OH}, \mathrm{Br})$ and arylalkyl ions (80,303). Lightner et al. (282) investigated various branched and unbranched alkylbenzenes by deuterium labelling and showed that, besides the predominant $\gamma-\mathrm{H}$ transfer, a considerable fraction of the migrating hydrogen atoms originates from nearly all other positions of the side chain. A marked hydrogen interchange was found to occur between the ortho and $\gamma$ positions; but, albeit to a lesser extent, the $\beta$ and nearly all of the remote positions of the side chain participate as well. The meta- (and probably para-) hydrogen atoms are not involved in the exchange. From their results, Lightner et al. (282) deduced that the eventual alkene loss takes place exclusively by hydrogen transfer from the $\gamma$ position, regardless of the preceding exchange steps involving remote positions. This conclusion was challenged by Wesdemiotis et al. (304), who observed formation of (unlabeled) $\mathrm{C}_{7} \mathrm{H}_{8}{ }^{+\cdot}$ ions from $\gamma, \gamma-\mathrm{d}_{2}$-labeled $n$-pentylbenzene ions $\left(65^{+\bullet}\right)$. A related FIK study by Borchers et al. (305) revealed that hydrogen exchange is completely suppressed 
at short ion lifetimes $\left(\tau \leqslant 10^{-10} \mathrm{~s}\right)$, but that hydrogen atoms originate from all positions $C^{\beta}-C^{\varepsilon}$, with $C^{\gamma}$ dominating. Apparently, at least for very short-lived ions, the alkene loss occurs partially by direct hydrogen transfer from other positions than $\mathrm{C}^{\gamma}$, possibly in a concerted mechanism. At longer lifetimes $\left(\tau \simeq 10^{-5}\right.$ s), however, slow hydrogen transfer within the aliphatic chain cannot be excluded strictly; on the contrary, this type of degenerate isomerization seems highly probable in analogy to the extensive reversible hydrogen abstraction reactions found in long-lived conventional and distonic ions, a subject recently reviewed by Hammerum (306). In any case, hydrogen exchange in $n$-alkylbenzene ions is a rather slow process, being far from complete equilibration of the hydrogen atoms involved $(282,304,305)$. This may be chiefly due to the poor "localized bond activation" of the secondary hydrogen donor sites at the chain, in contrast to ionized 1,3-diaryl-propanes (Sect. VI).

A very recent PEPICO/RRKM study by Baer et al. (307) provides new insights into the dissociation dynamics of the fragmentation of $63^{+\cdot}$. The authors found an extremely negative activation entropy $\left(-10.9 \mathrm{cal} \cdot \mathrm{mol}^{-1} \mathrm{~K}^{-1}\right)$, which, in combination with the rather low kinetic energy release, led them to assume an isomerized intermediate prior to dissociation. Interpretation of all previous evidence, in particular of the $\gamma /$ ortho hydrogen exchange discussed above, ascribes this role to the distonic ion $67^{+\cdot}$ (see also Sect. VI.C). A thermochemical estimate (cf., ref. 308) places the intermediate well between the conventional ion and the products $\left[\Delta H_{f}\left(63^{+*}\right)=197 \mathrm{kcal} \cdot \mathrm{mol}^{-1}, \Delta H_{f}\left(67^{+\cdot}\left(\mathrm{R}=\mathrm{CH}_{3}, \mathrm{R}^{\prime}=\mathrm{X}=\mathrm{H}\right) \simeq 212 \mathrm{kcal} \cdot \mathrm{mol}^{-1}\right.\right.$, $\left.\Sigma \Delta H_{f}\left(\mathbf{1 4}^{+\cdot}, \mathrm{C}_{3} \mathrm{H}_{6}\right) \simeq 221 \mathrm{kcal} \cdot \mathrm{mol}^{-1}(307)\right]$. The activation energy deduced by Baer et al. (307) for loss of $\mathrm{C}_{3} \mathrm{H}_{6}$ appears to be very close to the thermochemical threshold, in line with the rather slow and incomplete hydrogen exchange in low-energy $63^{+\cdot}$ ions, hence corroborating the two-step model for the McLafferty rearrangement (Scheme VII).

As another feature that reflects the complex isomerization channels of relatively simple long-chain alkylbenzene ions, carbon scrambling was reported to precede loss of $\mathrm{CH}_{3}{ }^{\circ}$ and $\mathrm{C}_{2} \mathrm{H}_{5}{ }^{-}$from $63^{+\cdot}$ and $65^{+\cdot}$ (304). Although the terminal alkyl groups were found to be expelled predominantly, the loss of carbon atoms from the inner positions of the chain and, most intriguingly, from the aromatic ring was observed also for metastable ions; a finding reminiscent of the fragmentation behavior of ionized methylbenzenes (Sect. IV.A).

Hydrogen transfer and exchange processes of simple alkylbenzene ions are also reflected in the chemistry of many functionalized derivatives. Beside ionized diarylalkanes, discussed in the next section, ionized hydrocinnamaldehyde, cinnamyl alcohol, 3-phenyl-1-propanol, 3-phenyl-1-propylamine, and other related $\omega$-functionalized $n$-alkylbenzene ions undergo repeated unimolecular hydrogen interchange, as reported by several authors (80,301-303,309-316). Some of these effects were considered as a probe for "internal solvation" of isolated molecular ions [i.e., for coiling of the aliphatic chain to stabilize the electron-deficient center of the ion, as proposed by Meyerson and Leitch (316)].

The ease of intramolecular hydrogen transfer depends markedly on the site-specific bond dissociation energies and proton (or hydrogen atom) affinities. Many of 
these data have been determined $(31,32,317)$ and are of great value for understanding the complex hydrogen migration processes in larger alkylbenzene ions (352).

\section{B. The $\left[91^{+}\right] /\left[92^{+}\right]$ratio in the mass spectra of $n$-alkylbenzenes}

The competing fragmentation to $\mathrm{C}_{7} \mathrm{H}_{7}{ }^{+}(m / z 91)$ and $\mathrm{C}_{7} \mathrm{H}_{8}{ }^{+} \cdot(m / z 92)$ ions of $n$ alkylbenzenes has been used as a sensitive probe for internal (excess) energy transferred to an ion by a given excitation technique, owing to the drastically different $k(E)$ curves of the two processes. Their kinetic parameters were determined very recently by Baer et al. (307). At very low internal energies, $\mathrm{C}_{7} \mathrm{H}_{8}{ }^{+} \cdot$ ions are formed almost exclusively whereas formation of $\mathrm{C}_{7} \mathrm{H}_{7}{ }^{+}$dominates at high energies. Parts of this topic have been reviewed by Harris and Beynon (318). Hanuš and Dolejšek (74) discussed the fundamental question of internal energy equilibration before fragmentation of excited ions by comparing the $\mathrm{C}_{7} \mathrm{H}_{7}{ }^{+}$and $\mathrm{C}_{7} \mathrm{H}_{8}{ }^{+\cdot}$ ion abundances for long-chain alkylbenzenes. (For formation of $\mathrm{C}_{7} \mathrm{H}_{7}{ }^{+}$ and $\mathrm{C}_{7} \mathrm{H}_{8}{ }^{+}$from long-chain $1, \omega$-diphenylalkanes, see Sect. VI.C.) The influence of energy dissipation in large ions, however, is difficult to separate from other factors influencing the relative abundances of fragment ions (319). Besides this fundamental aspect, the $\left[91^{+}\right] /\left[92^{+}\right]$ratio from ionized alkylbenzenes depends considerably on ion source conditions that affect the ions' residence time, such as the repeller potential $(320,321)$, and internal energy distribution, such as source temperature $(318,322)$. The latter factor (i.e., increase of $\left[91^{+}\right] /\left[92^{+}\right]$with increasing temperature) was attributed to the thermal energy of the neutral precursors prior to ionization and compared to the increase of $\left[91^{+}\right] /\left[92^{+}\right]$with increasing photon energy from PD experiments, yielding an equivalent of $0.2-0.3 \mathrm{eV}$ per $100 \mathrm{~K}$ rise of temperature.

Mukhtar et al. (323) reported ratios $1.0 \leqslant\left[91^{+}\right] /\left[92^{+}\right] \leqslant 6.9$ for photon energies of $2.41 \leqslant h v \leqslant 3.47 \mathrm{eV}$. A QET rate simulation was performed (324) by using $E_{a}\left(\mathrm{C}_{7} \mathrm{H}_{7}{ }^{+}\right)=2.6$ and $E_{a}\left(\mathrm{C}_{7} \mathrm{H}_{8}{ }^{+}\right)=1.4 \mathrm{eV}$. From $\mathrm{CE}$ and PD experiments, respectively, Harrison and Lin (325) and Chen et al. (326) reported considerably lower $E_{a}$ values. For slow-moving $63^{+\cdot}$ ions, Kingston et al. (327) found much lower $\left[91^{+}\right] /\left[92^{+}\right]$values, as did Welch et al. (328) for fast-moving ions. Nascon and Harrison (329) determined the $\left[91^{+}\right] /\left[92^{+}\right]$ratio for all homologs between 63 and n-decylbenzene. For "low-energy" collisions in a triple-quadrupole instrument, limiting ratios were found above $\approx 60 \mathrm{eV}$ collision energy. Depending on the target gas, these values decreased with increasing length of the alkyl chain.

Further reports $(330-334)$ on the $\left[91^{+}\right] /\left[92^{+}\right]$ratio may be mentioned. McLuckey et al. (331) inferred nonergodic behavior of $63^{+\cdot}$ ions. Griffiths et al. (335) and Mukhtar et al. (336) compared also the effect of photon and collisional activation on $\left[91^{+}\right] /\left[92^{+}\right]$and determined the disposition of excess energy into kinetic energy release for various ionized alkylbenzenes. Furthermore, $\left[91^{+}\right] /\left[92^{+}\right]$ratio from $63^{+\cdot}$ was studied by angle-resolved mass spectrometry (ARMS) (337). The recent PEPICO study (307) provided addi- 
tional insight in the $\left[91^{+}\right] /\left[92^{+}\right]$ratio as a "thermometer" for internal energy content. Overall, the fragmentation of $n$-butylbenzene ions has become much of a problem on its own.

Photodissociation spectra of various ionized alkylbenzenes with medium-sized alkyl chains were reported by Dunbar (338). Under the experimental conditions described there, all ions decomposed by simple $\beta$-cleavage rather than by hydrogen rearrangement. At present, it seems that no investigation has been reported concerning unimolecular $\gamma \leftrightarrows$ ortho hydrogen exchange initiated by light (or CE). In many cases hydrogen migrations may form longlived, particularly stable distonic ions, the PD spectra of which could well be different from those of the conventional isomers.

\section{Unsaturated, branched, and cyclic alkylbenzene ions}

A large number of studies have been published on the mass spectrometry of alkylbenzenes with unsaturated, branched and/or cyclic side groupings. No attempt will be made here to cover this field comprehensively. Secondary isotope effects accompanying methyl loss from ionized cumene and $t$-butylbenzene were reported by Nacson and Harrison (339) and Neeter and Nibbering (266), respectively. The decomposition of $t$-butylbenzene was studied recently by Brand and Baer (340) by using the PEPICO technique. Effects of strain energy on the fragmentation of $t$-butylbenzenes and alkylarenes in general were reviewed by Pihlaja et al. (341).

The long-standing question $(5,342)$ of the occurrence of the formal retro-DielsAlder reaction in the radical cations of tetralin and related compounds was reviewed recently by Kühne and Hesse (343). Clear evidence emerged from FIK studies by Levsen et al. (344) and Sindona et al. (345) that the RDA channel is dominant only at shortest ion lifetimes. The fragmentation channels competing with the formal RDA process (343) are reminiscent of the behavior of ionized toluene and ethylbenzene, in particular the initial 1,2 or 1,3 shift of an $\alpha-\mathrm{H}$ atom to the benzo nucleus (cf., $7 \mathbf{a}^{+\cdot}$ and $\mathbf{1 4}^{+*}$, Scheme I). A corresponding exchange between the benzylic and all of the aromatic hydrogen atoms in ionized tetralin was deduced by Levsen et al. (344) and others $(345,346)$. Analogous reversible hydrogen migrations were suggested by Groenewold and Gross (347) to explain partial epimerization of ionized 1-tetralol, with a preference for subsequent 1,2rather than 1,3-H shifts (348). As a characteristic feature, however, 1- and 2substituted tetralins, respectively, exhibit highly specific, 1,4 and 1,3 eliminations of small neutrals from positions 1 and 4 (e.g., 1-tetralol) and 2 and 4 (e.g., 2tetralol) $(349,350)$. This holds also for ionized 1- and 2-phenyltetralin (Sect. VI.C).

Fragmentation of ionized indanols was found to be more complex (351), including ring opening, as shown by Audier et al. (353-355). Lay et al. (356) studied ionized indan and other $\mathrm{C}_{9} \mathrm{H}_{10}{ }^{+}$ions by FIK, CID, and charge-stripping techniques and found remarkable structure retention of individual isomers (e.g., for ionized allyl- and propenylbenzene and indan). Incomplete carbon scrambling in ionized 4-methylstyrene was reported by Köppel et al. (357). For the next higher homologs, $\mathrm{C}_{10} \mathrm{H}_{12}{ }^{+}$, Dass and Gross (358) observed a pronounced trend to form 
cyclized isomers from open-chain, nonconjugated alkylbenzene ions. Similarly, related $\mathrm{C}_{10} \mathrm{H}_{10}{ }^{+}$ions $(357,359)$ also exist preferably in cyclized structures [e.g., ionized 1-methylindene $(360,361)$ ]. Elsewhere, Holman et al. (362) showed energydependent cyclization to occur in the covalent adduct of ionized butadiene and benzene $\left(\mathrm{C}_{10} \mathrm{H}_{12}{ }^{+}\right)$to 1 -methylindan type structures.

The overall trend appears to be cyclization of open-chain structures to cyclic isomers (e.g., of indan or tetralin type) as a preferred way of isomerization of these radical cations, as was also observed in solid matrix (363). Further work on stereochemical aspects of functionalized arylcyclohexane ions by Sharmit et al. (364) is also mentioned, showing that many energetically favorable elimination reactions occur in a stereospecific way (i.e., without preceding cleavage of the alicyclic ring). Specific ring opening of ionized benzocyclobutene to ortho-quinodimethane ions was observed by Groenewold et al. (365), again using the ionmolecule reaction with styrene as a probe (see also Sect. VI.C). Carbon randomization, on the other hand, was found by Wentrup-Byrne et al. (366) to occur in ionized cyclopropybenzene.

\section{RADICAL CATIONS OF HIGHER $\alpha, \omega$-DIPHENYLALKANES AND RELATED SPECIES}

The gas-phase reactivity of ionized alkylbenzenes bearing another aromatic nucleus at the aliphatic chain deserves a special discussion, which in a way may be affected by the reviewer's own research in this field. The additional arene moiety may interfere directly or indirectly with the ionized nucleus. Both types of interaction are extensions of what has been discussed for mononuclear alkylbenzene ions. On the one hand, $\mathrm{C}-\mathrm{C}$ bond formation between the rings is found, leading to cyclized intermediates and fragment ions; on the other hand, the second aryl group acts as a strong (localized) bond activator and/or proton acceptor within the ion. In addition, nonbonding interaction between the charged and the uncharged $\pi$ systems may occur in the case of sufficiently flexible diarylalkane ions $(367,368)$. Ionized arene dimers (e.g., $\left.\left[\mathbf{1}^{+\cdot} \cdot \mathbf{1}\right]\right)$ were found to be stabilized by $\leqslant 17$ $\mathrm{kcal} \cdot \mathrm{mol}^{-1}(368,369)$, without hydrogen scrambling (370). Sandwich-type association is assumed to be preferable $(371,372)$.

\section{A. Ionized diphenylmethanes, stilbenes, and related ions}

Diphenylmethane ions $\mathbf{7 0}^{+}$have been studied since the early days of organic mass spectrometry, and the results were reviewed (8). The simplest of all diphenylalkane ions, however, exhibits an extremely complex isomerization and fragmentation behavior (Scheme VIII), which has not been fully understood to date. Decomposition of ions $70^{+\cdot}$ to $\mathrm{C}_{7} \mathrm{H}_{7}{ }^{+}$is only moderately important at $70 \mathrm{eV}$; instead, abundant $\mathrm{C}_{13} \mathrm{H}_{11}{ }^{+}, \mathrm{C}_{13} \mathrm{H}_{9}{ }^{+}, \mathrm{C}_{12} \mathrm{H}_{9}{ }^{+}$, and $\mathrm{C}_{12} \mathrm{H}_{8}{ }^{+}$ions are formed by expulsion of $\mathrm{H}^{\circ}, \mathrm{H}_{2}$, and $\mathrm{CH}_{3}{ }^{\circ}$, as well as by combinations thereof. On the one hand, ions $70^{+*}$ have to be taken as derivatives of ionized toluene $\left(7^{+}\right)$, undergoing reversible rearrangements via ring-expanded isomers $\left(\mathbf{7 0}^{+\cdot} \leftrightarrows \mathbf{7 1}^{+\cdot} \leftrightarrows \mathbf{7 2}^{+} \cdot\right)$, to account for complete hydrogen and carbon scrambling prior to loss of $\mathrm{CH}_{3} \cdot(373,374$; 
see also refs. 400 and 422 ). Likewise, a $70^{+\cdot} \leftrightarrows 71^{+\cdot}$ type interconversion was suggested for ionized benzhydrol (375). On the other hand, ring closure occurs prior to this and other fragmentations, suggesting $70^{+\cdot}$ to be a benzo analog of ionized allylbenzene. Formation of fluorene-type structure $\left(73^{+\bullet}\right)$ prior to fragmentation was proposed by several authors $(376,377)$ in line with the fact that fragmentation to $\mathrm{C}_{7} \mathrm{H}_{7}{ }^{+}$does not occur at low energies $(378,379)$. Corresponding to the $\mathrm{C}_{7} \mathrm{H}_{7}{ }^{+} / \mathrm{C}_{7} \mathrm{H}_{8}{ }^{+}$manifold, an independent equilibration occurs on the level of the $\mathrm{C}_{13} \mathrm{H}_{11}{ }^{+}$ions $\left(74^{+} \leftrightarrows 7^{+}\right)(373-375,380)$. Similar to $7^{+*}$, these ions expel $\mathrm{H}_{2}$ and $\mathrm{CH}_{3}{ }^{+}$yielding $\mathrm{C}_{13} \mathrm{H}_{9}{ }^{+}\left[76^{+}\right.$, possibly via $\left.77^{+}(381)\right]$ and $\mathrm{C}_{12} \mathrm{H}_{8}{ }^{+}$, possibly $7^{+\cdot}(378)$. The structure(s) of these ions are far from established (81). Similar isomerization behavior was discussed by Berlin and Shupe (382) for ionized triphenylmethanes.

$\mathrm{C}_{13} \mathrm{H}_{9}{ }^{+}$ions are formed also from a variety of unsaturated hydrocarbons [e.g., by loss of $\mathrm{CH}_{3}{ }^{\circ}$ from ionized stilbene and 9,10-dihydrophenanthrene $(377,383-$ 389)]. Again, hydrogen and carbon scrambling of ionized stilbenes and in its vinylogs occurs certainly by initial cyclization followed by reversible ring expansion processes $(381,390)$. Earlier suggestions by Johnstone and Ward $(381,383)$ that cyclization of stilbene ions involve excited electronic states of the ionized cis isomer were substantiated by Gooden and Brauman (391) on the basis of PD spectrometry. Similar conclusions arise from Johnstone and Millard's work on ionized 1,3-diphenylpropene (392) and 1,2-diphenylethyl cations (377).

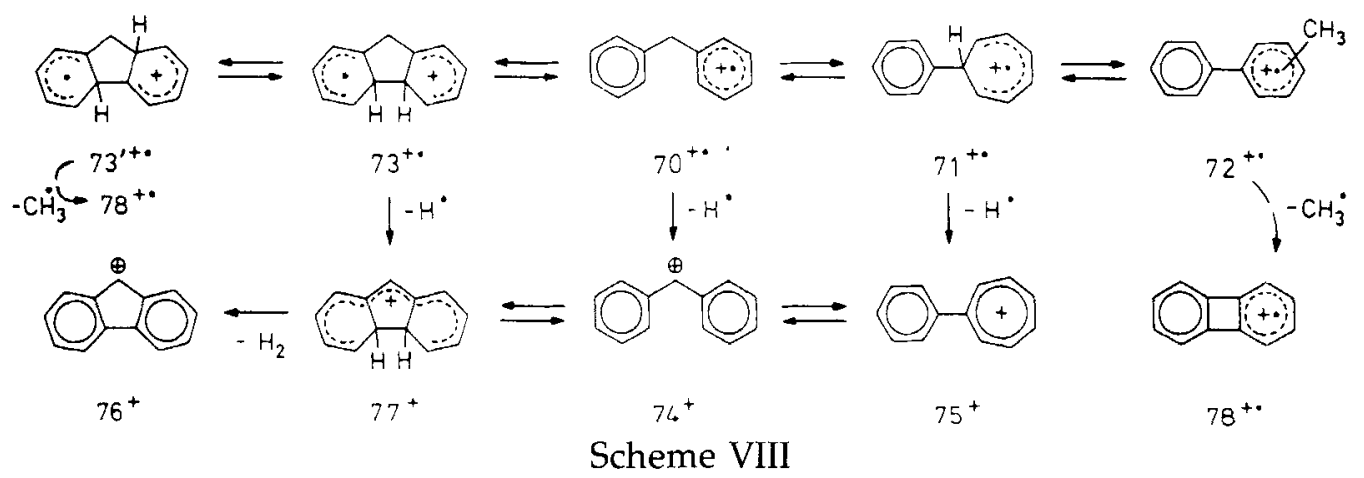

Model calculations on the propagation of hydrogen scrambling in ionized benzhydrol were reported by Williams et al. (375). A further, detailed investigation of the complex isomerization processes in numerous ionized diphenylmethane derivatives was performed by Neuert (379), including extensive, time-dependent hydrogen exchange as well as IE and AE measurements. The possibility of orbital interaction between the rings of substituted $70^{+}$and 1,2-diphenylethane ions $\left(80^{+*}\right)$ was studied by Pignataro et al. (393-395).

Two highly specific fragmentation reactions must be mentioned here. Bowie and White (396) studied the elimination of benzene from low-energy ionized stilbene, occurring essentially without scrambling. Ring closure to 1-phenylbenzocyclobutene ions may be involved in this case. Another highly specific fragmentation is the elimination of benzene or arenes from ortho-methyl- and orthohydroxy-substituted diphenylmethane ions $\left(7^{+}\right)$, observed by Meyerson et al. 
(397) (Scheme IX). This latter reaction, in particular, is a low-energy process of high structural significance $(398,399)$ owing to regio- and stereospecific hydrogen transfer (Sect. VI.C). A distonic intermediate is tentatively formulated in Scheme IX for this prototype reaction. Taken on the whole, however, mass spectrometry of diphenylmethanes, stilbenes, and other $\alpha, \omega$-diaryl compounds bearing unsaturated links between the rings is hardly understood in its details (400). Certainly, the ease of intramolecular cyclization and an increased barrier toward direct $\mathrm{C}$ $\mathrm{C}$ bond cleavage affect the fragmentation, but further efforts will be necessary to obtain deeper mechanistic insights into the isomerization and fragmentation of these species.

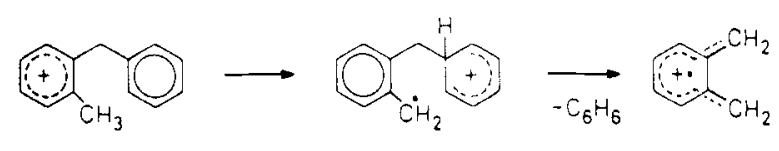

79
?

Scheme IX

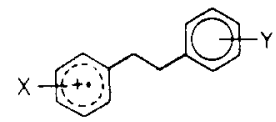

80

\section{B. Ionized 1,2-diphenylethanes}

Ionized 1,2-diphenylethanes $\left(\mathbf{8 0}^{+\cdot}\right)$ do not undergo the complex isomerization processes discussed above, although loss of $\mathrm{H}_{2}$ was reported to occur for certain cases (401). In general, the facile cleavage of the central $C-C$ bond in $80^{+\cdot} \mathrm{com}-$ pletely supresses hydrogen exchange and cyclization routes, giving rise to particularly stable benzyl ions and radicals. Therefore, $80^{+\cdot}$ and a large number of substituted derivatives were studied by McLafferty et al. (121) to test the validity of the quasiequilibrium theory by following the electronic effects of substituents at one or both of the two (electronically isolated) arene rings. In addition to other factors, the influence of strongly electron-donating and -withdrawing groups on the reactive ion and on the transition state was considered, suggesting "loosening" and "tightening effects" on some of the bonds and internal rotors. Whereas a minor influence on the benzylic cleavage is deduced for the $\mathrm{NO}_{2}$ group, a strong "tightening effect" is attributed to the $\mathrm{NH}_{2}$ group on the formation of $\mathrm{C}_{7} \mathrm{H}_{6} \mathrm{NH}_{2}{ }^{+}$. Other studies of ionized 1,2-diphenylethanes $(227,393,394)$ and their relevance for generating $\mathrm{C}_{7} \mathrm{H}_{7}{ }^{+}$ions (Sect. IV.B) have been mentioned.

\section{Ionized 1,3-diphenylpropanes 2-benzylindans, phenyl-benzocycloalkanes, and other 1, $\omega$-diphenylalkanes}

The ease of $\mathrm{C}-\mathrm{C}$ bond cleavage in ions $79^{+\cdot}$ and $80^{+\bullet}$ is a precedent for the particularly labile $\mathrm{C}^{\alpha}-\mathrm{H}$ and $\mathrm{C}^{\gamma}-\mathrm{H}$ bonds in the next higher homolog, ionized 1,3-diphenylpropane $\left(81^{+\bullet}\right.$ ) (Scheme X). Accordingly, as shown by Kuck and Grützmacher $(85,308)$, the McLafferty rearrangement is the predominant fragmentation of $81^{+\bullet}$, in contrast to simple alkylbenzene ions such as $62^{+\bullet}$ and $63^{+\bullet}$. Both $\mathrm{C}_{7} \mathrm{H}_{8}{ }^{+\cdot}$ and $\mathrm{C}_{7} \mathrm{H}_{7}{ }^{+}$fragments exhibit the reversible hydrogen exchange between the $\gamma$ and ortho (as well as the $\alpha$ and ortho') positions. These two fourhydrogen interchange sets are linked by a similarly fast hydrogen exchange be- 
tween the ortho and ortho' positions, establishing an eight-hydrogen interchange system with the distonic ion $82^{+\cdot}$ and the tautomer $83^{+\cdot}$ as the intermediates. The three isomers $81^{+}, \mathbf{8 2}^{+\bullet}$, and $83^{+\cdot}$ were estimated (308) to have similar heats of formation, enabling nearly thermoneutral hydrogen transfer throughout the interchange. The number of exchange cycles was estimated by model calculations to be $0.4-0.8,3$, and $5-8$ for unstable ions formed at 70 and $12 \mathrm{eV}$ and for metastable ions, respectively. Thus, the hydrogen exchange between the $\gamma$ and ortho positions for $\mathbf{8 1}^{+\cdot}$ is much faster than for simple $n$-alkylbenzene ions, owing to the energetically much more favorable hydrogen transfer.

The hydrogen atoms at the meta and para positions of the rings as well as at $\mathrm{C}^{\beta}$ of the chain were found not to be involved in the interchange process. This is in sharp contrast to the fast proton (or hydride) ring-walk in protonated arenes, which involves all of the ring hydrogens (see Part II), suggesting that the distonic ion $82^{+\cdot}$ might not be an unperturbated, (positively charged) Wheland complex carrying the "isolated" radical electron at the remote benzyl moiety; it rather could bear spin density in the $\sigma$-complex and charge at the benzyl moiety, as formulated in $82^{\prime+}$. Use of more recent thermochemical data concerning the stability of the cyclohexadienyl radical $\left(3^{\circ}\right)(402,403)$ corroborate this conclusion. In the case of substituted $\mathbf{8 1}^{+\cdot}$ ions, however, an electron-donating substituent $\left(\mathrm{OCH}_{3}\right)$ at the meta position stabilizes the Wheland-type distonic ion $82^{+\cdot}$ much more than at the para position, without affecting the $\mathrm{AE}$ of the rearrangement ions $\mathrm{C}_{7} \mathrm{H}_{7}\left(\mathrm{OCH}_{3}\right)^{+\cdot}$ (85). Therefore, the authors (85) attributed the pronounced substituent effect on the ratio $\left[\mathrm{C}_{7} \mathrm{H}_{7} \mathrm{X}^{+\cdot}\right] /\left[\mathrm{C}_{7} \mathrm{H}_{7}^{+}\right]$in $\mathbf{8 1} 1^{+\cdot}$ and its derivatives to the relative stability of the corresponding distonic ion intermediate $\mathbf{8 2}^{+}$, which depends primarily on the local proton affinity of the hydrogen acceptor site, rather than on the stability of the fragment ions (287).

These conclusions were corroborated by an investigation combining the sub-

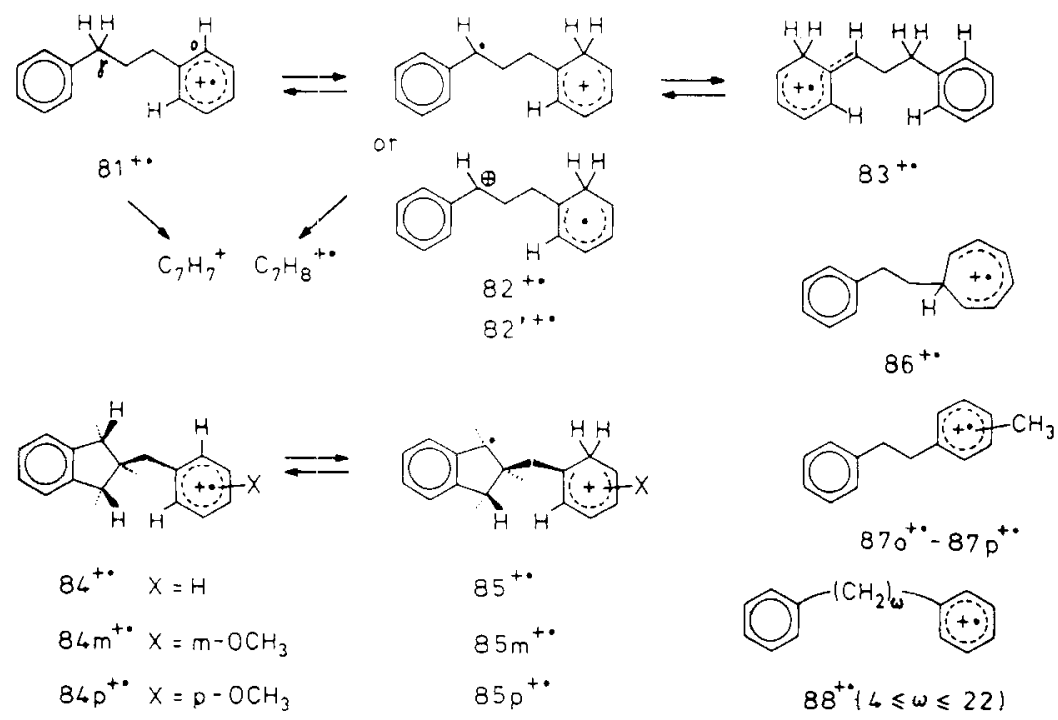

Scheme X 
stituent effect and the time dependence of the intramolecular hydrogen exchange processes $(178,404)$. For ionized 2-benzylindan $84^{+}$and its methoxy derivatives $84 \mathrm{~m}^{+\cdot}$ and $84 \mathrm{p}^{+\bullet}$, the hydrogen exchange was found to be highly stereoselectively restricted to four atoms only $\left(\mathrm{H}^{1, c i s,} \mathrm{H}^{3, c i s}\right.$, and $\left.\mathrm{H}^{\text {ortho }}\right)$. In comparison to the unsubstituted ion $84^{+}$, the exchange is decelerated by the para- $\mathrm{OCH}_{3}$ group and accelerated by the meta-OCH 3 group at the benzyl moieties. In the latter case, full equilibration of the four hydrogen atoms was observed for the metastable ions, reflecting an exoergic hydrogen transfer equilibrium $84 \mathrm{~m}^{+\cdot} \leftrightarrows 85 \mathrm{~m}^{+\cdot}(178)$. Further substituted 2-benzylindans ( $\left.\mathrm{X}=\mathrm{CH}_{3}, \mathrm{~F}, \mathrm{OH}, \mathrm{N}\left(\mathrm{CH}_{3}\right)_{2}\right)$ have also been studied (405), showing substituent-modulated increase of the hydrogen exchange rate and slightly reduced stereospecificity in some cases.

Attempts to study the hydrogen exchange in $81^{+\cdot}$ and $84^{+\cdot}$ by FIK proved unsuccessful due to the low exchange rate, but the rate of $\gamma-\mathrm{H}$ transfer for $84^{+\cdot}$ was found to be considerably greater than for $\mathbf{8 1}^{+*}$, probably for entropic reasons (unpublished results). It should be noted here that the hydrogen exchange in ionized 1, $\omega$-diphenylalkanes is yet relatively slow, that is, by far not as fast as the ring-to-ring proton exchange in the carresponding protonated hydrocarbons. For example, for protonated 1,3-diphenylpropane $[81+\mathrm{H}]^{+}$and 2-benzylindan [84 $+\mathrm{H}^{+}$, all of the protons at the aromatic rings are equilibrated within $\simeq 10^{-6} \mathrm{~s}$ (406-410) (see Part II).

The specificity of the $\gamma \leftrightarrows$ ortho hydrogen exchange in ionized 1,3-diphenylpropane $\left(\mathbf{8 1}^{+}\right.$) is in line with the retention of the carbon skeleton, revealed by comparison of the fragmentation of $81^{+*}, 86^{+*}$, and $870^{+}-87 \mathrm{p}^{+\cdot}$ and their labeled analogs (89). All of them showed different MIKE spectra, indicating that the skeletal rearrangements are suppressed by energetically favorable fragmentation paths. Ionization and appearance energies were used to estimate the lower limits of the $\mathrm{C}_{7} \mathrm{H}_{8}{ }^{+}$type isomerization of these ions (Sect. IV.A).

For higher 1, $\omega$-diphenylalkane ions $88^{+\cdot}(4 \leqslant \omega \leqslant 22)$, studied by the same authors (320), the relatively high rate and particularly high regioselectivity of hydrogen exchange found for $\mathbf{8 1}^{+\cdot}$ and $\mathbf{8 4}^{+\cdot}$ are distinctly reduced. $\mathrm{C}^{\gamma}$ remains the major donor site for hydrogen exchange, however, as found for the simple $n$-alkylbenzenes $(1,282,285)$, leading to two essentially separated hydrogen exchange sets. Accordingly, hydrogen exchange for ionized 1,5-diphenylpentane $8^{+\cdot}(\omega=5)$, as an exception, occurs between the two rings because here the distonic ion intermediate is common to both exchange sets. With the whole series of homologs, the maximum ratio $\left[\mathrm{C}_{7} \mathrm{H}_{8}{ }^{+}\right] /\left[\mathrm{C}_{7} \mathrm{H}_{7}{ }^{+}\right]=1.7,\left(\left[91^{+}\right] /\left[92^{+}\right]=0.59\right)$ in the $70 \mathrm{eV}$ mass spectra was found for $\mathbf{8 1}^{+\cdot}(\omega=3)$, decreasing to a minimum for $\omega=5$ and then slowly increasing again [considerably slower than for the simple $n$-alkylbenzenes (321)] up to $\left[\mathrm{C}_{7} \mathrm{H}_{8}{ }^{+}\right] /\left[\mathrm{C}_{7} \mathrm{H}_{7}{ }^{+}\right] \simeq 1.5\left(\left[91^{+}\right] /\left[92^{+}\right] \simeq 0.67\right)$ for $1,22-$ diphenyldocosane $8^{+^{+}}(\omega=22)$. The "activated" $\mathrm{C}^{\omega}-\mathrm{H}$ bonds were found to play no significant role as donor sites in either hydrogen exchange or fragmentation to $\mathrm{C}_{7} \mathrm{H}_{8}{ }^{+}$, suggesting that also with very long aliphatic chains, no internal solvation occurs. On the other hand, the metastable ions of the long-chain $1, \omega-$ diphenylalkanes exhibit a number of rather peculiar fragmentation reactions, pointing to complex isomerization steps via distonic ion intermediates and/or C$\mathrm{C}$ bond formation between the rings. The interaction of formally remote $\pi$-systems 
has been of interest over the years. For example, Caluwe et al. (411) reported the mass spectra of long-chain $1, \omega$-di-( $\alpha$-naphthyl)-alkanes. A recent study by Ikeda et al. (412) described "excitation hopping" between the two identical chromophores of $1, \omega$-di-( $\beta$-naphthyl)-alkanes.

Ionized phenyl-substituted benzocycloalkanes such as $89^{+\bullet}$ and $90^{+\cdot}$ (Scheme $\mathrm{XI}$ ) represent cases of combined 1 , $\omega$-diphenylalkane structure (i.e., $89^{+\cdot}$ comprises $70^{+\bullet}$ and $79^{+*}, 90^{+}$combines $80^{+^{-}}$and $81^{+\bullet}$ ); hence their isomerization and fragmentation behavior reflect some of the features of the simpler ions discussed above. Here, loss of benzene is a dominating fragmentation channel instead of formation of $\mathrm{C}_{7} \mathrm{H}_{8}{ }^{+}$and $\mathrm{C}_{7} \mathrm{H}_{7}{ }^{+}$. Again, a specific hydrogen transfer, possibly directly to the ipso position of the acceptor ring, initiates the cleavage of the corresponding $C-C$ bond. Gross et al. (413) were the first to report that ionized 1-phenyltetralin $\left(\mathbf{8 9}^{+\bullet}\right)$ undergoes a highly regio- and stereoselective 1,4-elimination of $\mathrm{C}_{6} \mathrm{H}_{6}$. This fragmentation is reminiscent of the loss of benzene from ionized (ortho-methyl)-substituted diphenylmethanes $\left(79^{+*}\right)$ discussed above (397) (Sect. VI.A, see also ref. 423). This reaction was also found by Puschmann (414) to occur for 1-aryltetralin ions, and, with much lesser regioselectivity, for homologous phenylbenzocycloalkane ions. Particularly noteworthy is the highly stereospecific elimination of benzene from ionized trans-1,4-diphenyltetralin $91^{+*}$ (414). Similar to $81^{+\cdot}$ and $84^{+*}$, the hydrogen donor site is strongly activated, and electron-donating substituents at the acceptor nucleus govern the mass spectrometric fragmentation by affecting its proton (or hydrogen atom) affinity. Later, Gallagher et al. (415) showed in a detailed study that 1- and 2-phenyltetralin ions $\left(89^{+}\right.$and $\left.90^{+}\right)$undergo slow intramolecular hydrogen exchange prior to loss of $\mathrm{C}_{6} \mathrm{H}_{6}$ as well as $\mathrm{CH}_{3}{ }^{\circ}, \mathrm{C}_{2} \mathrm{H}_{4}$, and $\mathrm{C}_{8} \mathrm{H}_{8}$. Loss of $\mathrm{C}_{6} \mathrm{H}_{6}$ is the by far most favorable fragmentation in both cases $\left(E_{a} \simeq 14\right.$ and $\simeq 7 \mathrm{kcal} \cdot \mathrm{mol}^{-1}$, respectively); nevertheless, the hydrogen exchange for $89^{+\cdot}$ and $90^{+\cdot}$ appears to be considerably less specific than for $81^{+\cdot}$ and $84^{+\cdot}$. Several exchange channels were found to compete with each other [e.g., interchange of the benzylic hydrogen with those at the benzo nucleus, associated with epimerization at C-1 and possibly C-4, similar to ionized tetralin itself (Sect. V.C)]. Another hydrogen exchange was suggested to occur between $C-4$ and the phenyl ring similar to that found for $81^{+}$and $84^{+}$

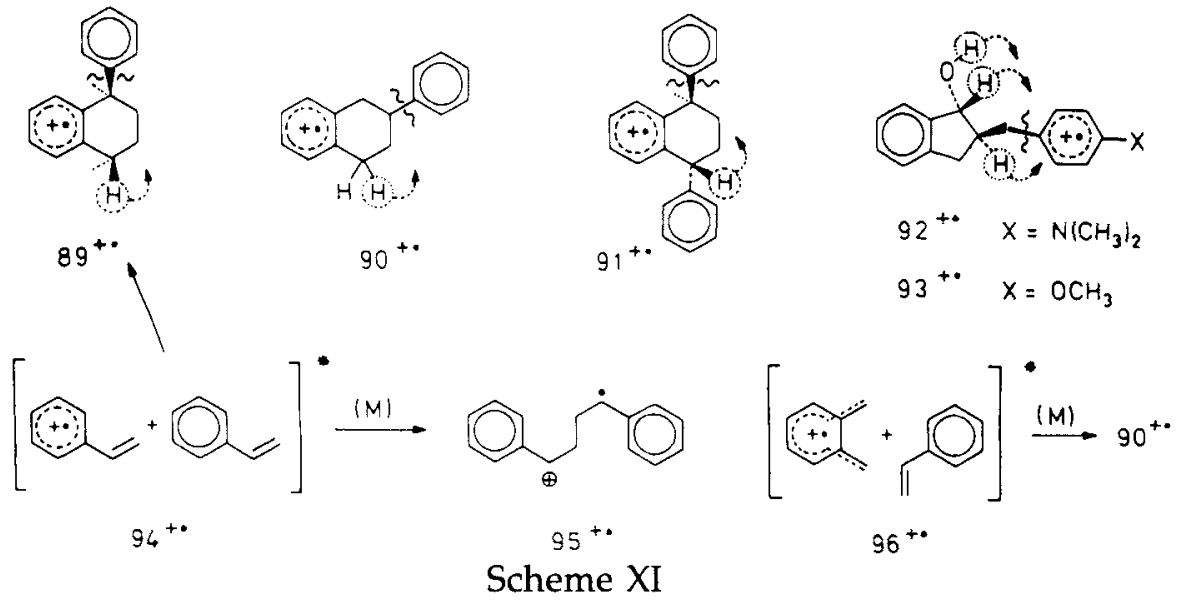


type ions; by contrast, the authors (415) assumed the para position to be involved along with the two ortho positions. Further isomerization channels were proposed to precede the other fragmentation processes. Isomeric ions $\mathbf{9 0}^{+}$exhibited predominant 1,3-elimination of $\mathrm{C}_{6} \mathrm{H}_{6}$ as well as loss of $\mathrm{CH}_{3}{ }^{\circ}$ and $\mathrm{C}_{8} \mathrm{H}_{8}$.

The phenyltetralin ions $89^{+\bullet}$ and $90^{+\bullet}$ have been of particular interest because of their role as potential adducts of the gas-phase (Diels-Alder) cycloaddition of ionized and neutral styrene (Scheme XI). In an early ICR study, Wilkins and Gross (416) found that the adduct $94^{+\cdot}$ expels $\mathrm{C}_{6} \mathrm{H}_{6}$, suggesting $89^{+\cdot}$ to be formed by Diels-Alder cycloaddition under low-pressure conditions. Ionized cyclooctatetraene did not undergo this ion-molecule reaction. Later, Groenewold et al. (417) compared the CID spectra of the collisionally stabilized adduct $94^{+\cdot}$ formed in a HPMS ion source with $\mathrm{C}_{16} \mathrm{H}_{16}{ }^{+\cdot}$ ions from various alkylbenzene-type precursors and deduced the distonic ion $95^{+\bullet}$ to be formed as the product of the ion-molecule reaction. Thus, surprisingly, the thermochemically most stable product, which is certainly $89^{+\bullet}(414)$, is not formed under high pressure conditions. In contrast, as shown by Chess et al. (418) in a corresponding ICR/HPMS work, ionized orthoquinodimethane does react with styrene to give a complex $\left(96^{+*}\right)$ which shows all features of $90^{+*}$, both at low and high pressures, suggesting the formation of a covalent cycloadduct.

The specific hydrogen transfer leading to loss of an arene neutral has gained only little attention as compared to the McLafferty rearrangement. Due to the necessity of protonation of the ipso carbon atom to cleave the corresponding $\mathrm{C}$ $\mathrm{C}$ bond, however, the reaction strongly depends on the local proton affinity at that position, rendering the arene loss a rather structure-specific reaction. Most of the diphenylalkane ions discussed above exhibit arene loss (e.g., $\mathbf{7 9}^{+}, \mathbf{8 1}^{+}$,

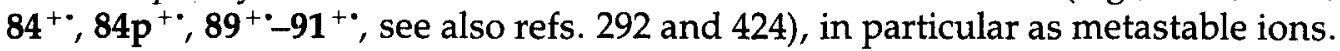
Similar stereo- and regiospecific intramolecular transfer reactions of benzylic hydrogen atoms to the ipso position of an electron-rich arene ring were found by Kuck and Filges (419) to occur in ionized 2-benzyl-1-indanols $92^{+*}$ and $93^{+*}$, as well as in simpler, suitably substituted 3-arylpropanols (419). It was proposed that protonation at the ipso position of the benzyl moiety initiates the remarkably specific unidirectional transfer of up to three hydrogen atoms to the electron-rich arene ring, as indicated in Scheme XI, probably involving ion-molecule intermediates.

It is appropriate to mention at this point that the hydrogen transfer processes found for ionized diphenylalkanes may have implications for larger arylaliphatic ions of general interest. Thus, 1,3-diphenylpropane ions $\mathbf{8 1}^{+\cdot}$ represent the prototype of ionized styrene oligomers and polymers. Mass spectrometry of polystyrene mixtures have gained much interest through recent years (420), and pronounced differences were found depending on the substitution pattern of the monomer (421). It appears possible that intramolecular hydrogen transfer processes and formation of distonic ions related to $67^{+\bullet}$ and $82^{+\bullet}$ govern the mass spectrometric fragmentation of these important materials. Application of powerful modern techniques of ion production, excitation, and separation will provide insight into the role of isomerization paths in such large alkylbenzene ions. 


\section{PROSPECTS}

Radical cations of alkylbenzenes have been studied in enormous detail throughout more than 30 years. A pronounced falloff of understanding of their gas-phase chemistry is registered by going from the small ions like ionized benzene $\left(1^{+}\right)$ and toluene $\left(7^{+*}\right)$, simple $n$-alkylbenzenes as $63^{+\cdot}$ to complex ions of diphenylalkanes such as $\mathbf{8 1} 1^{+\cdot}$ and $\mathbf{8 8 ^ { + }}$. Hopefully, insights from investigations of the smaller ionic systems will be transferred to the larger ones, maybe even to polystyrene ions, by applying the multitude of modern mass spectrometric techniques. It is felt that, with increasing size of the ions, the isomerization and fragmentation behavior of alkylbenzene radical cations will approach the reactivity known from general organic chemistry, due to low-energy charge- or radical-triggered reaction paths. By pursuing the chemistry of these systems by means of mass spectrometry, in particular by energy-selecting and bimolecular ion techniques, the intellectual gap between the peculiar gas-phase chemistry of small radical cations and general organic chemistry of ionized species will further diminish.

\section{ACKNOWLEDGMENTS}

The author thanks Professor Dr. H. Budzikiewicz for suggesting this review and to the Arbeitsgemeinschaft Massenspektrometrie (AGMS) for encouraging recognition. He is particularly grateful to Professor Dr. H.-F. Grützmacher for many stimulating discussions over the years, which have contributed so much to the author's inspiration in mass spectrometry and organic chemistry. Special thanks are due to the coworkers from his laboratory mentioned in the references and to Dr. U. Neuert for help in handling the text. Acknowledgment is also due to Prof. John L. Holmes and to Dr. Sharon G. Lias for kindly providing preprints of their recent work. Finally, the author wishes to express his gratitude to the editor of this journal and to two colleagues for careful refereeing.

\section{REFERENCES}

1. Grubb, H. M.; Meyerson, S. In: "Mass Spectrometry of Organic Ions"; McLafferty, F. W., Ed., Academic Press: New York, 1963; Chap. 10.

2. Meyerson, S. Org. Mass Spectrom. 1986, 21, 197-208.

3. Quayle, A. Org. Mass Spectrom. 1987, 22, 569-585.

4. Reed, R. I. "Ion Production by Electron Impact"; Academic Press: London, 1962.

5. Budzikiewicz, H.; Djerassi, C.; Williams, D. H. "Mass Spectrometry of Organic Compounds"; Holden-Day: San Francisco, 1967.

6. Spiteller, G. In: "Massenspektrometrie"; Kienitz, H., Ed., Verlag Chemie, Weinheim, 1968; chap. D3.

7. Harrison, A. G., In: "Topics in Organic Mass Spectrometry"; Burlingame, A. L., Ed.; Wiley-Interscience: New York, 1970.

8. Bursey, J. T.; Bursey, M. M.; Kingston, D. G. I. Chem. Rev. 1973, 73, 191-234.

9. Kingston, D. G. I.; Bursey, J. T.; Bursey, M. M. Chem. Rev. 1974, 74, 215-242.

10. Kingston, D. G. I.; Hobrock, B. W.; Bursey, M. M.; Bursey, J. T. Chem. Rev. 1975, 75, 695-730.

11. Holmes, J. L. Org. Mass Spectrom. 1985, 20, 169-183.

12. Williams, D. H.; Howe, I. "Principles of Organic Mass Spectrometry"; McGraw-Hill: London, 1972. 
13. Cooks, R. G.; Beynon, J. H.; Caprioli, R. M.; Lester, G. R. "Metastable Ions"; Elsevier: Amsterdam, 1973.

14. Ausloos, P., Ed.; "Ion-Molecule Reactions"; Plenum Press: New York, 1975.

15. Beckey, H. D. "Principle of Field Ionization and Field Desorption Mass Spectrometry"; Pergamon: London, 1977.

16. Levsen, K. "Fundamental Aspects of Organic Mass Spectrometry"; Verlag Chemie: Weinheim, 1978.

17. Cooks, R. G., Ed. "Collision Mass Spectrometry"; Plenum Press: New York, 1978.

18. McLafferty, F. W., Ed. "Tandem Mass Spectrometry"; Wiley-Interscience: New York, 1983.

19. Harrison, A. G. "Chemical Ionization Mass Spectrometry"; CRC Press: Boca Raton, 1983.

20. Chapman, J. R. "Practical Organic Mass Spectrometry"; Wiley: Chichester, England, 1985.

21. "Specialists' Periodical Reports: Mass Spectrometry"; Vol. 9; Rose, M. E., Sen. Rep.; The Royal Society of Chemistry: London, 1987; and previous volumes 1-8 (1971-1985).

22. Bowers, M. T., Ed. "Gas Phase Ion Chemistry", Vol. 2; Academic Press: New York, 1979.

23. Bowers, M. T., Ed. "Gas Phase Ion Chemistry", Vol. 3; Academic Press: Orlando, 1984.

24. Speranza, M.; Sefzik, M. D.; Henis, J. M. S.; Gaspar, P. P. J. Am. Chem. Soc. 1977, 99, 5583-5589.

25. Williams, D. H.; Hvistendahl, G. J. Am. Chem. Soc. 1974, 96, 6755-6757.

26. Meyerson, S.; Rylander, P. N. J. Am. Chem. Soc. 1957, 79, 1058-1061.

27. Field, F. H.; Franklin, J. L. J. Chem. Phys. 1954, 22, 1895-1904.

28. Rosenstock, H. M.; Draxl, K.; Steiner, B. W.; Herron, J. T. J. Phys. Chem. Ref. Data 1977, 6, Suppl. No. 1.

29. Walder, R.; Franklin, J. L. Int. J. Mass Spectrom. Ion Phys. 1980, 36, 85-112.

30. Lias, S. G.; Liebman, J. F.; Levin, R. D. J. Phys. Chem. Ref. Data 1984, 13, 695-808.

31. Lias, S. G.; Bartmess, J. E.; Hólmes, J. L.; Levin, R. D.; Liebman, J. F.; Mallard, W. G. J. Phys. Chem. Ref. Data 1988, 17, Suppl. No. 1.

32. Aue, D. H.; Bowers, M. T. In ref. 22; chap. 9.

33. Momigny, J.; Brakier, L.; D'Or, L. Bull. Cl. Sci., Acad. Roy. Belg. 1962, 48, 1002-1015.

34. MacDonald, C. G.; Shannon, J. S. Austr. J. Chem. 1963, 15, 771-785.

35. Jennings, K. R. Z. Naturforsch. A. 1967, 22 454-459.

36. Horman, I.; Yeo, A. N. H.; Williams, D. H. J. Am. Chem. Soc. 1970, 92, 2131-2132.

37. Perry, W. O.; Beynon, J. H.; Baitinger, W. E.; Amy, J. W.; Caprioli, R. M.; Renaud, R. N.; Leitch, L. C.; Meyerson, S. J. Am. Chem. Soc. 1970, 92, 7236-7238.

38. Dickinson, R. J.; Williams, D. H. J. Chem. Soc. B 1971, 249-251.

39. Beynon, J. H.; Caprioli, R. M.; Perry, W. O.; Baitinger, W. E. J. Am. Chem. Soc. 1972, 94, 6828-6833.

40. Gallup, G. A.; Steinheider, D.; Gross, M. L. Int. J. Mass Spectrom. Ion Phys. 1976, 22, 185-188.

41. Borchers, F.; Levsen, K. Org. Mass Spectrom. 1975, 10, 584-594.

42. Köppel, C.; Schwarz, H.; Borchers, F.; Levsen, K. Int. J. Mass Spectrom. Ion Phys. 1976, $21,15-20$.

43. Cooks, R. G.; Beynon, J. H.; Litton, J. F. Org. Mass Spectrom. 1975, 10, 503-506.

44. Keough, T.; Ast, T.; Beynon, J. H.; Cooks, R. G. Org. Mass Spectrom. 1973, 7, 245-247.

45. Jones, E. G.; Bauman, L. E.; Beynon, J. H.; Cooks, R. G. Org. Mass Spectrom. 1973, 7, 185-192.

46. Baer, T.; Willett, G. D.; Smith, D.; Philips, J. S. J. Chem. Phys. 1979, 70, 4076-4085.

47. Gross, M. L.; Russell, D. H.; Aerni, R. J.; Bronczyk, S. A. J. Am. Chem. Soc. 1977, 99, 3603-3609.

48. Russell, D. H.; Gross, M. L. J. Am. Chem. Soc. 1980, 102, 6279-6284.

49. Guilhaus, M.; Kingston, R. G.; Brenton, A. G.; Beynon, J. H. Org. Mass Spectrom. 1985, $20,424-425$.

50. Kinter, M. T.; Bursey, M. M. Org. Mass Spectrom. 1987, 22, 775-778.

51. Rosenstock, H. M.; Dannacher, J.; Liebman, J. F. Radiat. Phys. Chem. 1982, 20, 7-28.

52. Eyler, J. R.; Campana, J. E. Int. J. Mass Spectrom. Ion Proc. 1983/1984, 55, 171-188. 
53. Knight, J. S.; Freeman, C. G.; McEwan, M. J.; Anicich, V. G.; Huntress, W. T., Jr. J. Phys. Chem. 1987, 91, 3898-3902.

54. Tasaka, M.; Ogata, M.; Ichikawa, H. J. Am. Chem. Soc. 1981, 103, 1885-1891.

55. Ausloos, P.; Lias, S. G.; Buckley, T. J.; Rogers, E. E. Int. J. Mass Spectrom. Ion Proc. 1989, in press.

56. Lias, S. G.; Ausloos, P. J. Chem. Phys. 1985, 82, 3613-3624.

57. Kuck, D.; Schneider, J.; Grützmacher, H.-F. J. Chem. Soc., Perkin Trans. 2, 1985, 689-696.

58. Rylander, P. N.; Meyerson, S.; Grubb, H. M. J. Am. Chem. Soc. 1957, 79, 842-846.

59. Davidson, R. A.; Skell, P. S. J. Am. Chem. Soc. 1973, 95, 6843-6845.

60. Meyerson, S.; Rylander, P. N. J. Chem. Phys. 1957, 27, 901-904.

61. Burr, J. G.; Meyer, R. A. J. Chem. Phys. 1964, 40, 2046-2047.

62. Rinehart, K. L.; Buchholz, A. C.; Van Lear, G. E.; Cantrill, H. L. J. Am. Chem. Soc. 1968, 90, 1983-1985.

63. Siegel, A., J. Am. Chem. Soc. 1970, 92, 5277-5278.

64. Howe, I.; McLafferty, F. W. J. Am. Chem. Soc. 1971, 93, 99-105.

65. Meyer, F.; Harrison, A. G. J. Chem. Phys. 1965, 43, 1778-1782.

66. Baldwin, M. A.; McLafferty, F. W.; Jerina, D. M. J. Am. Chem. Soc. 1975, 97, 6169-6174.

67. Levsen, K.; Beckey, H.-D. Int. J. Mass Spectrom. Ion Phys. 1974, 14, 45-55.

68. Levsen, K.; Beckey, H.-D. Org. Mass Spectrom. 1974, 9, 570-581.

69. Dewar, M. J. S.; Landman, D. J. Am. Chem. Soc. 1977, 99, 2446-2453.

70. Grotemeyer, J.; Grützmacher, H.-F., Org. Mass Spectrom. 1982, 17, 353-359.

71. Stapleton, J.; Bowen, R. D.; Williams, D. H. J. Chem. Soc., Perkin Trans. 2 1979, 12191226.

72. Dolejšek, Z.; Hanuš, V.; Prinzbach, H. Angew. Chem. 1962, 74, 902.

73. Lifshitz, C.; Bauer, S. H. J. Phys. Chem. 1963, 67, 1629-1635.

74. Hanus, V.; Dolejšek, Z. Coll. Czech. Chem. Commun. 1963, 28, 652-657.

75. Hoffman, M. K. Z. Naturforsch. A 1974, 29, 1077-1080.

76. Hoffmann, R. Tetrahedron Lett. 1970, 2907-2909.

77. Gajewski, J. J.; Gortva, A. M. J. Am. Chem. Soc. 1982, 104, 334-335.

78. Meyerson, S.; McCollum, J. D.; Rylander, P. N. J. Am. Chem. Soc. 1961, 83, 1401-1403.

79. Traeger, J. C.; McLoughlin, R. G. J. Chem. Thermodyn. 1978, 10, 505-506.

80. Nibbering, N. M. M.; de Boer, T. J. Org. Mass Spectrom. 1968, 1, 365-390.

81. McLafferty, F. W.; Kornfeld, R.; Haddon, W. F.; Levsen, K.; Sakai, I.; Bente, P. F.; III; Tsai, S.-C.; Schüddemage, H. D. R. J. Am. Chem. Soc. 1973, 95, 3886-3892.

82. Levsen, K.; McLafferty, F. W.; Jerina, D. M. J. Am. Chem. Soc. 1973, 95, 6332-6335.

83. Burgers, P. C.; Terlouw, J. K.; Levsen, K. Org. Mass Spectrom. 1982, 17, 295-298.

84. Occolowitz, J. L.; Cerimele, B. J.; Brown, P. Org. Mass Spectrom. 1974, 8, 61-76.

85. Kuck, D.; Grützmacher, H.-F. Org. Mass Spectrom. 1978, 13, 81-89.

86. McLoughlin, R. G.; Morrison, J. D.; Traeger, J. C., Org. Mass Spectrom. 1978, 13, 483485.

87. Williams, D. H.; Bowen, R. D. Org. Mass Spectrom. 1976, 11, 223-230.

88. Bartmess, J. E. J. Am. Chem. Soc. 1982, 104, 335-337.

89. Kuck, D.; Grützmacher, H.-F. Org. Mass Spectrom. 1979, 14, 86-97.

90. Winkler, J.; McLafferty, F. W. J. Am. Chem. Soc. 1973, 95, 7533-7535.

91. McLafferty, F. W.; Winkler, J. J. Am. Chem. Soc. 1974, 96, 5182-5189.

92. Jackson, J.-A. A.; Lias, S. G.; Ausloos, P. J. Am. Chem. Soc. 1977, 99, 7515-7521.

93. Venema, A.; Nibbering, N. M. M.; de Boer, T. J. Tetrahedron Lett. 1971, 2141-2142.

94. Ausloos, P.; Jackson, J.-A. A.; Lias, S. G. Int. I. Mass Spectrom. Ion Phys. 1980, 33, 269283.

95. Dunbar, R. C. J. Am. Chem. Soc. 1975, 97, 1382-1384.

96. Shen, J.; Dunbar, R. C.; Olah, G. A. J. Am. Chem. Soc. 1974, 96, 6227-6229.

97. Sen Sharma, D. K.; Kebarle, P. Can. J. Chem. 1981, 59, 1592-1601.

98. McLafferty, F. W.; Bockhoff, F. M. J. Am. Chem. Soc. 1979, 101, 1783-1786.

99. Ausloos, P. J. Am. Chem. Soc. 1982, 104, 5259-5265.

100. Buschek, J. M.; Ridal, J. J.; Holmes, J. L. Org. Mass Spectrom. 1988, 23, 543-549.

101. Hoffman, M. K.; Bursey, M. M. Tetrahedron Lett. 1971, 2539-2542.

102. Bursey, M. M.; Hoffman, M. K.; Benezra, S. A. Chem. Commun. 1971, 1417-1418. 
103. Ausloos, P.; Lias, S. G. Chem. Phys. Lett. 1977, 47, 495-498.

104. Dunbar, R. C.; Shen, J.; Olah, G. A. J. Am. Chem. Soc. 1972, 94, 6862-6864.

105. Rabrenovic, M.; Brenton, A. G.; Ast, T. Org. Mass Spectrom. 1983, 18, 587-595.

106. Cooks, R. G.; Beynon, R. H.; Bertrand, M; Hoffman, M. K.; Org. Mass Spectrom. 1973, 7, 1303-1312.

107. Kingston, E. E.; Beynon, J. H.; Ast, T.; Flammang, R.; Maquestiau, A. Org. Mass Spectrom. $1985,20,546-555$.

108. Traeger, J. C.; McLoughlin, R. G. J. Am. Chem. Soc. 1977, 99, 7351-7352.

109. Traeger, J. C.; McLoughlin, R. G. Int. J. Mass Spectrom. Ion Phys. 1978, 27, 319-333.

110. Eyler, J. R. J. Am. Chem. Soc. 1976, 98, 6831-6834.

111. Dunbar, R. C., Fu, E. W. J. Am. Chem. Soc. 1973, 95, 2716-2718.

112. Dunbar, R. C. J. Am. Chem. Soc. 1973, 95, 472-476.

113. Yamamoto, Y.; Takamuku, S.; Sakurai, H. I. Am. Chem. Soc. 1972, 94, 661-663.

114. Yamamoto, Y.; Takamuku, S.; Sakurai, H. Bull. Chem. Soc. Japan 1971, 44, 2104-2107.

115. Kramer, J. M.; Dunbar, R. C. J. Chem. Phys. 1974, 60, 5122-5123.

116. Dunbar, R. C.; Klein, R. J. Am. Chem. Soc. 1977, 99, 3744-3746.

117. Buttrill, S. E., Jr. J. Chem. Phys. 1974, 61, 619-624.

118. Lifshitz, C. J. Chem. Phys. 1975, 62, 1602-1603.

119. Buttrill, S. E., Jr. J. Chem. Phys. 1975, 62, 1603-1604.

120. Stebbings, W. L.; Taylor, J. W. Int. J. Mass Spectrom. Ion Phys. 1972, 9, 471-484.

121. McLafferty, F. W.; Wachs, T.; Lifshitz, C.; Innorta, G.; Irving, P. J. Am. Chem. Soc. 1970, 92, 6867-6880.

122. Smith, R. D.; Futrell, J. H. Org. Mass Spectrom. 1976, 11, 445-457.

123. Jacobsen, D. B.; Byrd, G. D.; Freiser, B. S. Inorg. Chem. 1984, 23, 553-557.

124. Jacobson, D. B.; Freiser, B. S. J. Am. Chem. Soc. 1984, 106, 1159-60.

125. Reeher, J. R.; Flesch, G. D.; Svec, H. J. Org. Mass Spectrom. 1976, 11, 154-166.

126. Andrews, L.; Keelan, B. W. J. Am. Chem. Soc. 1980, 102, 5732-5736.

127. Kelsall, B. J.; Andrews, L.; McGarvey, G. J. J. Phys. Chem. 1983, 87, 1788-1795.

128. Meyerson, S.; Rylander, P. N. J. Phys. Chem. 1958, 62, 2-5.

129. Meyer, F.; Haynes, P.; McLean, S.; Harrison, A. G. Can. J. Chem. 1965, 43, 211-218.

130. Venema, A.; Nibbering, N. M. M.; Maurer, K. H.; Rapp, U. Int. J. Mass Spectrom. Ion Phys. 1975, 17, 89-91.

131. Meyer, F.; Harrison, A. G. J. Am. Chem. Soc. 1964, 86, 4757-4761.

132. Nacson, S.; Harrison, A. G. Org. Mass Spectrom. 1986, 21, 309-312.

133. Yeo, A. N. H.; Williams, D. H. Chem. Commun. 1970, 886-887.

134. Howe, I.; Uccella, N. A.; Williams, D. H. J. Chem. Soc., Perkin Trans 2 1973, 76-80.

135. Köppel, C.; McLafferty, F. W. Chem. Commun. 1976, 810-811.

136. Tajima, S.; Tsuchiya, T. Org. Mass Spectrom. 1974, 9, 265-273.

137. Holmes, J. L.; Blair, A. S.; Weese, G. M.; Osborne, A. D.; Terlouw, J. K. Adv. Mass Spectrom. 1978, 7, 1227-1230.

138. Brown, P. Org. Mass Spectrom. 1969, 2, 1085-1101.

139. Brown, P. Org. Mass Spectrom. 1969, 2, 1317-1324.

140. Brown, P. Org. Mass Spectrom. 1970, 3, 639-646.

141. Brown, P. J. Am. Chem. Soc. 1968, 90, 2694-2696.

142. Brown, P. J. Am. Chem. Soc. 1968, 90, 4459-4461.

143. Brown, P. J. Am. Chem. Soc. 1968, 90, 4461-4462.

144. Lightner, D. A.; Majeti, S.; Quistad, G. B. Tetrahedron Lett. 1970, 3857-3860.

145. Majeti, S.; Lightner, D. A. Tetrahedron Lett. 1970, 1683-1686.

146. Meyerson, S.; Fields, E. K. Org. Mass Spectrom. 1969, 2, 1309-1314.

147. McLafferty, F. W.; Bockhoff, F. M. Org. Mass Spectrom. 1979, 14, 181-184.

148. Grotemeyer, J.; Grützmacher, H.-F. In: "Current Topics in Mass Spectrometry and Chemical Kinetics"; Beynon, J. H., McGlashan, M. L., Eds., Heyden: London, 1982; p. 29-59.

149. Kuck, D.; Prior, G.; Grützmacher, H.-F.; Müller, D. R.; Richter, W. J. Adv. Mass Spectrom. $1989,11 A, 750-751$.

150. Levsen, K.; Beckey, H. D. Int. J. Mass Spectrom. Ion Phys. 1972, 9, 63-79.

151. Bruins, A. P.; Ferrer-Correia, A. J.; Harrison, A. G.; Jennings, K. R.; Mitchum, R. K. Adv. Mass Spectrom. 1978, 7, 355-358. 
152. McIver, R. T., Jr. Org. Mass Spectrom. 1975, 10, 396-399.

153. Mukhtar, E. S.; Griffiths, I. W.; Harris, F. M.; Beynon, J. H. Org. Mass Spectrom. 1981, 16,51 .

154. Curtis, J. M.; Boyd, R. K.; Shushan, B.; Morgan, T. G.; Beynon, J. H. Org. Mass Spectrom. 1984, 19, 207-216.

155. Dunbar, R. C. In ref. 22; chap. 14.

156. Dunbar, R. C. In ref. 23; chap. 20.

157. Dymerski, P. P.; Fu, E. W.; Dunbar, R. C. J. Am. Chem. Soc. 1974, 96, 4109-4114.

158. Teng, H. H.-I; Dunbar, R. C. J. Chem. Phys. 1978, 68, 3133-3138.

159. Fu, E. W.; Dymerski, P. P.; Dunbar, R. C. J. Am. Chem. Soc. 1976, 98, 337-342.

160. Morgenthaler, L. N.; Eyler, J. R. Int. J. Mass Spectrom. Ion Phys. 1981, 37, 153-158.

161. Honovich, J. P.; Dunbar, R. C. Int. J. Mass Spectrom. Ion Phys. 1982, 42, 33-42.

162. Keelan, B. W.; Andrews, L. J. Am. Chem. Soc. 1981, 103, 822-828.

163. Olesik, S.; Baer, T.; Morrow, J. C.; Ridal, J. J.; Buschek, J.; Holmes, J. L. Org. Mass Spectrom. 1989, 24, 1008-1016.

164. Dunbar, R. C.; Honovich, J. P.; Asamoto, B. J. Phys. Chem. 1988, 92, 6935-6939.

165. Molenaar-Langeveld, T. A.; Nibbering, N. M. M.; de Boer, T. J. Org. Mass Spectrom. $1971,5,725-734$.

166. Nibbering, N. M. M.; de Boer, T. J. Tetrahedron 1968, 24, 1435-1440.

167. Venema, A.; Nibbering, N. M. M.; de Boer, T. J. Org. Mass Spectrom. 1972, 6, 675-680.

168. Venema, A.; Nibbering, N. M. M. Org. Mass Spectrom. 1974, 9, 1234-1238.

169. Hoffmah, M. K.; Amos, T. L. Tetrahedron Lett. 1972, 5235-5238.

170. Meyer, F.; Harrison, A. G. Can. J. Chem. 1964, 42, 2008-2017.

171. Barnes, C. S.; Occolowitz, J. L. Austr. J. Chem. 1963, 16, 219-224.

172. Molenaar-Langeveld, T. A.; Nibbering, N. M. M. Tetrahedron 1972, 28, 1043-1054.

173. Shannon, J. S. Austr. J. Chem. 1962, 15, 265-277.

174. Venema, A.; Nibbering, N. M. M. Tetrahedron Lett. 1974, 3013-3014.

175. Florencio, H.; Heerma, W.; Dijkstra, G. Org. Mass Spectrom. 1977, 12, 269-274.

176. Tait, J. M. S.; Shannon, T. W.; Harrison, A. G. J. Am. Chem. Soc. 1964, 84, 4-8.

177. Hoffman, M. K.; Bursey, M. M. Chem. Commun. 1971, 824-825.

178. Kuck, D.; Grützmacher, H.-F. Adv. Mass Spectrom. 1980, 8, 867-878.

179. Schwarz, H. Top. Curr. Chem. 1978, 73, 231-263.

180. Chang, T. C.; Johnston, M. V. J. Phys. Chem. 1987, 91, 884-891.

181. Meyerson, S.; Puskas, I.; Fields, E. K. J. Am. Chem. Soc. 1966, 88, 4974-4980.

182. Butcher, A. R.; Thomas, C. B. Org. Mass Spectrom. 1979, 14, 448-454.

183. Baldwin, M. A.; Carter, D. M.; Gilmore, J. Org. Mass Spectrom. 1982, 17, 45-48.

184. Doering, W. von E.; Knox, L. H. J. Am. Chem. Soc. 1954, 76, 3203-3206.

185. Doering, W. von E.; Knox, L. H. J. Am. Chem. Soc. 1957, 79, 352-356.

186. Jones, R. L.; Dorfman, L. M. J. Am. Chem. Soc, 1974, 96, 5715-5722.

187. Vincow, G.; Dauben, H. J., Jr.; Hunter, F. R.; Volland, W. V. J. Am. Chem. Soc. 1969, 91, 2823-2827.

188. McLoughlin, R. G.; Morrison, J. D.; Traeger, J. C. Org. Mass Spectrom. 1979, 14, 104108.

189. Koenig, T.; Chang, J. C. I. Am. Chem. Soc. 1978, 100, 2240-2242.

190. Lifshitz, C.; Goldenberg, M.; Malinovich, Y.; Peres, M. Org. Mass Spectrom. 1982, 17, 453-454.

191. Bombach, R.; Dannacher, J.; Stadelmann, J.-P. Chem. Phys. Lett. 1983, 95, 259-261.

192. Lossing, F. P. Can. J. Chem. 1971, 49, 357-362.

193. Houle, F. A.; Beauchamp, J. L. J. Am. Chem. Soc. 1978, 100, 3290-3294.

194. Abboud, J.-L. M.; Hehre, W. J.; Taft, R. W. J. Am. Chem. Soc. 1976, 98, 6072-6073.

195. Akopyan, M. E.; Vilesov, F. I.; Lopatin, S. N. Khim. Vys. Energ. 1972, 6, 110-114.

196. Koenig, T.; Snell, W.; Chang, J. C. Tetrahedron Lett. 1976, 4569-4572.

197. Baer, T.; Morrow, J. C.; Shao, J. D.; Olesik, S. J. Am. Chem. Soc. 1988, 110, 5633-5638.

198. Bombach, R.; Dannacher, J.; Stadelmann, J.-P. J. Am. Chem. Soc. 1983, 105, 4205-4211.

199. Cone, C.; Dewar, M. J. S.; Landman, D. J. Am. Chem. Soc. 1977, 99, 372-376.

200. Dewar, M. J. S.; Landman, D. J. Am. Chem. Soc. 1977, 99, 4633-4639.

201. Dewar, M. J. S.; Landman, D. J. Am. Chem. Soc. 1977, 99, 7439-7445. 
202. Dill, J. D.; Schleyer, P. v. R.; Pople, J. A. J. Am. Chem. Soc. 1977, 99, 1-8.

203. Gallup, G. A.; Norbeck, J. M. J. Am. Chem. Soc. 1975, 97, 970-972.

204. Siegel, A. J. Am. Chem. Soc. 1974, 96, 1251-1252.

205. Hvistendahl, G.; Undheim, K.; Györösi, P. Org. Mass Spectrom. 1973, 7, 903-905.

206. Gardner, R. J. Org. Mass Spectrom. 1971, 5, 83-85.

207. Tamas, J.; Hegedüs-Vadja, J.; Messmer, A. Acta Chim. Acad. Sci. Hung. 1979, 99, 193200.

208. Köppel, C.; Dymerski, P. P.; Bockhoff, F. M.; McLafferty, F. W. Adv. Mass Spectrom. $1976,7,295-296$.

209. Leung, H.-W.; Ichikawa, H.; Li, Y.-H.; Harrison, A. G. J. Am. Chem. Soc. 1978, 100, 24792484.

210. Bass, L. M.; Bowers, M. T. Org. Mass Spectrom. 1982, 17, 229-236.

211. Proctor, C. J.; McLafferty, F. W. Org. Mass Spectrom. 1983, 18, 193-197.

212. Hoffman, M. K.; Wallace, J. C.; J. Am. Chem. Soc. 1973, 95, 5064-5065.

213. Buschek, J. M.; Holmes, J. L. Org. Mass Spectrom. 1988, 23, 765-769.

214. McLafferty, F. W.; Todd, P. J.; McGilvery, D. C.; Baldwin, M. L. J. Am. Chem. Soc. 1980, $102,3360-3363$.

215. Fetterolf, D. D.; Yost, R. A. Int. J. Mass Spectrom. Ion Phys. 1982, 44, 37-50.

216. Wieting, R. D.; Staley, R. H.; Beauchamp, J. L. J. Am. Chem. Soc. 1974, 96, 75527554 .

217. Takamuku, S.; Sagi, N.; Nagaoka, K.; Sakurai, H. J. Am. Chem. Soc. 1972, 94, 6217-6218.

218. Bruins, A. P.; Nibbering, N. M. M. Tetrahedron Lett. 1974, 2677-2680.

219. Bruins, A. P.; Nibbering, N. M. M. Tetrahedron 1974, 30, 493-499.

220. McCrery, D. A.; Dunbar, R. C. J. Am. Chem. Soc. 1978, 100, 2902-2904.

221. Wexler, S.; Clow, R. P. J. Am. Chem. Soc. 1968, 90, 3940-3945.

222. Giardini-Guidoni, A.; Zocchi, F. Trans. Faraday Soc. 1968, 64, 2342-2347.

223. Yamamoto, Y.; Takamuku, S.; Sakurai, H. J. Am. Chem. Soc. 1969, 91, 7192-7194.

224. Kuck, D.; Bäther, W. Org. Mass Spectrom. 1986, 21, 451-457.

225. Dewar, M. J. S.; Dougherty, R. C. "The PMO Theory of Organic Chemistry"; Plenum: New York, 1975.

226. Ward, R. S.; Cooks, R. G.; Williams, D. H. J. Am. Chem. Soc. 1969, 91, 2727-2732.

227. McLafferty, F. W.; Bursey, M. M. J. Am. Chem. Soc. 1968, 90, 5299-5300.

228. Harrison, A. G.; Kebarle, P.; Lossing, F. P. J. Am. Chem. Soc. 1961, 83, 777-780.

229. Shapiro, R. H.; Serum, J. W. Org. Mass Spectrom. 1969, 2, 533-539.

230. Bruins, A. P.; Nibbering, N. M. M.; de Boer, T. J. Tetrahedron Lett. 1972, 1109-1110.

231. Cassidy, C. J.; Freiser, B. S.; Russell, D. H. Org. Mass Spectrom. 1983, 18, 378-387.

232. Russell, D. H.; Freiser, B. S.; McBay, E. H.; Canada, D. C. Org. Mass Spectrom. 1983, 18, 474-485.

233. Farmer, J. B.; Lossing, F. P.; Marsden, D. G. H.; McDowell, C. A. J. Chem. Phys, 1956, 24, 52-55.

234. McLafferty, F. W. Anal. Chem. 1962, 34, 16-25.

235. Dieckmann, J.; Thomson, J. B.; Djerassi, C. J. Org. Chem. 1967, 32, 3905-3919.

236. Shapiro, R. H.; Jenkins, T. F. Org. Mass Spectrom. 1969, 2, 771-780.

237. Richter, W. J.; Vetter, W. Org. Mass Spectrom. 1969, 2, 781-790.

238. Cram, D. J.; I. Am. Chem. Soc. 1949, 71, 3863-3870.

239. Cram, D. J.; J. Am. Chem. Soc. 1964, 86, 3767-3772.

240. Olah, G. A.; Porter, R. D. J. Am. Chem. Soc. 1971, 93, 6877-6887.

241. Olah, G. A.; Spear, R. J.; Forsyth, D. A. J. Am. Chem. Soc. 1976, 98, 6284-6289.

242. Nibbering, N. M. M.; de Boer, T. J. Org. Mass Spectrom. 1969, 2, 157-174.

243. Venema, A.; Nibbering, N. M. M.; de Boer, T. J. Org. Mass Spectrom. 1970, 3, 1589-1592.

244. Grützmacher, H.-F. Org. Mass Spectrom. 1970, 3, 131-140.

245. Uccella, N. Org. Mass Spectrom. 1975, 10, 494-502.

246. Hehre, W. J. J. Am. Chem. Soc. 1972, 94, 5919-5920.

247. Apeloig, Y.; Franke, W.; Rappoport, Z.; Schwarz, H.; Stahl, D. J. Am. Chem. Soc. 1981, $103,2770-2780$.

248. Jefford, C. W.; Mareda, J.; Perlberger, J.-C.; Burger, U. J. Am. Chem. Soc. 1979, 101, 13701378 . 
249. Nibbering, N. M. M.; Nishishita, T.; Van de Sande, C. C.; McLafferty, F. W. J. Am. Chem. Soc. 1974, 96, 5668-5669.

250. Köppel, C.; McLafferty, F. W. J. Am. Chem. Soc. 1976, 98, 8293-8294.

251. Köppel, C.; Van de Sande, C. C.; Nibbering, N. M. M.; Nishishita, T.; McLafferty, F. W. J. Am. Chem. Soc. 1977, 99, 2883-2888.

252. Barlabas, M. P.; McLafferty, F. W. Org. Mass Spectrom. 1982, 17, 640-642.

253. Dunbar, R. C.; Kim, M. S.; Olah, G. A. J. Am. Chem. Soc. 1979, 101, 1368-1370.

254. DeFrees, D. J.; McIver, R. T., Jr.; Hehre, W. J. J. Am. Chem. Soc. 1980, 102, 3334-3338.

255. Meot-Ner (Mautner), M. J. Am. Chem. Soc. 1982, 104, 5-10.

256. Pollack, S. K.; Raine, B. C.; Hehre, W. J. J. Am. Chem. Soc. 1981, 103, 6308-6313.

257. Wolf, J. F.; Harch, P. G.; Taft, R. W.; Hehre, W. J. J. Am. Chem. Soc. 1975, 97, 29022904.

258. Wolf, J. F.; Harch, P. G.; Taft, R. W. J. Am. Chem. Soc. 1975, 97, 2904-2906.

259. Fornarini, S.; Muraglia, V. J. Am. Chem. Soc. 1989, 111, 873-877.

260. Bäther, W.; Grützmacher, H.-F. Int. J. Mass Spectrom. Ion Proc. 1985, 64, 193-212.

261. Morton, T. H. Tetrahedron 1982, 38, 3195-3243.

262. McAdoo, D. J. Mass Spectrom. Rev. 1988, 7, 363-393.

263. Rylander, P. N.; Meyerson, S. J. Am. Chem. Soc. 1956, 78, 5799-5802.

264. Meyerson, S.; Hart, H. J. Am. Chem. Soc. 1963, 85, 2358-2359.

265. Meyerson, S. Org. Mass Spectrom. 1989, 24, 267-270.

266. Neeter, R.; Nibbering, N. M. M. Org. Mass Spectrom. 1973, 7, 1091-1101.

267. Uccella, N. A.; Williams, D. H. J. Am. Chem. Soc. 1972, 94, 8778-8784.

268. Nibbering, N. M. M.; de Boer, T. J. In: "Some Newer Physical Methods in Structural Chemistry", Bonnett, R., Davies, J. G., Eds., United Trade Press: London 1967; pp. 4756.

269. Köppel, C.; Schwarz, H.; Bohlmann, F. Org. Mass Spectrom. 1973, 7, 869-873.

270. Schwarz, H.; Köppel, C.; Bohlmann, F. Org. Mass Spectrom. 1973, 7, 1211-1213.

271. Houriet, R.; Elwood, T. A.; Futrell, J. H. J. Am. Chem. Soc. 1978, 100, 2320-2324.

272. Lay, J. O., Jr.; Gross, M. L. J. Am. Chem. Soc. 1983, 105, 3445-3451.

273. Colosimo, M.; Bucci, R. J. Chem. Soc., Perkin Trans. 2 1982, 461-464.

274. kieu My, N.; Schilling, M.; Schwarz, H. Org. Mass Spectrom. 1987, 22, 254-258.

275. Schwarz, H.; Bohlmann, F. Org. Mass Spectrom. 1973, 7, 23-28.

276. Schwarz, H.; Bohlmann, F. Org. Mass Spectrom. 1973, 7, 29-35.

277. Schwarz, H.; Bohlmann, F. Org. Mass Spectrom. 1973, 7, 395-399.

278. kieu My, N.; Schwarz, H. Org. Mass Spectrom. 1987, 22, 248-250.

279. Meyerson, S. Appl. Spectrosc, 1955, 9, 120-130.

280. McLafferty, F. W. Anal. Chem. 1959, 31, 2072-2075.

281. McLafferty, F. W. In: "Mass Spectrometry of Organic Ions"; McLafferty, F. W., Ed., Academic Press: New York, 1963; Chap. 7.

282. Lightner, D. A.; Quistad, G. B.; Irwin, E. Appl. Spectrosc. 1971, 25, 253-258.

283. Boer, F. P.; Shannon, T. W.; McLafferty, F. W. J. Am. Chem. Soc. 1968, 90, 7239-7248.

284. Kinney, I. W., Jr.; Cook, G. L. Anal. Chem. 1952, 24, 1391-1396.

285. McCollum, J. D.; Meyerson, S. J. Am. Chem. Soc. 1959, 81, 4116-4117.

286. Gilpin, J. J. Chem. Phys. 1958, 28, 521-522.

287. Occolowitz, J. L. Anal. Chem. 1964, 36, 2177-2181.

288. Gorfinkel, M. I.; Ivanovskaia, L. Yu.; Koptyug, V. A. Org. Mass Spectrom. 1969, 2, 273281.

289. Aczel, T.; Lumpkin, H. E. Anal. Chem. 1960, 32, 1819-1822.

290. Pelah, Z.; Wilson, J. M.; Ohashi, M.; Budzikiewicz, H.; Djerassi, C. Tetrahedron 1963, $19,2233-2240$.

291. McLafferty, F. W.; Bursey, M. M.; Kimball, S. M. J. Am. Chem. Soc. 1966, 88, 5022-5023.

292. Kingston, E. E.; Eichholzer, J. V.; Lyndon, P.; MacLeod, J. K.; Summons, R. E. Org. Mass Spectrom. 1988, 23, 42-47.

293. McLafferty, F. W. "Interpretation of Mass Spectra", 3rd ed.; University Science Books: Mill Valley, Ca, 1980; Chap. 9.

294. Nicoletti, R.; Lightner, D. A. J. Am. Chem. Soc. 1968, 90, 2997-2998.

295. Nicoletti, R.; Lightner, D. A. Tetrahedron Lett. 1968, 4553-4556. 
296. Nakata, H.; Tatematsu, A. Tetrahedron Lett. 1969, 4303-4306.

297. Lightner, D. A.; Majeti, S.; Nicoletti, R.; Thommem, E. Intra-Science Chem. Rept. 1972, $6,113-125$.

298. MacLeod, J. K.; Djerassi, C. Tetrahedron Lett. 1966, 2183-2187.

299. Duffield, A. M.; Beugelmans, R.; Budzikiewicz, H.; Lightner, D. A.; Williams, D. H.; Djerassi, C. J. Am. Chem. Soc. 1965, 87, 805-810.

300. Gerrard, A. F.; Djerassi, C. J. Am. Chem. Soc. 1969, 91, 6808-6814.

301. Nibbering, N. M. M.; de Boer, T. J. Tetrahedron 1968, 24, 1427-1434.

302. Nibbering, N. M. M.; de Boer, T. J. Tetrahedron 1986, 24, 1415-1426.

303. Venema, A.; Nibbering, N. M. M.; de Boer, T. J. Org. Mass Spectrom. 1970, 3, 583-595.

304. Wesdemiotis, C.; Schwarz, H.; Borchers, F.; Heimbach, H.; Levsen, K. Z. Naturforsch. B 1978, 33, 1150-1164.

305. Borchers, F.; Levsen, K.; Wesdemiotis, C.; Schwarz, H. Int. J. Mass Spectrom. Ion Phys. $1978,28,203-207$.

306. Hammerum, S. Mass Spectrom. Rev. 1988, 7, 123-202.

307. Baer, T.; Dutuit, O.; Mestdagh, H.; Rolando, C. J. Phys. Chem. 1988, 92, 56745679.

308. Kuck, D.; Grützmacher, H.-F. Org. Mass Spectrom. 1978, 13, 91-102.

309. van der Greef, J.; Nibbering, N. M. M. Org. Mass Spectrom. 1979, 14, 537-542.

310. Venema, A.; Nibbering, N. M. M. Org. Mass Spectrom. 1974, 9, 628-630.

311. Wolkoff, P.; van der Greef, J.; Nibbering, N. M. M. J. Am. Chem. Soc. 1978, 100, 541545.

312. Lightner, D. A.; Sunderman, F. W.; Hurtado, L.; Thommen, E. Org. Mass Spectrom. 1970, 3, 1325-1331.

313. Schwarz, H.; Köppel, C.; Bohlmann, F. Org. Mass Spectrom. 1973, 7, 881-885.

314. Schwarz, H.; Wesdemiotis, C.; Hess, B.; Levsen, K. Org. Mass Spectrom. 1975, 10, 595605.

315. Köppel, C.; Schwarz, H. Org. Mass Spectrom. 1976, 11, 101-102.

316. Meyerson, S.; Leitch, L. C. J. Am. Chem. Soc. 1971, 93, 2244-2247.

317. Bartmess, J. E.; McIver, R. T., Jr. In ref. 22; chap. 11.

318. Harris, F. M.; Beynon, J. H. In ref. 23; chap. 19.

319. McAdoo, D. J.; Bente, P. F., III; Gross, J.L.; McLafferty, F. W. Org. Mass Spectrom. 1974, $9,525-535$.

320. Kuck, D.; Grützmacher, H.-F. Z. Naturforsch. B 1979, 34, 1750-1764.

321. Kuck, D. Doctoral thesis; Universität Bielefeld, 1976.

322. Griffiths, I. W.; Mukhtar, E. S.; Harris, F. M.; Beynon, J. H. Int. J. Mass Spectrom. Ion Phys. 1982, 43, 283-292.

323. Mukhtar, E. S.; Griffiths, I. W.; Harris, F. M.; Beynon, J. H. Int. J. Mass Spectrom. Ion Phys. 1981, 37, 159-166.

324. Griffiths, I. W.; Harris, F. M.; Mukhtar, E. S.; Beynon, J. H. Int. J. Mass Spectrom. Ion Phys. 1981, 41, 83-88.

325. Harrison, A. G.; Lin, M. S. Int. J. Mass Spectrom. Ion Phys. 1983, 51, 353-356.

326. Chen, J. H.; Hayes, J. D.; Dunbar, R. C. J. Phys. Chem. 1984, 88, 4759-4764.

327. Kingston, E. E.; Morgan, T. G.; Harris, F. M.; Beynon, J. H. Int. J. Mass Spectrom. Ion Phys. 1982, 43, 261-272.

328. Welch, M. J.; Pereles, D. J.; White, E., V Org. Mass Spectrom. 1985, 20, 425-426.

329. Nacson, S.; Harrison, A. G. Int. J. Mass Spectrom. Ion Proc. 1985, 63, 325-337.

330. Dawson, P. H.; Sun, W.-F. Int. J. Mass Spectrom. Ion Phys. 1982, 44, 51-59.

331. McLuckey, S. A.; Sallans, L.; Cody, R. B.; Burnier, R. C.; Verma, S.; Freiser, B. S.; Cooks, R. G. Int. J. Mass Spectrom. Ion Phys. 1982, 44, 215-229.

332. Singh, S.; Thacker, M. S.; Harris, F. M.; Beynon, J. H. Org. Mass Spectrom. 1985, 20, 156-157.

333. McLuckey, S. A.; Ouwerkerk, C. E. D.; Boerboom, A. J. H.; Kistemaker, P. G. Int. J. Mass Spectrom. Ion Proc. 1984, 59, 85-101.

334. Dawson, P. H. Int. J. Mass Spectrom. Ion Proc. 1985, 63, 339-341.

335. Griffiths, I. W.; Mukhtar, E. S.; March, R. E.; Harris, F. M.; Beynon, J. H. Int. J. Mass Spectrom. Ion Phys. 1981, 39, 125-132. 
336. Mukhtar, E. S.; Griffiths, I. W.; March, R. E.; Harris, F. M.; Beynon, J. H. Int. J. Mass Spectrom. Ion Phys. 1981, 41, 61-82.

337. Waddell, D. S.; Boyd, R. K.; Brenton, A. G.; Beynon, J. H. Int. J. Mass Spectrom. Ion Proc. 1986, 68, 71-90.

338. Dunbar, R. C. J. Am. Chem. Soc. 1973, 95, 6191-6197.

339. Nacson, S.; Harrison, A. G. Org. Mass Spectrom. 1985, 20, 429-430.

340. Brand, W. A.; Baer, T., Int. J. Mass Spectrom. Ion Phys. 1983, 49, 103-112.

341. Pihlaja, K.; Jalonen, J.; Franck, R. W.; Meyerson, S. Mass Spectrom. Rev. 1982, 1, 107 124.

342. Budzikiewicz, H.; Brauman, J. I.; Djerassi, C. Tetrahedron 1965, 21, 1855-1879.

343. Kühne, H.; Hesse, M. Mass Spectrom. Rev. 1982, 1, 15-28.

344. Levsen, K.; Borchers, F.; Stolze, R.; Budzikiewicz, H. Org. Mass Spectrom. 1978, 13, 510 512.

345. Sindona, G.; Weber, R.; Levsen, K. Adv. Mass Spectrom. 1980, 8, 879-885.

346. Stolze, R.; Budzikiewicz, H. Org. Mass Spectrom. 1978, 13, 25-29.

347. Groenewold, G. S.; Gross, M. L. Org. Mass Spectrom. 1982, 17, 269-273.

348. Gross, M. L.; DeRoos, F. L. J. Am. Chem. Soc. 1976, 98, 7128-7132.

349. Gross, M. L.; Chiu, E.; Pokorny, D.; DeRoos, F. L. Org. Mass Spectrom. 1977, 12, 55-62.

350. Wojinski, S. F.; Gross, M. L. Org. Mass Spectrom. 1979, 14, 135-139.

351. Groenewold, G. S.; Gross, M. L.; Zey, R. Org. Mass Spectrom. 1982, 17, 416-423.

352. Kuck, D. Org. Mass Spectrom. 1989, 24, 1077-1080.

353. Audier, H. E.; Denhez, J. P.; Milliet, A.; Moustapha, C. Int. J. Mass Spectrom. Ion Phys. $1983,47,471-474$.

354. Audier, H. E.; Milliet, A.; Denhez, J. P. Bull Soc. Chim. Fr. II 1983, 202-206.

355. Audier, H. E.; Denhez, J. P.; Messaoudi, A. Org. Mass Spectrom. 1985, 20, 155.

356. Lay, J. O., Jr.; Gross, M. L.; Zwinselman, J. J.; Nibbering, N. M. M. Org. Mass Spectrom. $1983,18,16-21$.

357. Köppel, C.; Schwarz, H.; Bohlmann, F. Org. Mass Spectrom. 1974, 9, 324-331.

358. Dass, C.; Gross, M. L. Org. Mass Spectrom. 1985, 20, 34-40.

359. Fu, E. W.; Dunbar, R. C. J. Am. Chem. Soc. 1978, 100, 2283-2288.

360. Dass, C.; Gross, M. L. J. Am. Chem. Soc. 1983, 105, 5724-5729.

361. Dass, C.; Gross, M. L. Org. Mass Spectrom. 1983, 18, 542-546.

362. Holman, R. W.; Rozeboom, M. D.; Gross, M. L.; Warner, C. D. Tetrahedron 1986, 42, 6235-6244.

363. Andrews, L.; Harvey, J. A.; Kelsall, B. J.; Duffey, D. C. J.Am. Chem. Soc. 1981, 103, 64156422 .

364. Sharvit, J.; Mandelbaum, A. Org. Mass Spectrom. 1976, 11, 488-498.

365. Groenewold, G. S.; Chess, E. K.; Gross, M. L. Org. Mass Spectrom. 1984, 19, 519 520.

366. Wentrup-Byrne, E., Gülacar, F. O.; Müller, P.; Buchs, A. Org. Mass Spectrom. 1977, 12, 636-637.

367. Meot-Ner (Meutner), M.; Sieck, L. W.; Ausloos, P. J. Am. Chem. Soc. 1981, 103, 53425348.

368. Meot-Ner (Mautner), M. Acc. Chem. Res. 1984, 17, 186-193.

369. Meot-Ner (Mautner), M.; Hamlet, P.; Hunter, E. P.; Field, F. H. J. Am. Chem. Soc. 1978, 100, 5466-5471.

370. Sieck, L. W.; Gordon, R., Jr. Int. J. Mass Spectrom. Ion Phys. 1976, 19, 269-286.

371. Liu, S.; Jarrold, M. F.; Bowers, M. T. J. Phys. Chem. 1985, 89, 3127-3134.

372. Milosevich, S. A.; Saichek, K.; Kinchey, L.; England, W. B.; Kovacic, P. J. Am. Chem. Soc. 1983, 105, 1088-1090.

373. Bradshaw, T. K.; Bowie, J. H.; White, P. Y. Chem. Commun. 1970, 537-538.

374. Bowie, J. H.; White, P. Y.; Bradshaw, T. K. J. Chem. Soc., Perkin Trans. 2 1972, 19661969.

375. Williams, D. H.; Ward, R. S.; Cooks, R. G. J. Chem. Soc. (B) 1968, 522-525.

376. Robinson, G. E.; Thomas, C. B.; Vernon, J. M. J. Chem. Soc. (B) 1971, 1273-1282.

377. Johnstone, R. A. W.; Millard, B. J. Z. Naturforsch. A 1966, 21, 604-608.

378. Eland, J. H. D.; Danby, C. J. J. Chem. Soc. 1965, 5935-5943. 
379. Neuert, U. Doctoral thesis, Universität Hamburg, 1975.

380. Bohlmann, F.; Köppel, C.; Müller, B.; Schwarz, H.; Weyerstahl, P. Tetrahedron 1974, 30, 1011-1013.

381. Johnstone, R. A. W.; Ward, S. D. J.Chem. Soc. (C) 1968, 1805-1807.

382. Berlin, K. D.; Shupe, R. D. Org. Mass Spectrom. 1969, 2, 447-466.

383. Johnston, R. A. W.; Ward, S. D. I. Chem. Soc. (C) 1968, 2540-2543.

384. Donaghue, P. F.; White, P. Y.; Bowie, J. H.; Roney, B. D.; Rodda, H. J. Org. Mass Spectrom. 1969, 2, 1061-1065.

385. Bowie, J. H.; Donaghue, P. F.; Rodda, H. J.; Simons, B. K. Org. Mass Spectrom. 1968, 1, 3965-3979.

386. Güsten, H.; Klasinc, L.; Marsel, J.; Milivojevic, D. Org. Mass Spectrom. 1971, 5, 357-358.

387. Bowie, J. H.; White, P. Y. Org. Mass Spectrom. 1972, 6, 135-139.

388. Maquestiau, A.; Van Haverbeke, Y.; Delalieu, F. Org. Mass Spectrom. 1971, 5, 1015-1017.

389. Güsten, H.; Klasinc, L.; Marsel, J.; Milivojevié, D. Org. Mass Spectrom. 1972, 6, 175-178.

390. Moller, I.; Pedersen, C. T. Acta Chem. Scand. 1968, 22, 706-708.

391. Gooden, R.; Braumann, J. I. J. Am. Chem. Soc. 1982, 104, 1483-1486.

392. Johnstone, R. A. W.; Millard, B. J. J. Chem. Soc. (C) 1966, 1955-1959.

393. Pignataro, S.; Mancini, V.; Innorta, G.; Distefano, G. Z. Naturforsch. A. 1972, 27, 534536.

394. Innorta, G.; Torrini, S.; Pignataro, S.; Mancini, V. Org. Mass Spectrom. 1973, 7, 1399_ 1406.

395. Pignataro, S.; Mancini, V.; Ridyard, J. N. A.; Lempka, H. J. Chem. Commun. 1971, 142143.

396. Bowie, J. H.; White, P. Y. Aust. J. Chem. 1971, 24, 205-208.

397. Meyerson, S.; Drews, H.; Fields, E. K. J. Am. Chem. Soc.1964, 86, 4964-4967.

398. Budzikiewicz, H.; Swoboda, J. Chem. Ber. 1965, 98, 3264-3269.

399. Hart, H.; Buehler, C. A.; Waring, A. J.; Meyerson, S. J. Org. Chem. 1965, 30, 331-334.

400. Meyerson, S. Org. Mass Spectrom. 1970, 3, 119-125.

401. Manville, J. F.; Smith, P. J. Org. Mass Spectrom. 1971, 5, 95-97.

402. McMillen, D.F.; Golden, D. M. Ann. Rev. Phys.Chem. 1982, 33, 493-532.

403. Egger, K. W.; Cocks, A. T. Helv. Chim. Acta 1973, 56, 1516-1536.

404. D. Kuck, Z. Naturforsch. B 1984, 39, 369-374.

405. Kuck, D., in preparation.

406. Kuck, D.; Bäther, W.; Grützmacher, H.-F. J. Am. Chem. Soc. 1979, 101, 7154-7157.

407. Kuck, D. Int. J. Mass Spectrom. Ion Phys. 1983, 47, 499-502.

408. Kuck, D.; Bäther, W.; Grützmacher, H.-F. Int. J. Mass Spectrom. Ion Proc. 1985, 67, 7591.

409. Bäther, W.; Kuck, D.; Grützmacher, H.-F. Org. Mass Spectrom. 1985, 20, 589-591.

410. Kuck, D.; Fastabend, U. Adv. Mass Spectrom. 1989, 11A, 904-905.

411. Caluwe, P.; Shimade, K.; Szwarc, M. I. Am. Chem. Soc. 1973, 95, 1433-1436.

412. Ikeda, T.; Lee, B.; Kurihara, S.; Tazuke, S.; Ito, S.; Yamamoto, M. J. Am. Chem. Soc. $1988,110,8299-8304$.

413. Gross, M. L.; Wilkins, C. L.; Regulski, T. G. Org. Mass Spectrom. 1971, 5, 99-101.

414. Puschmann, M. Doctoral thesis, Universität Hamburg, 1974.

415. Gallagher, I. I.; Chess, E. K.; Arghestani, S. M.; Gross, M. L. Org. Mass Spectrom. 1983, $18,118-126$.

416. Wilkins, C. L.; Gross, M. J. J. Am. Chem. Soc. 1971, 93, 895-901.

417. Groenewold, G. S.; Chess, E. K.; Gross, M. J. J. Am. Chem. Soc. 1984, 106, 539-543.

418. Chess, E. K.; Lin, P.-H.; Gross, M. L. J. Org. Chem. 1983, 48, 1522-1527.

419. Kuck, D.; Filges, U. Org. Mass Spectrom. 1988, 23, 643-653.

420. Derrick, P. J. Adv. Mass Spectrom. 1985, 85-115.

421. Bletsos, I. V.; Hercules, D. M.; vanLeyen, D.; Benninghoven, A. Macromolecules 1987, $20,407-413$.

422. Meyerson, S.; Hart, H.; Leitch, L. C. J. Am. Chem. Soc. 1968, 90, 3419-3423.

423. Meyerson, S.; Field, E. K. Org. Mass Spectrom. 1971, 5, 1227-1228.

424. Shao, J.-D.; Baer, T. Int. J. Mass Spectrom. Ion Proc, 1988, 86, 357-367. 